Florida International University FIU Digital Commons

7-30-2012

\title{
Time Spent with Children and Working Parents' Willingness to Medicate ADHD-like Behaviors
}

Bora Pajo

Florida International University, bpajo001@fiu.edu

DOI: $10.25148 /$ etd.FI12110709

Follow this and additional works at: https://digitalcommons.fiu.edu/etd

\section{Recommended Citation}

Pajo, Bora, "Time Spent with Children and Working Parents' Willingness to Medicate ADHD-like Behaviors" (2012). FIU Electronic Theses and Dissertations. 729.

https:// digitalcommons.fiu.edu/etd/729 


\title{
FLORIDA INTERNATIONAL UNIVERSITY
}

\author{
Miami, Florida
}

\section{TIME SPENT WITH CHILDREN AND WORKING PARENTS' WILLINGNESS TO MEDICATE ADHD-LIKE BEHAVIORS}

A dissertation submitted in partial fulfillment of the requirements for the degree of DOCTOR OF PHILOSOPHY

in

SOCIAL WELFARE

by

Bora Pajo

2012 
To: $\quad$ Interim Dean Michelle Ciccazzo

R. Stempel College of Public Health and Social Work

This dissertation, written by Bora Pajo, and entitled Time spent with children and working parents' willingness to medicate ADHD-like behaviors, having been approved in respect to style and intellectual content, is referred to you for judgment.

We have read this dissertation and recommend that it be approved.

Hugh Gladwin

Paul H. Stuart

Miriam Potocky

David Cohen, Major Professor

Date of Defense: July 30, 2012

The dissertation of Bora Pajo is approved.

Interim Dean Michelle Ciccazzo

R. Stempel College of Public Health and Social Work

Dean Lakshmi N. Reddi

University Graduate School

Florida International University, 2012 
C) Copyright 2012 by Bora Pajo

All rights reserved. 


\section{DEDICATION}

To the men who raised me: my unconditionally loving father, Mezin, and my extraordinarily caring brother, Erind. To the woman I profoundly miss: my mother, Ludmilla. 


\section{ACKNOWLEDGMENTS}

I am deeply grateful to my mentor, Dr. David Cohen, for his constant guidance, care, patience, and support throughout the years I have known him. Because of his close attention to detail, high quality standards, and excellent work ethics, I find myself completely transformed, intelectually and personally. His enthusiasm, open-mindness, and the ability to view the world through various lenses, consistently challenged and improved my thinking process and made me eager to become a better researcher. I am thankful for his continous encouragement that I explore my own ideas, find my own niche, and be passionate about my own work. Beyond everything else, I value the fact that his entire mentorship was oriented towards improving and honing the necessary skills for my future success.

I am thankful to Dr. Miriam Potocky for being tremendously supportive throughout my dissertation work. I truly value her crucial help with designing and navigating the statistical section, as well as her personal advice and support to navigate the surrounding social world and regain my confidence. I thank Dr. Paul Stuart for his continuously thoughtful and helpful comments on my dissertation and for always being kind and supportive from the very beginning of my doctoral studies. I would like to thank Dr. Hugh Gladwin for administering the dataset for the original study, and for his helpful suggestions with designing the questions in the questionnaire and throughout this study.

I also thank Dr. Richard Beaulaurier for his thoughtful feedback in my proposal and dissertation draft that utlimately improved this study, for increasing my passion and 
interest in qualitative research during my doctoral course work, and for personally being caring and encouraging. I thank Dr. Mark Macgowan for being instrumental in solving my financial support and for always being responsible and punctual. I am thankful to Dr. Sarah Mahler for her constant support and faith in my ideas. Without her help, I may have never been a student of Florida International University.

The financial support I received from the Center for Research on U.S. Latino HIV/AIDS and Drug Abuse (CRUSADA) during my first year of the doctoral program, the graduate research assistantship through the NIMH funded study (PI: David Cohen) during my second year, and the teaching assistantship from the School of Social Work during my second and third year, are all highly appreciated. In 2012, I was supported by Florida International University Dissertation Year Fellowship.

In addition, I would like to thank Mariana Sanchez for offering her assistance with the Spanish translation of open-ended answers and the original study questionnaire, as well as for always being a caring friend. I appreciate the help and encouragement of all my other friends in the program, Jackie Cruz-Wagener, Beverly Ruffin, Sheila Vakharia, Julietta Hernandez, Sharon Aaron, and Adelaida Rosario. Also, I am grateful to my friends Shannon Hughes, LeTania Severe, and Kirsten Iba Onsted for their moral support and kindness from the very beginning of my doctoral studies.

Finally, I want to thank my family. My father's pride in me, his enthusiasm, and encouragement have always been a propelling force. I also thank Mira for always finding the silver lining in every difficult situation I have been through. My brother Erind has been my supporting wall during my doctoral school years and beyond. I appreciate his 
kindness, love, and unrelentless care. I thank my sister in law Judith for offering her creative and practical perspective and for always being enthusiastic and willing to discuss the ins and outs of my dissertation. I am grateful to my $7 \frac{1}{2}$ years old niece Ludmilla Antonia, for her gorgeous drawings and for brightening my life from the moment she was born.

I thank my mother-in-law, Hamide, for being so encouraging and supportive of my studies. Beyond everything I greatly appreciate her sense of pride and her complete faith in me. My entire graduate school experience would have been very different without the attention and support of my father-in-law, Bujar, who eagerly followed every step of my dissertation progress, and turned into a celebration every small achievement. His encouragement, love, and moral investment in my studies has been priceless. Also, I am thankful to my brother-in-law Edmond, and his wife Sonila, for always being interested in my work, their continuous support, and faith in me. The picture wouldn't be complete without the joyful presence of their adorable children Lura and Marin.

Last, but not least, I want to thank my loving husband Elton Islamaj for being a true blessing since the moment our lives became one. His unbeliveable encouragement, love, great enthusiasm, and his amazing ability to see the forest when I was lost in the middle of trees, kept me going regardless of all circumstances. Thank you for being you. 


\section{ABSTRACT OF THE DISSERTATION \\ TIME SPENT WITH CHILDREN AND WORKING PARENTS' WILLINGNESS TO MEDICATE ADHD-LIKE BEHAVIORS}

by

Bora Pajo

Florida International University, 2012

Miami, Florida

\section{Professor David Cohen, Major Professor}

ADHD, which refers to one of the most common behavioral problems among children, is subject to controversial arguments surrounding its nature and its primary treatment with psychiatric medications. At the heart of the problem are parents, whose responsibility includes providing pivotal information to clinicians for the diagnosis and deciding whether their children will receive medications. This study investigates the relationship between working parents' willingness to medicate ADHD-like behaviors and the time they are able to spend with their children during a regular workday. The importance of time spent with children derives from the observation that it is likely to influence not only parents' judgments of their children's behaviors but the behaviors themselves. The relationship was investigated using a subsample of 551 working parents (452 parents reporting no child with problems and 99 parents reporting child with problems) drawn from a population-based telephone survey of parents in the Miami-Dade and Broward counties of Florida. A series of path analyses, controlling for selected sociodemographic and family variables, showed that spending more time with their children 
during a regular workday was significantly related to being less willing to medicate ADHD-like behaviors. The association was stronger for parents reporting having a child with emotional and behavioral problems $(\beta=-.20)$ and faint for other parents $(\beta=-.06)$. The interpretation of the study findings emphasizes the vagueness surrounding the nature of ADHD and the events and procedures leading to the diagnosing of a child, as well as the delicate situations in which parents find themselves. 


\section{TABLE OF CONTENTS}

CHAPTER

PAGE

INTRODUCTION

1

Statement of the Problem

Definitions and Concepts 2

Time spent with children 3

Other problematic childhood behaviors $\quad 5$

$\begin{array}{ll}\text { Theoretical background } & 6\end{array}$

CHAPTER II: LITERATURE REVIEW 11

Parental Time $\quad 11$

$\begin{array}{ll}\text { Work and Parental Time } & 13\end{array}$

Marital Status and Time Spent with Children $\quad 25$

Gender and Time Spent with Children $\quad 27$

Race and Ethnicity and Time Spent with Children 29

Characteristics of Children and Parental Time $\quad 30$

Available Parental Time and Child Development 31

Relationships Between Time and Choices $\quad 33$

Parents of ADHD Diagnosed Children $\quad 36$

The Nature of ADHD $\quad 37$

$\begin{array}{lr}\text { Treatment of ADHD } & 40\end{array}$

Diagnosing ADHD $\quad 41$

Similar Emotional and Behavioral Problems 45

Theoretical Model: Merton's Functionalist Perspective 48

Aims and Hypotheses $\quad 52$

CHAPTER III: METHODOLOGY 56

Data Source $\quad 56$

The original study $\quad 56$

$\begin{array}{ll}\text { Research Design } & 58\end{array}$

$\begin{array}{ll}\text { Measures } & 58\end{array}$

Intervening variable $\quad 59$

Exogenous variables $\quad 60$

Endogenous variables 63

Open-ended variable $\quad 65$

Data Analytical Plan and Preparation $\quad 65$

Part I: Details of the quantitative analysis $\quad 66$

Rationale for path analysis 66

Steps of the analysis 67

Data preparation $\quad 68$

Part II: Details of the preparation of the open-ended variable $\quad 71$

Human Participants Consideration 
CHAPTER IV: RESULTS $\quad 81$

Part I: Results of the Quantitative Analysis $\quad 81$

Demographic representativeness $\quad 81$

Parents of both groups $\quad 81$

Race and ethnicity $\quad 82$

Gender, family types, children, and work satisfaction $\quad 84$

Distribution of parental time with children 85

Distribution of willingness to medicate behaviors $\quad 86$

$\begin{array}{ll}\text { Correlations and crosstabs } & 88\end{array}$

Results of path analyses $\quad 90$

Willingness to medicate ADHD-like behaviors 91

Willingness to medicate ODD-like behaviors 96

Willingness to medicate behaviors related to depression 97

Willingness to medicate suicidal talk 99

Summary of quantitative results 101

Part II: Results from the Open-Ended Variable 102

The most challenging aspect of childrearing for both groups 103

Challenging aspects of childrearing and race and ethnicity 104

Challenging aspects of childrearing and gender 108

Challenging aspects of childrearing and family type 111

$\begin{array}{ll}\text { Highlights of the open-ended answers } & 114\end{array}$

Limitations

CHAPTER V: DISCUSSION 117

Part I: Addressing the controversy of ADHD 117

$\begin{array}{ll}\text { The number of children per family } & 119\end{array}$

Discipline and control versus lack of available time 121

Ranking of behaviors 123

Part II: Discussion of Theoretical Implications $\quad 125$

$\begin{array}{ll}\text { Part III: Future Studies } & 127\end{array}$

$\begin{array}{ll}\text { Cause-effect relationships } & 127\end{array}$

Quality of time 128

Race, ethnicity, culture, and medication of behaviors $\quad 130$

One-parent families versus two-parent families $\quad 132$

Gender, time, and medication of behaviors $\quad 133$

$\begin{array}{ll}\text { Implications for social work } & 134\end{array}$

$\begin{array}{ll}\text { REFERENCES } & 137\end{array}$

$\begin{array}{ll}\text { VITA } & 150\end{array}$ 


\section{LIST OF FIGURES}

FIGURE

PAGE

1. Search of publications on parental time 136

2. Distribution of time spent with children for both groups of parents

3. Willingness to medicate ADHD for parents reporting child with problems

92

4. Willingness to medicate ADHD for parents reporting no child with problems

5. Willingness to medicate suicidal talk for parents reporting child with problems

7. Willingness to medicate suicidal talk for parents reporting no child with problems

100

8. Percentages of each group of parents and the most challenging aspect of childrearing

103 


\section{LIST OF TABLES}

TABLE

1. Central distribution for continuous numerical variables

2. Frequencies of the most challenging aspect of childrearing

3. Willingness to medicate behaviors for both groups of parents

4. Willingness to medicate behaviors across race and ethnicity

5. Pearson's correlation table for the numerical continuous variables

6. The most challenging aspects of childrearing and race and ethnicity

7. The most challenging aspects of childrearing and gender

8. The most challenging aspects of childrearing and family type
PAGE

69

75

87

88

89

106

109

112 


\section{CHAPTER I: INTRODUCTION}

\section{Statement of the Problem}

An increasing number of children in the United States take psychiatric drugs to control their behaviors. One of the most common diagnoses for problematic behaviors of children is Attention Deficit Hyperactivity Disorder (ADHD). From 2003 to 2007 the number of diagnosed children increased annually by $5.5 \%$, affecting almost $10 \%$ of United States school age children (CDC, 2010). Consequently, a growing number of parents come face to face with the intricate details of handling the possibility of ADHD for their child. In addition to being the linking center of all the dynamics around them (i.e., teachers, doctors, and children), parents also occupy a central role in diagnosing and medicating their children. But, how do these parents decide their course of action when most of them are not doctors and a well-publicized controversy persists about ADHD? Some firmly maintain that ADHD is a common neurobehavioral disorder of childhood, while others claim the label refers to various medicalized temperamental, educational, and cultural differences and difficulties of children. To complicate parents' situation further, the use of psychiatric drugs on young children is continuously criticized and questioned by some experts writing in scientific articles and aired by the media. Thus, a better understanding of parents of ADHD diagnosed children may improve the quality of assistance provided to these parents by the helping professions. It would also provide some depth in understanding of the problem of ADHD itself and the complex dynamics between institutions of education, health care, and family. 
This study examines one aspect of these parents' situations - their willingness to medicate ADHD-like behaviors - and focuses on one category of parents, working parents. This study also compares whether and how working parents who report of having a child with emotional and behavioral problems differ in their willingness to medicate ADHD-like behaviors from parents reporting no child with problems. More specifically, this study investigates the possibility of a relationship between the time these two groups of working parents report spending with children in a regular workday, and their willingness to medicate ADHD-like behaviors. In addition, this study offers a comparison between parents' willingness to medicate ADHD-like behaviors and other behaviors related to similar childhood problems such as ODD, depression, and suicidal ideation. Finally, this study explores parents' answers to an open-ended question regarding the most challenging aspect of raising a child.

\section{Definitions and Concepts}

This study investigates the relationship between working parents' willingness to medicate children's behaviors known and labeled as Attention Deficit Hyperactivity Disorder (ADHD) and the time parents are able to spend with children in a regular workday. To do so, this study employs a directional hypothesis that has its rootsalthough modified — in the functionalist perspective: the idea that every consequence of a social phenomenon resembles different parts of an engine that altogether contribute to the existence of that phenomenon. Such consequences of a particular phenomenon could be recognized (intended) or unrecognized (unintended) by the people involved (Merton, 1938). Robert Merton's theory of purposive actions allows for a detailed understanding 
of intended and unintended actions within the functionalist perspective. His theory of purposive actions also distinguishes itself from the traditional functionalist perspective since it addresses the criticism of the functionalist perspective and simultaneously supports different investigations and explanations of the same action. This makes Merton's theory of purposive actions suitable for this research.

A directional hypothesis that the more time working parents spend with their children, the less willing they are to medicate children's ADHD-like behaviors, is at the center of this study. Moreover, parents' willingness to medicate ADHD-like behaviors is contrasted with their willingness to medicate similar disruptive childhood behaviors such as oppositional defiant disorder (ODD), depression, and suicidal ideation. The current research furthers scientific knowledge by bringing to light a new perspective to look at these complex health and social issues, namely, by using a derivative of functionalist perspective and by drawing attention to the amount of time parents spend with children an exceedingly obvious yet unexplored area. Functionalism is infrequently used to understand health related issues and its application in a new area could add a nuance to its traditional use. On the other hand, this study offers a comparison of willingness to medicate different behaviors. From a practical viewpoint, this information along with the information from the answers to the open-ended question could help practitioners gain a better understanding of these parents but also could generate new practical tools to aid parents.

Time spent with children. The time working parents spend with their children may be conceived as having two main characteristics: the amount of time (i.e., actual 
hours spent together), and the quality of time (i.e., activities engaged in). If measuring the amount of time parents spend with children is a difficult task, accurately measuring the quality of time parents spend with children is a daunting one. In both cases, researchers must almost always rely on participants' self reports (obtained by means of questionnaires or time diaries), and since time available to spend with children is in our society an emotional issue and a desired commodity for most parents, the data thus obtained is often questionable. Time in itself is a difficult construct, as indicated by Sorokin and Merton's still relevant statement about defining social time: "thus far our investigation has disclosed the facts that social time, in contrast to the time of astronomy, is qualitatively and not purely quantitative; that its qualities derive from the beliefs and customs common to the group; and that they serve further to reveal rhythms, pulsations, and beats of the societies in which they are found" (1936, p. 623). Therefore the construct of time spent with children is complex and socially embedded.

The possibility of a relationship between parental time and willingness to medicate problematic behaviors, and the pertinence of evaluating the relationship, rests on the importance of parental time with children emerging from numerous discussions in the scientific literature (Hsin, 2009; Sandberg \& Hofferth, 2001). Stated simply, spending time with children is likely to influence parents' judgments of children's behaviors (Carstensen, Isaacowitz, \& Charles, 1999) as well as the behaviors themselves (Kalenkoski, Ribar, \& Stratton, 2007). In turn, both parental judgments and children's behaviors are crucial ingredients in the diagnosis and treatment of an ADHD child (Fernández \& Arcia, 2004). Because of ADHD’s controversial nature (Gornall, 2007) and 
the lack of biological markers to diagnose it, parents' perceptions play key roles in diagnosing and treating ADHD. Thus, it is intriguing to explore whether a relationship exists between the time spent with children and willingness to medicate ADHD-like behaviors for working parents. Time spent with children was only measured among working parents in this dataset. But, since an exploration of this topic, to my knowledge, has never been done, it is more efficient to focus on the group of parents who already have limited available time during regular workdays. Such limitation allows for some minimal level of control for biases in their reports.

Other problematic childhood behaviors. This study also examines whether and how willingness to medicate ADHD-like behaviors differs from willingness to medicate other similar childhood problematic behaviors for working parents. Better understanding whether and how parents rank and differentiate among behaviors they are willing to medicate, adds a layer of understanding on parents' perceptions of children' behaviors. ADHD, ODD, depression, and suicidal ideation share some similar characteristics, such as: (1) a lack of biological markers that weakens the validity of their disease or disorder attributions, (2) the ongoing controversy about their nature, (3) their perception as disruptive behaviors by the involved adults such as parents and teachers, (4) the increase in the number of children diagnosed during recent years, and (5) the fact that all are identified and diagnosed based on caretakers' accounts (Munkvold, Lundervold, Lie, \& Manger, 2009). The behaviors also obviously differ because they have consequences in different areas of children's lives (for example, an ADHD child may have trouble doing homework, an ODD child may have difficulties getting along with friends, a depressed 
child may be spending time alone, whereas a child with suicidal ideation may be talking and living with ideas about killing oneself).

Understanding whether parents differentiate between such behaviors and are more likely to medicate one rather than another is important because it implies that some behaviors are taken more seriously by parents. In that case, parents might benefit from ways to prevent or handle problematic behaviors rather than facing the decision to medicate their children. In terms of theory, finding a pattern in whether and how parents differentiate between deserving-to-medicate and tolerable behaviors, may simultaneously imply an urge to control the perceived consequences of such behaviors rather than behaviors per se as well as the lack of other means besides medication to change the behaviors and their consequences. I believe this latter finding could be a small contribution to the complex issue of understanding social reactions to mental illness. Finally, a possible differentiation between deserving to medicate behaviors may give some indication on how parents are personally and emotionally affected by these behaviors.

Theoretical background. By exploring these relationships using Merton's theory of purposive action, this study attempts to look anew at the practical parental problems related to identifying and managing ADHD. Merton defines purposive action as one that involves motives and consequently a choice between alternatives (Merton, 1936, p. 895). The motives or the purposes of a social action even when considered as known, are often nebulous and hazy (Merton, 1936, p. 896). In his book Social Theory and Social Structure, Merton (1957) defines motives behind social actions as manifest and latent 
functions. Manifest functions are "those objective consequences for a specified unit (person, subgroup, social, or cultural system), which contribute to its adjustment or adaptation and were so intended." Latent functions "refer to unintended and unrecognized consequences of the same order" (p. 117). Merton emphasizes the importance of identifying latent functions because "finding the latent function of a practice which is not common knowledge, unrecognized, and unintended, is a greater increment in knowledge than findings concerning manifest functions" (p. 122). Thus, in order to understand purposive action, one needs to comprehend its two posited types of functions but be particularly attentive to the latent function. Merton's purposive action is used to explain people's behaviors in trying to reach a specific social goal. In their attempts to reach social goals people employ the means available to them (usually, traditional means such as education and employment). In the face of scarcity of traditional means, people try other means to reach the social goal, including criminal means (deviance) and entrepreneurial means (innovation). Most importantly, Merton's theory of purposive action and his recognition of latent function marks his departure from the traditional functionalism, since the latent function attempts to capture seemingly irrational social behaviors (Merton, 1948, p.116) that are commonly inexistent in a traditional functionalist perspective. Traditionalist functionalist perspective developed grand theories attempting to explain the world as a whole with static functional characteristics, whereas Merton emphasizes the importance of empirical inquiries that may conclude to unique dynamics in specific circumstances (Meja \& Stehr, 1998) rather than one size fits all. 
Based on this reasoning, this study hypothesizes that the latent (unintended and unrecognized) function of administering medications to control or manage ADHD-like behaviors is to compensate for the lack of parental time while trying to reach a certain goal. The goal could differ depending on the consequences of a specific child's disruptive behavior. For a child exhibiting ADHD-like behaviors the parental goal may be to ensure the child's academic success in school; for a child exhibiting ODD-like behaviors the goal may be to increase the child's positive socializations with adults; for a child exhibiting depressive or withdrawn behaviors the goal may be to increase the child's cheerfulness and social or interpersonal involvement; and for a child voicing suicidal thoughts, the goal may be to have the child not voice any such thoughts, not engage in suicidal or self-harming behavior, or voice thoughts indicating desire to fulfill positive future plans.

This research follows the logic that: the manifest function of medicating a child with any of the aforementioned disruptive behaviors would be to avoid negatively valued or harmful consequences tied to the behaviors; while the latent, unrecognized, and unintended function of medicating a child would be to compensate for the lack of parental time which, if more abundantly available, might enable the parent to reach the goal without the aid of medications (i.e., would work as the straightforward traditional means, whereas medicating behaviors would be either a deviant or innovative means to reach the same goal).

Consequently, to test a relationship between the time spent with children and willingness to medicate problematic behaviors, it is important to compare the 
hypothetical relationship between working parents reporting having a child with problems and working parents reporting no child with problems. This division is based on reasoning that parents reporting no child with problems are less likely to have faced the complex situation of negotiating with teachers and clinicians while trying to understand the problematic behaviors of their child. Their answers on willingness to medicate different behaviors may not be as useful, or may be less hypothetical, as those of parents who report of having a child manifesting behavioral, psychological, or emotional problems. However, comparing the two groups is necessary to distinguish possible differences. This study also attempts to provide information that can be later used in interventions designs aiming to assist parents who have a child diagnosed with emotional and behavioral problems. To do so, this research also explores and compares parents' short, open-ended statements on what constitutes the most difficult aspect of raising a child. The information gained from that investigation adds to the understanding of similarities and differences between parents reporting child with problems and parents who do not.

To test the relationship between time spent with children and working parents' willingness to medicate ADHD-like behaviors, this research uses primary data drawn from an original National Institute of Mental Health (NIMH) funded study (PI: David Cohen). The original study collected data on 1146 parents interviewed by phone in Miami-Dade and Broward counties in the State of Florida between May and October of 2009. This research employs only the 551 parents who reported being employed (99 of these parents reported having a child with emotional and behavioral problem whereas 452 
reported no child with emotional and behavioral problems). Using path analysis-a statistical technique used to examine causal relationships between two or more variables and that is based upon a linear equation system — this study measures the strength of the relationship between the independent variable (available parental time) and the dependent variables (willingness to medicate behaviors). To gain a deeper understanding of parental concerns, this study also analyzes one open-ended answer from these parents to a question asking them to identify the most difficult aspect of raising a child. 


\section{CHAPTER II: LITERATURE REVIEW}

\section{Parental Time}

Spending time with children appears extremely important for their wellbeing, health, and academic performance (Hofferth \& Sandberg, 2001; Hsin, 2009; Kalenkoski et al., 2007)—although such time is not always abundantly available for parents. Moreover, people's perception of time (i.e., how much time one has available, whether one spends enough time on a particular task, or the amount of time needed to perform a task) varies greatly from one person to another (Lueck, 2007). Such differences in time perception, although often unrecognized by people, are powerful enough to distort one's ability to judge and to reason (Carstensen, Isaacowitz, \& Charles, 1999). Emotional states of people (i.e., mood, anxiety, pressure, happiness) also seem to influence not simply their ability to make decisions and reach their goals (Carstensen et al., 1999) but also their perception of the amount of time needed or spent on a particular event (Lueck, 2007).

Naturally, time is a needed commodity for all human beings, perhaps more so for working parents of children with behavioral problems. Although all parents are usually actively involved in understanding their children's behaviors, parents of children with behavioral problems may face the task of taking health decisions with controversial consequences (i.e., the decision to control or alter children's behaviors with medications). The amount of time parents spend with their children or the amount of time they spend making health care decisions regarding their children's behaviors has so far escaped the gaze of research focused on parents of ADHD children. An attentive perusal of the 
literature (Pajo \& Cohen, 2012) shows that only one out of 36 studies where parents of ADHD children are the primary informant mentions time. Charach, Skyba, Cook, and Antle (2006) report that parents frequently express concerns regarding the limited available time they have to decide on medication use for their children.

Although most people could agree on the importance or desirability of spending time with children, the actual time in a given day that parents can afford to spend with them depends on a number of external factors. To examine the literature on parental time six different databases (Social Work Abstracts, Social Service Abstracts, PsycInfo, Eric, Sociological Abstracts, and Anthropology Plus) were searched using keywords or variations of "parental time," "time spent with children," "parents' time with children," and "time with children." Figure 1 (p. 140) details the number of records from each keyword from each database. The searches yielded a total of 928 records. After removing duplicates and other publications not related to time parents spend with children, 41 scientific articles based on 35 empirical studies were examined. These studies were organized by subject around five different headings, discussed presently: (1) work and parental time; (2) marital status and parental time; (3) gender and parental time; (4) race and ethnicity and parental time; and (5) children's characteristics and parental time. Although studies were published between 1988 and 2010 ( 2 studies were published before 2000 and 39 were published during the last ten years), these reports were based on data collected between the 1980s and the early 2000s. 


\section{Work and Parental Time}

If not the defining activity, work could be seen as a major activity of an adult's life-an activity likely to occupy a substantial amount of time. Logically, time spent working outside one's home should limit the amount of time spent on everything else in an adult's life, including the time spent with children. Although this study focuses exclusively on working parents, it is important to notice from the literature the differences on parental time between working and non-working parents. Twenty-four (based on 18 empirical studies) out 41 publications contributed findings on the relation between parental work and time with children; 11 were conducted in the United States, 3 in Australia, and 1 each in the Netherlands, Sweden, France, and Canada.

The three studies conducted in Australia (presented in 4 publications) were based on data collected from (1-2) the Australian Bureau of Statistics between 1992 and 2006 (Craig, Mullan, \& Blaxland, 2010; Craig \& Mullan, 2010); (3) the Longitudinal Study of Australian Children from 2004 to 2006, (Browna, Broomb, Nicholson, \& Bittman, 2010), and (4) the Household Income and Labor Dynamics in Australia (HILDA) survey that collected data from 2001 to 2002 (Reynolds \& Alterasis, 2007). Findings from these studies reveal that the work load—combined household and work-for full time working mothers has increased since 1992 more than for full time working fathers or part time working mothers (Craig et al., 2010). The family-work tension however seems to trigger a need for working fewer hours for mothers with preschool children but not for other mothers whose children are older (Reynolds \& Alterasis, 2007). In regards to children's lifestyles, full time maternal employment or maternal unemployment seem to have the 
same direct effect. Children of mothers who work full time or are stay-at-home mothers are reported to spend more time watching television, to be less involved in physical activities, and generally to weigh more than children of mothers who work part time (Browna et al., 2010).

It may be of importance to note here that the subjects of the aforementioned studies are only mothers. These findings are, therefore, inconclusive in terms of family dynamics, fathers' employment status, as well as fathers' time with children. In addition, the Craig et al. (2010) study measures the work of mothers as the combination of work outside of home and the work done at home. That allows for little insights about which type of work makes up the heavier load for these mothers. This feature is often encountered among studies focused on the work-family balance, perhaps because such discussion is highly gendered (Pocock, Skinner, \& Williams, 2008).

An ethnographic study conducted in Sweden video-recorded 300 hours of semistructured interviews with 8 dual earner couples to gain some insights on ways dual earning parents manage their time with children (Forsberg, 2009). Because of its sampling size limitations, its findings may not be generalized, but they carefully delineate working parents' needs to utilize specific time managing strategies such as delegating, alternating, and multitasking. The study includes important insights in terms of time management for dual earning parents, but its findings have little implications on whether part-time working parents or homemakers are also utilizing similar time management skills. 
Some insight on how work influences parental time is available from a study conducted in the Netherlands (reported in three publications) that surveyed 1008 fathers and 929 mothers in 2007 (Roeters, Van Der Lippe, \& Kluwer, 2009). This study reveals a direct relationship between parents' working hours and time spent with children: longer working hours are associated with less time with children, more restrictive organization norms in the family, higher stress for parents, and less flexibility in time organization. Parents were asked to rate the frequency of parent-child activities such as having dinner or watching television together. Also, they were asked to estimate how often they would be thinking about work or work related issues while in the company of children. Finally, these parents were asked to rate their parent-child relationships based on their perceived closeness with children. These data revealed that dual earning parents seem to have a lower quality of time with their children. In the same study, researchers tried to differentiate the parent-child time among mothers and fathers in relation to their working time. It concludes that both mothers and fathers who work full time are generally less involved in activities with their children, even though they react differently to their work demands (Roeters et al., 2009). Although work demands shorten the time spent with children for both mothers and fathers, mothers have additional household chores that shorten their time with children even further. Therefore, fathers seem more likely to engage in leisure activities than mothers (Roeters et al., 2009). A third publication from the same study shows that parents generally prioritize the type of activities with their children and due to work demands are likely to cut one-to-one activities rather than 
family activities (Roeters \& Treas, 2010). This study draws a direct relationship between work outside of home and time spent with children.

Using the Canadian General Social Survey on Time Use, Beaujot and Andersen (2007) conducted phone interviews with 5943 parents in 1998 to collect data on time use. Even more advanced than other studies in the same topic, these researchers attempted to associate the type of parents' work on leisure and family time. Through daily dairies, they estimated paid and unpaid work (i.e., child care, household work, yard work or home maintenance), parents' perceptions of time crunch (i.e., plans to slow down in the coming year, consider oneself a workaholic, tend to cut sleep, worry about not spending enough time with family and friends, constantly under stress, would like to spend more time alone, feel trapped in daily routine, try to accomplish more than they can handle), and controlled for age, education, gender, and household income. Using least square regression, researchers found that hours of work (paid and unpaid), more than types of work, are directly related to leisure and family time. Most importantly, time crunch was reported as higher for parents with children who worked full time compared to other parents.

In sum, studies conducted outside United States seem to agree that full time working parents generally experience time pressures in regard to the time they spend with children. They are forced to organize their day more strictly than other parents, or prioritize and cut out certain activities in order to cope with the lack of available time. 
These studies also hint that although both parents are involved and spend time with their children, fathers may differ from mothers in the type of activities they engage with children.

The American Time Use Survey collected data from 3525 mothers and 241 fathers (all parents of preschoolers) through two-wave phone interviews (2000-2001 and 2003-2005). This study shows that full time working mothers experience greater amounts of time pressure, feel often hurried, engage in multitasking, and are less involved in quality time with their children than part time working mothers. Full time working mothers were reported to read to children as much as similarly situated fathers but not as much as part time working mothers. Full time working mothers were also reported to laugh less with their children and about $55 \%$ of them felt they had too little time with their youngest child compared to $32 \%$ of part time working mothers. Full time working fathers spent almost the same amount of time with their children as full time working mothers but were less likely to feel they had too little time with their youngest child compared to similarly situated mothers (Milkie, Raley, \& Bianchi, 2009). Again it is noted that full time working parents seem to have some conflict between the time they spend working and the time they spend with children, although gender more than actual time seems to influence their perception of available time. It also seems of importance to note here a major limitation of this study: the large gap between the number of mothers and fathers. That may limit the generalization of differences between working fathers and mothers more than the differences between part time and full time working mothers. 
However, a similar finding was reported from a study conducted in 1997 where 860 parents of children of age 18 or younger were asked to report how much time they spent with children during workdays and non-workdays. The data came from the National Study of the Changing Workforce. Dual earning parents were more likely to feel under time pressure, but unlike the previous study only $64 \%$ of mothers compared to $71 \%$ of fathers felt they had less time with their children. Researchers report that fathers in this study spent more time working and commuting than mothers and that could be why they felt as having less available time for their children (Nomanguchi, Milkie, \& Bianchi, 2005).

Another report on the same study compares the data from 1997 to the Quality of Employment Survey taken in 1977. The researcher attempted to make the surveys comparable by matching parents' age (between 18 and 64), number and age of children (18 or younger), and their working hours per week (20 hours or more). The analysis of this comparison concluded that in 1997 parents experienced a higher work-family conflict although they reported spending the same amount of time with children. This was true specifically for fathers who in 1997 were more involved in family work and parental care (Nomanguchi, 2009). The findings from this comparison study face a few noteworthy limitations. First, a big gap exists between 18 to 64 years of age and each age subgroup within may be associated with different characteristics that make it difficult to blend them together. Second, the same could be accurate about children's age because for example parents of a toddler may encounter different issues and time constraints from parents of an adolescent. Third, other characteristics of these parents were not accounted 
for, such as education status, income level, race and ethnicity. These characteristics may be important when comparing two different surveys conducted at different times. Regardless of limitations, once again, this study confirms the strong relationship between working time and time spent with children as well as the influence of gender on parents' perception of time.

Another study that also analyzes data from the National Study of the Changing Workforce (where 1314 parents were interviewed) found that work-family conflict was associated with the level of "satisfaction" (i.e., parents with higher job satisfaction and parents with higher marital satisfaction reported less work-family conflict). One intriguing finding from this study: full time working fathers were generally more satisfied with their available family time than full time working mothers (Hill, 2005), a finding that agrees with the Milkie et al. (2009) study but not the Nomanguchi (2009) study. Some relations between gender, work, and time spent with children appear to call for further investigations.

The types of demands in the work-family relationship are the focus of a study that used data from the National Study of the Changing Workforce (Voydanoff, 2005). This research explored three types of work demands: (1) time based, (2) strain based, and (3) boundary spanning demands. The time based demands such as working extra hours and strain based demands such as pressure from work, were more likely to be associated with work-family conflict. It is important to note that findings from these two latter studies do not exclude each other in terms of what influences family-work conflict. For example, satisfaction levels either with work or family could lessen the family-work conflict, but 
higher demands on time or pressure could in turn cause less satisfaction on the job and increase the family-work conflict.

The work-family balance has been the focus of investigation for yet another study. Using time dairies and surveys (National Survey of Parents) of 933 parents, the researchers examined the quality of parental time in relation to parents' feelings of workfamily balance. This study allowed for collection of various data on children-parent types of leisure activities as well as on general feelings of parents about their job satisfaction and work-family balance. The work-family balance and the time spent with children are reported as complex issues although this study brings some insights on the actual daily conflict for parents. Researchers conclude that time spent in routine care was associated with less work-family balance whereas time spent in leisure activities was associated with a better work-family balance for most mothers but not fathers. Parents who felt they spent too much time or too little time with children were also less satisfied with their jobs and work-family balance (Milkie, Kendig, Nomanguchi, \& Denny, 2010).

Time dairies data from 226 couples with children collected in 1981 reveal that dual earning couples spend less time with their children than single earning couples. Full time working fathers seem to reduce the amount of leisure activities and television watching but not the time directly related to children. Full time working mothers on the other hand seem to have less available time with children not necessarily because of their full time work, but because they are also more involved in household work (Nock \& Kingston, 1988). This finding hints that gender rather than working time may be more related to time spent with children. 
Slightly different, the National Longitudinal Survey of Youth - Child Supplement (1979 to 1994) collected yearly data from 12,686 men and women who were 14-21 years old in 1971. Aiming at finding a relationship between parental work schedules and adolescent depression, the researchers gathered data on maternal and paternal night shifts, the number of meals shared together with children, and the time spent together. They measured the time parents spend with children by the number of activities parents and adolescents reported, such as going to the church, movies, shopping, or outings. Based on analysis from structural equation modeling this study concluded that increased work at night by mothers was significantly associated with a lower quality of home environment and fewer meals together but not necessarily with adolescents' depression levels (Han \& Miller, 2008). The authors further showed that irregular shifts by both mothers and fathers increased the likelihood of mothers knowing where the child was, and this in turn, reduced levels of adolescent depression.

Another report (Han, 2008) from the same study shows that maternal work shifts may be related to more problem behaviors among children. Problem behaviors were measured on six dimensions: antisocial behavior, anxiousness, depression, headstrongness, hyperactivity, immaturity, and dependency. Han concluded that behavioral problems were highest among children of single mothers who worked at night, and more so for children of mothers who worked as a cashier or other service occupation. Children of parents who both worked night shifts were also problematic, but less so than children of single mothers who worked during night shifts. The least behavioral problems were noted among children whose fathers worked night shifts but whose mothers worked 
during the day. These findings suggest that night shifts work of parents seems to relate to children's behavior problem. On the other hand, this study provides little information on other characteristics of the families who participated, such as parents' education level, their income, race and ethnicity, and whether it is the gendered interaction between parents and children rather than night shifts work that influence children's behaviors. These other characteristics may affect children's behavior problems in unknown ways.

A more recent study, conducted between 2002 and 2004, also examined parents' work schedule in relation to parental behaviors by interviewing 55 dual earning parents. It concluded that mothers' work schedule did not influence their parental behaviors, the amount of time they spent with children, or their knowledge of children's activities. On the other hand, fathers whose wives worked night shifts were more engaged with their children. These fathers appeared to spend more time with children, had extensive knowledge on children's life and activities, and received more disclosures from them (Barnett \& Gareis, 2007). The study implies that parental behaviors may not change because of mothers' working hours or their schedules, but the amount of time fathers spend with children seem to relate to mothers' working schedules.

Another study based on data from the 1996 Survey of Income and Program Participation (SIPP) examined 4476 school age children and their matched pairs of both parents to investigate the relationship between parental employment and children's academic performance. Researchers collected weekly data on work histories for a period of four months. Regression analysis revealed that mothers' employment was not associated with children's academic performance. However, fathers' involuntary work 
separation (i.e., being fired) was associated with lower grades, school suspension or class repetition for children. Researchers had hypothesized that parental job loss may influence children's academic performance because of income instability, however, they found that involuntary job losses for fathers was associated with school suspension and class repetition for children among lower and higher income families. The only difference mediated by income was that fathers' involuntary job loss was more commonly associated with class repetition among lower income and more commonly associated with school suspension among higher income families (Kalil \& Ziol-Guest, 2008). This study, therefore, implies that there is little relationship between employment status and children's academic performance, but perhaps family dynamics are related to children's academic performance.

A similar study attempted to measure the relation between first year maternal employment and children's development outcome for 1483 children taken from the Fragile Families and Child Wellbeing Study (FFCW) from 1998 to 2000. Researchers were interested in two developmental outcomes: (1) receptive vocabulary size and (2) number of behavior problems. Results from this study indicate that first-year maternal employment is associated with lower vocabulary scores for White, but not Black or Hispanic children and with elevated levels of behavior problems for Hispanic, but not White or Black children. Similar to the Kalil and Ziol-Guest (2008) study, researchers concluded that such discrepancies point out that first year maternal employment is not related to children's vocabulary size and number of behaviors, but could be due to other 
dynamics, in this case, perhaps differences among racial and ethnic groups (Berger, Brooks-Gunn, Paxson, \& Waldfogel, 2008).

A third study attempted to examine the relationship between maternal employment and children's development. Data were taken from National Longitudinal Survey of Youth, from where a sample of US residents born between 1957 and 1964 were interviewed from 1979 to 1989 . This study measured vocabulary, reading levels, and mathematics achievement for children of 3-4 years old and 5-6 years old. It concludes that maternal employment is associated with lower vocabulary scores for 3-4 years old children as well as lower reading and mathematical skills for 5-6 years old children (Ruhm, 2004). This study is conducted at least 10 years earlier than both previous studies on this similar topic, and besides maternal employment and children's level of reading and mathematics, there is little other information. For example there are no data on racial or ethnicity variables of these parents, or on fathers' employment situation.

Studies conducted in the United States point to a possible relationship between parental work and time spent with children. However, although many of these publications appeared after 2000, with the exception of two studies, the data in these reports are somewhat outdated. Some of these studies were conducted one or two decades ago and much of the dynamics have changed. For example, there has been an increase of 20\% of dual earning families in the United States since 1998 (US Department of Labor, 2010). Studies that were conducted more recently also included and considered a larger number of variables when analyzing the relationship between parents' work and parental 
time — such as education, income, race and ethnicity—whereas older studies provide limited information on other possibly influential variables. It is of particular interest to note here that both sets of studies-conducted within or outside of United States-maintain that working parents experience higher limitations to their available time with children.

The data used in this current study is only focused on working parents, but it includes recent information on parents' reports of work satisfaction, and the number of hours they are capable to spend with their children in a regular workday. It also includes relatively complete information for a thorough investigation that can contextualize the relationship between time and willingness to medicate through a number of parental characteristics such as gender, marital status, income, race, and ethnicity.

\section{Marital Status and Time Spent with Children}

Four new studies ( 3 conducted in the United States and 1 study comparing data from the United States and the United Kingdom), and one previously discussed report added information on the relationship between marital status and the available time spent with children. Kalenkoski, Ribar, and Stratton (2007) compared time dairies from 2003 and 2004 American Time Use Survey data (based on 21,023 individuals) and from the United Kingdom Time Use study of 2000 (based on 2,642 individuals). They concluded that single parents in both countries spend more time in childcare and time in activities with children than their married or cohabiting counterparts. Single parents in the United States worked more hours and spend more time commuting than single parents in the United Kingdom, but the time spent with children seemed to be higher for both groups of single parents in both countries. 
These findings are contradicted by other studies that suggest that children in single parent families spend more time in passive activities such as watching television or playing alone (Sandberg \& Hofferth, 2001). Sandberg and Hofferth (2001)—using data from Hofferth (2001), discussed in the previous section-measured the way children spent their time and the activities in which they are involved. They defined time with children in (1) time engaged with children, and (2) time accessible to but not engaged with children. The authors interpret the greater amount of single parent children in time accessible but not engaged with children as relating to parents' lack of available time and their limited financial means compared with married or cohabiting parents (Sandberg \& Hofferth, 2001).

Based on the same Child Development Supplement of the Panel Study of Income as Hofferth (2001), Folbre, Yoon, Finnoff and Fuligni (2005) critique how other researchers have conceptualized the measure of time and re-analyze the data based on another set of standards. They divide time devoted to children as being spent in active and passive care with a specific set of activities for each group (for example, passive care was considered the time that parents may spend with children but without interacting whereas in active care time both parent and child were engaged in interaction with each other). Different from Kalenkoski et al. (2007) and like Sandberg and Hofferth (2001), this study concludes that children in single parent families spent a relatively greater amount of time in passive care compared to children in two-parent families in the United States (10.4 hours per week compared to 7.6 hours per week). Active care was also different for children in single parent families compared to two-parent families in this 
study (24 hours per week for single parents compared to 31 hours per week for twoparent families). Kendig and Bianchi (2008) also conclude that single mothers spend less time with their children than married mothers mostly because of social structural disadvantages (Kendig \& Bianchi, 2008). This study used American Time Use Surveys of 2003 and 2004 by selecting 4,309 married and 1,821 single mothers of children 13 years old or younger.

Clearly, the difficulties of measuring time are present in most studies but one can still conclude that marital status is perhaps related to the available time parents spend with their children. As shown the findings are inconclusive as to whether single or married parents spend more or less time with children and whether that time is passive or active. But, it is somewhat conclusive that marital status should be an important variable when researchers focus on measuring parents' available time with children.

\section{Gender and Time Spent with Children}

Two studies conducted in the United States that focused exclusively on how mothers and fathers spend their time with children seem to agree that mothers spend more time with their children than fathers. Abroms and Goldscheider (2002) used data collected on 13,930 women taken from the Public Use Microdata Sample of United States in 1990. After closely investigating the relationship between employment and parental time pressure for single mothers, married ones, cohabiting with a partner, and cohabiting with another adult, they found that mothers tend to adjust their working hours according to their specific home situation. Married mothers were inclined to leave the 
financial burden to their spouse and avoid work. Mothers cohabiting with an adult or a partner differed depending on the relationship built with the partner/adult.

Fathers, on the other hand, seem to have recently increased the amount of time they spend with children and become more involved in their children's daily development (Sayer et al., 2004). This research examined time diary data from the 1960s to the late 1990s. United States National Time Use data collected in 1965 (417 mothers and 326 fathers), 1975 (369 mothers and 239 fathers), 1985 (334 mothers and 184 fathers), and 1998 (274 mothers and 141 fathers) were used after adjustments to make the surveys comparable. Researchers found that although mothers still spend a greater amount of time in childcare, fathers' engagement in childcare has increased over time. The quality of time spent with children also seems to differ; fathers spent more time in leisure and educational activities and mothers were more engaged in chores such as feeding, bathing, and cleaning (Sayer et al., 2004).

While the most recent data in these studies date from 1998, the trend of fathers' increasing engagement in childcare activities may have further grown more recently. Both these studies suggest that the amount of time and the quality of time mothers and fathers spend with their children may differ. It would be necessary therefore to see how the association between gender and time spent with children stands, specifically for working mothers and fathers. Whereas the amount of time spent with children may vary because of gender when one parent is homemaker, the situation may vary when both mothers and fathers are working. It is difficult to draw a directional hypothesis based on 
this literature, but it is important to investigate the influence of gender on time spent with children and willingness to medicate for working parents.

\section{Race and Ethnicity and Time Spent with Children}

Three studies (all conducted in the United States-one already detailed in sections above) shed light on the possible relationship between race and ethnicity and available time with children. Because of financial difficulties and the fact that they often do not live with their biological children, African American fathers are less likely to spend time with their children compared to White parents (Golden, 2008). Using data from May Supplement on Work and Work at Home of the Current Population Survey (CPS) of 50,000 families from 1997 to 2004, Golden examined the association between race, flexibility of work, marital status, and work at home. The results suggest that African American mothers and fathers were less likely to have flexible hours of work. Mothers were generally working more at home, especially if they were married or had young children. Additionally, higher educated African American parents were more likely to have access to flexible working hours compared to others (Golden, 2008). But if employment, income, marital status, and family size are controlled for, African American parents are reported to spend about the same time with their children as White parents (Hofferth, 2003).

Hispanic parents, on the other hand, are more likely to utilize relatives and extended family members in childcare responsibilities compared to any other ethnic group (Delgado \& Canabal, 2006). Using a subsample of 192 people self identified as of Latino origin and 2,226 self identified as non Latino from the 1997 National Study of 
Workforce, this study focused on negative spillover from work to family among Latino and non Latino population. Examining life satisfaction, time with family, working hours, and pressure from work, researchers suggest that Latinos may enjoy specific family dynamics that keep them generally happier and with lower negative spillover from work to family. For example, Latino parents are more likely to share meals together and spend time in leisure activities with their children (Hofferth, 2003) than any other ethnic groups. Race and ethnicity cannot be looked at in isolation from other variables such as employment, income, and education. Studies have shown that once these other variables are controlled for, race and ethnicity may not influence the amount of time parents spend with children (Golden, 2008).

The current study allows for a thorough analysis of different groups in regards to race and ethnicity. Because of the nature of the original study, the sample is equally divided between African Americans, Hispanic, and White parents living in Miami-Dade and Broward counties of South Florida. The subgroup of working parents taken from the original study also saves the same equal division between African Americans, Hispanic, and White parents. Although the literature may not be conclusive about the direction of this hypothesis, the variable of race and ethnicity seems an important variable to add to the analysis.

\section{Characteristics of Children and Parental Time}

Insights on how the characteristics of the child may influence the distribution of parental time are scarce. Two reports (both conducted in the United States and one study detailed in sections above) bring some data on the matter. The number of children in a 
family may also influence the available parental time. Mothers in larger families face the burden of more chores and are likely to occupy themselves mostly in passive care and supervision compared to mothers in smaller families (Hofferth, 2001). Sex of the child is also related to parental time. Parents spend more time with children of the same sexmothers pay more attention to their daughters and fathers are more likely to engage in activities with their sons (Hofferth, 2001; Zick \& Bryant, 1996).

Using National Time Use data from 1975 to 1981, Zick and Bryant (1996) investigated the data on 2,100 families. They found that both age of a child (parents being more involved with younger children) and the sex of the child (fathers spending more time with sons, mothers spending more time with daughters) influenced the distribution of parental time within the family. Thus, the number of children per household, the age and sex of children are likely to influence the amount of time spent with them. The present study has collected information only on the number of children per household and it is certainly an important variable to examine further as it may influence the available time of parents and indirectly their willingness to medicate problematic behaviors.

\section{Available Parental Time and Child Development}

The scientific literature has established that a few characteristics of parents and children are likely to influence the amount and the quality of time parents are able to spend with their children. As discussed to this point, work, work satisfaction, marital status, gender, race and ethnicity, and characteristics of children may be used as predictors of the amount and the quality of time parents spend with their children. Since parents are usually the primary actors in the socialization process of their children, 
parental time is important for children's development. Although parental time is only mentioned in passing in the literature relating to parents of ADHD children, it certainly occupies a prominent position in the child rearing literature. As noted at the beginning of this dissertation, parental time with children is strongly associated with positive child development and wellbeing outcomes (Hofferth \& Sandberg, 2001; Hsin, 2009; Kalenkoski et al., 2007).

The time parents are able to spend with their children affects children's wellbeing and their academic performance (Hofferth \& Sandberg, 2001) - problems that are present among most ADHD children. Language acquisition, for example, relates to the development of the child at an early age and is the primary means of managing child behavior (Rice, 1989, p. 155). To develop language, children need opportunities to interact with other people, to listen to conversations, and be able to practice words and sentences and elicit responses to them (Hofferth \& Sandberg, 2001; Rice, 1989). Language development, in turn, requires time from the parent to engage in interaction with the child and it may also be reflected in academic performance of the child. Although Rice's study does not mention parental time as such, it is an educated guess that parents need to spend time with their children in order to nourish their language development.

The type of activities children engage in with parents at home also influences their reading capabilities. Hofferth and Sandberg's (2001) study of 2,818 American children' use of time before and in early school years also shows that cognitive achievement and various behaviors were affected by engaging in learning activities with 
parents. This same study revealed that having meals together with parents was associated with less external and internal problems for the child. Additionally, active leisure time was associated with higher scores in applied problems tests and reduced problem behaviors (Hofferth \& Sandberg, 2001). Genetic influences on language, reading, and academic development of the child are also discussed in the literature on child development, but non-genetic factors are responsible for more than half of the variance for most complex behaviors (Plomin, 1989, p. 108).

Informal training of the child, outside and prior to formal schooling, appears crucial for child development — production of human capital of the child — but is also perceived as an investment and time costly from the parent (Leibowitz, 2003). Leibowitz's study finds that although the time parents (specifically mothers) spend with their children may have been reduced because of their work demands, it may also enrich the environment for some children and the quality of time spent may balance the reduction of the actual time. Thus, the time parents spend with children seems to leave its marks on children's development, wellbeing, and academic performance.

\section{Relationships Between Time and Choices}

Scientists have always been concerned with the understanding of time from various disciplines such as theoretical physics, anthropology, astronomy, philosophy, and economics (Carstensen et al., 1999). We know time is an essential commodity in a number of everyday life situations. Its implications are also known to be crucial when we decide or judge about different life circumstances. Among such circumstances-when time is deemed valuable-are decisions related to medical treatment (Rieskamp \& 
Hoffrage, 2008). Studies have noticed an important difference on decisions when people feel under time pressure or conceptualize time as ample (Carstensen et al., 1999). To take decisions, people need enough information on a particular topic. Once all the information is obtained and all the dynamics are clear, we are able to take decisions that seem to fit us best. Clearly, time is crucial in being able to gather and process the information on a particular topic. However, it seems that people often find themselves in need to take decisions quickly without evaluating all the possible information. In fact, if feeling under time pressure, people accelerate their decision making process and tend to employ selective information (Rieskamp \& Hoffrage, 2008). If we were to apply this finding to parents of ADHD children, we could wonder whether under time pressure they become selective in processing the information around them and rush into deciding whether or not to medicate their children.

Difficulties of parents of ADHD children as they attempt to determine their child's "normal status" (Kendall, 1999), battle with the health care and education system (Blum, 2007), decide on the best working treatment for their children (Taylor, O’Donoghue, \&Houghton, 2006), or struggle with the trial and error phase of medications (Dennis, Davis, Johnson, Brooks, \& Humbl, 2008), are well documented in the literature. What is not apparent, however, is the amount of time these parents generally spend with their children, or the amount of time they need to make a decision on medicating or not medicating ADHD-like behaviors of their children. Under constraints of time, their understanding or perception of such behaviors may be based on selective information. 
When an individual experiences time pressure while trying to take a decision, the individual may attempt to adjust the pressure by simplifying the decision making strategy (Dhar \& Nowlis, 1999; Rieskamp \& Hoofrage, 2008) and give emphasis to emotional goals (Carstensen, 2006). Socioemotional selectivity theory recognizes the importance of time in the pursuit of social goals (Carstensen et al., 1999). According to this theory, when time is perceived as open-ended, knowledge-related goals are prioritized. In contrast, when time is perceived as limited, emotional goals assume primacy (Carstensen et al., 1999, p. 165). Perception of the available time, therefore, seems to influence people's decisions, choices, and the pursuit of goals.

Attempting to conceptualize reasons behind parents' choice to medicate autistic children, one study found that when parents perceived themselves as being under high stress, had many children to take care of, or had late born children, they were more likely to opt for medications (Konstantareas, Homatidis, \& Cesaroni, 1995, p. 445). This study concluded that patterns of medicating were not related to the severity of the child's behaviors but to the particular situations of parents. Turning to parents of ADHD children, we know that their accounts of children's behaviors are the basis for diagnosing and treating children (Arcia et al., 2004). In order to judge these children's behaviors, parents need to observe them, implying the necessity of time with them. Therefore, the available time with children is likely to influence parents' judgments of children's behaviors, which could lead to the next decision of medicating or not medicating such behaviors. Naturally, having time to think and reason is also likely to influence such decisions for these parents. 


\section{Parents of ADHD Diagnosed Children}

Parents of ADHD children often find themselves in a complex situation (Hansen \& Hansen, 2006). They are an intrinsic part of the ADHD phenomenon, deeply involved in all facets of ADHD (Arcia et al., 2004; Hansen \& Hansen, 2006; Kendall, 1998).

Parents are usually the first to be notified by teachers concerning their children's ADHDlike behavior (Cohen, 2006; Sax \& Kautz, 2003) or to notice their children's difficulties themselves. They use their own judgment about their child's behavior to follow up with a professional, and to decide whether to follow that professional's recommendations (Arcia \& Fernandez, 2003; Bussing \& Gary, 2001; Hansen \& Hansen, 2006). Professionals are expected to listen to parents' accounts of their child's behavior, and parents are usually in charge of choosing and providing treatment for their ADHD child. To make these decisions, parents of ADHD children might try to employ their own cognitive schemas (Arcia et al., 2004), opinions from friends and family (Jackson \& Peters, 2008), and acquired knowledge from reported findings, researchers, and media (Taylor et al., 2006) — all of these likely in some dynamic interaction. As noted, parents are key actors in handling issues of academic performance, in providing accurate accounts of their child's behaviors, and in administering medications. The decisions that parents face may seem daunting and complex, especially since it may seem that professionals' recommendations are entangled in a web of controversies and that mainstream treatment involves the long-term use of psychiatric drugs. 


\section{The Nature of ADHD}

A national survey of children's health published by the Centers for Disease Control and Prevention (CDC) in 2003 concluded that around 4.4 million children from the ages of 4 to 17 are diagnosed with ADHD in the United States and around 2.5 million of them take psychiatric medication to control their condition. A more recent CDC study focusing on capturing the diagnostic rates of ADHD children reports a 5.5\% increase from 2003 to 2007 (Pastor and Reuben, 2008). In 2007, 9.5\% of US children (5.4 million children) aged 4 to 17 years were diagnosed as having ADHD, 66.3\% of whom $(2.7$ million) were prescribed stimulants such as methylphenidate and amphetamines (CDC, 2010).

Nevertheless, the diagnostic label of ADHD remains controversial. Sometimes it refers to a common "neurobehavioral disorder" of childhood (Barkley, 2000), and at other times to various medicalized temperamental, educational, and cultural differences and difficulties of children (Timimi \& Leo, 2009). Although the ADHD construct is commonly treated as representing a valid disorder or psychopathological entity in the fields of psychiatry, pediatrics, psychology, and education, critiques from within each of these fields and others have contested its validity since its inception (review by Cohen, 2006; Timimi \& Leo, 2009). Debates about the relative merits of the positions, augmented by societal ambivalence about medicating children, give rise to controversies widely aired by the media (e.g., America's Medicated Kids, BBC, 2010; The Medicated Child, PBS: Frontline, 2007). 
The language employed to define the controversial diagnosis of ADHD variously includes "problem," "condition," "disorder," "disability," and "illness" or "disease" (e.g. Arcia et al., 2004; Charach et al., 2006; Blum, 2007). Occasionally, it includes less negatively loaded terms such as "individual difference" (Carpenter \& Austin, 2007), "behavioral difference" (Jacobson, 2006) or "evolutionary advantage" (Armstrong, 2006). This variety of labels probably reflects uncertainties among researchers on what ADHD is. For example, the term ADHD appears sometimes as a common neurobehavioral disorder of impulse control (Barkley, 2000) and impaired working memory (Rucklidge, 2006), accompanied by brain volume abnormalities (Castellanos et al., 2002), and at other times as an indicator of the lack of fit of a child's temperament with a fixed structured environment (Diller \& Tanner, 1996), as a questionable label for normal disruptive or inattentive child behavior (Leo, 2002; Stolzer, 2005), or as a cultural construct (Timimi \& Taylor, 2004).

Uncertainty about the nature of ADHD is also present in the Diagnostic and Statistical Manual of Mental Disorders, $4^{\text {th }}$ edition, text revision (American Psychiatric Association, 2000), where the diagnostic criteria for ADHD are all qualified by the undefined "often" (often forgets, often fidgets, often easily) and includes unclear descriptors such as "details," "careless mistakes," or "necessary tasks" that are sometimes seen as vague and subjective (Barnes, Cerrito, \& Levi, 2003; Schwartz, 2005). These same qualifiers are present in the proposed revisions of the ADHD definition for the DSM-5 scheduled for publication in 2013 where additional undefined qualifiers and descriptors are added as examples to explain the wording of definitions such as "misses 
details," "work is inaccurate," "poor time managements," "easily sidetracked," "unrelated thoughts," and others.

The proposed changes of the ADHD definition also include lowering the number of present symptoms from 6 to 4 for adult ADHD and dividing ADHD into three separate disorders based on hyperactivity, inattention, and impulsiveness. Furthermore, four new criteria are added to diagnose hyperactivity and impulsivity subtypes of ADHD on adults and children: (1) tends to act without thinking (for example making important decision at the spur of the moment such as impulsively buying items); (2) is often impatient while waiting for others (for example feeling restless when waiting on someone or speeding through traffic); (3) is uncomfortable doing things slowly and systematically; and (4) finds it difficult to resist temptations or opportunities (for example an adult may commit to a relationship after only a brief acquaintance or a child may grab toys off a store shelf). Criticism towards these revisions-although not yet published-has already begun. The upcoming version of DSM is seen as lowering the bar for many personality and behavioral problems that will cause an increase the number of people diagnosed as mentally ill (Frances, 2011). An increase in the number of people diagnosed will naturally increase the number of users for psychiatric drugs via prescription. Some 9,000 researchers from the Society for Humanistic Psychology (a section of the American Psychological Association) have expressed their disagreement towards changes in the new DSM. They have signed a petition, within sixty days of the proposed changes, against lowering diagnostic thresholds pointing out that the new changes of DSM may lead to excessive medicalization, may put vulnerable population at risk, and falsely 
increase the number of people diagnosed (Balt, 2011). The petition also noted that the newly proposed disorders have no grounds in the scientific literature. In a particular section concerning ADHD, the open petition notes that: "The reclassification of ADHD to the new grouping of neurodevelopmental disorders seems to suggest that ADHD has a definitive neurological basis. This change in combination with the proposal to lower the diagnostic threshold for this category, poses high risk of exacerbating the extant overmedicalization and over-diagnosis of this category."

\section{Treatment of ADHD}

Researchers' discussions about the validity of ADHD can become argumentative at times (Barkley, 2002; Jureidini, 2002), even more so when the topic of the use of psychiatric medication arises. Medication remains the mainstay treatment for ADHD diagnosed (ADHD) children (Bressman \& Nass, 2002; Mccracken et al., 2003), but the issue remains mired in controversy. The ability of drugs to reduce behaviors seen as ADHD symptoms is well established (Biederman, Spencer, Wilens, Prince, \& Faraone, 2003; Wilens, Biederman, \& Spencer, 2002), but so are warnings about these medications' potential side effects, such as insomnia, increased blood pressure, anxiety, depression, loss of appetite and weight, tics, and growth suppression (Breggin, 2000). In 2006 the Drug Safety and Risk Management Advisory Committee of the Food and Drug Administration (FDA) voted for a black box warning to be attached to stimulants used to treat ADHD, advising consumers of their cardiovascular risks probably caused by chronic elevation of heart rate and blood pressure (Nissen, 2006). These concerns about the potential hazardous effect of stimulants on cardiovascular and central nervous systems 
were opposed by arguments that although ADHD patients should be aware of potential side effects, the opinions on stimulants shared with the Committee may have been pejorative and biased against psychostimulants (Biederman, 2006).

More recently, researchers published findings that showed an association between methylphenidate use — the leading psychostimulant for ADHD — and sudden unexplained death among children without prior heart conditions (Gould et al., 2009). Although appraised to be the first methodologically rigorous study to identify that link (Vitiello \& Towbin, 2009), this study was still criticized for not underscoring that stimulants are innocuous and have therapeutic uses (Vitiello \& Towbin, 2009).

\section{Diagnosing ADHD}

The process of diagnosing ADHD faces a number of challenges. To diagnose the condition, professionals are forced to rely solely on adults' observations of children's behaviors because of lack of any test or measure that can detect the condition (Wolraich, 1999). The current version of DSM-IV requires that parents and teachers report their observed behaviors of children, but the suggestions for the DSM-5 include an addendum that when direct teachers' reports are unavailable, "weight will be given to the information provided to parents from teachers" (APA, 2010). Second, the effects of stimulant medications on children' behaviors are similar regardless of diagnosis or lack of diagnosis (Wolraich, 1999, p.163) which limits a clear understanding on why and who gets labeled as ADHD. Also, ADHD-like behaviors are common among all children (i.e., Barkley, 2005; Cline \& Fay, 2006; Heininger \& Weiss, 2001; Runkel, 2007; Sonna, 2005), an additional factor that complicates the diagnosing process. 
Even though ADHD-like behaviors are common among all children and medications also have an effect on behaviors of all children, it is typically up to the parents to distinguish between ADHD-like and non-ADHD-like behaviors. Studies report that parents are often confused when faced with the task of such distinction (Arcia et al., 2004; Malacrida, 2001; Kendall, 1998; Hansen \& Hansen, 2006). However, the literature suggest that the differences between an ADHD and non-ADHD children are: (1) the frequency of such behaviors (Barkley, 2005; Biederman, 2003) or-if we use the language of DSM-IV-how often they occur, (2) the relation between behaviors and poor academic performance, which is also the primary incentive for parents to seek a diagnosis (Arcia et al., 2004; Malacrida, 2001), and (3) the appearance of disruptive behaviors in more than one setting (Perry, Hatton, \& Kendall, 2005).

Therefore, to determine whether a child does or does not "have" ADHD, the authorized professional relies upon the perception of "how often" or the frequency of the behaviors reported by parents and teachers (Wolraich, 1999). In 2003, Barnes, Cerrito, and Levi conducted a study in a large urban university where they interviewed 115 students to measure the understanding of "often" as used to define the diagnosis of ADHD in DSM-IV. The authors found that the frequency of a behavior qualified as occurring often changed from one respondent to the next (Barnes et al., 2003), meaning that perceptions of the frequency of ADHD-like behaviors can change from one parent to another.

In turn, the authorized professional who often diagnoses ADHD within a 30minute visit (Sonna, 2005) relies upon interpretations of parents and/or teachers of the 
child's behavior (Reiff \& Tippins, 2004). In fact, it is typically up to the parents' judgment of their child's behavior to follow up with a professional to seek a diagnosis (Arcia \& Fernández, 2003; Bussing \& Gary, 2001; Hansen \& Hansen, 2006), usually initiated by the child's teacher because of the child's poor academic performance (Blum, 2007; Cohen, 2006; Leslie et al., 2007). It is unclear when and how the relationship between the frequency of problem behaviors and poor academic performance is established, but it seems that once this relation is perceived as accurate, usually initiated by teachers (Malacrida, 2001), the door to a diagnosis of ADHD becomes a strong possibility and parents consider seeking a professional (Arcia et al., 2004; Perry et al., 2008). Pediatricians, child psychologists, and child psychiatrists are among the common authorities who diagnose ADHD (Biederman, 2003). Because of the well-recognized effect of medications on improving children's performance, one may question whether the purpose of having an ADHD diagnosis is having access to medications.

It should also be added here, that professionals throughout the world are trained to selectively attend to what patients say, directing dialogue along a trajectory leading to a diagnosis (Mechanic, 1995; Waitzkin, 1991). They even interrupt patients' narratives to gain the needed information within a desired time frame, avoiding digressions and irrelevancies (Mechanic, 1995). This attitude could explain why the parents of ADHD children perceive doctors as interested solely in prescribing medication, not caring about the child's problem (Charach et al., 2006; Concannon \& Tang, 2005; Olanyian, DosReis, Garriett, Mychailyszyn, Anixt, \& Rowe, 2007), and lacking an understanding of the social and family dimensions of the child's problem (Cohen, 2006; Dennis, Davis, 
Johnson, Brooks, \& Humbl, 2008). It clearly seems that the meeting between the professional and the parent is characterized as an often predisposed to diagnose or not diagnose professional with an anxious parent, triggered by the child's performance at school.

Although poor academic performance is usually blamed upon ADHD, this is not an uncontested idea. In fact, Jacobson's study shows that all children show behaviors that could be related to ADHD, regardless of gender or academic success (Jacobson, 2006, p. 171). This field study in American and British classrooms showed wide fluctuations of attention within every child, and the degree of ADHD-like behaviors was so extensive that the researcher deemed it impossible to differentiate ADHD from non-ADHD children (Jacobson, 2006). In an attempt to define ADHD, one might perhaps reach the conclusion that ADHD seems to entail common children's problematic behaviors that are perceived by caretaker adults as occurring "often" and as causing poor academic performance - a perception usually initiated by teachers and diagnosed by a willing professional.

As shown, the way ADHD is diagnosed varies mainly on parents' perceptions, which could vary according to the time available to them to observe and judge such behaviors. The problem, however, is that a diagnosis of ADHD is followed by the option of using psychiatric medication to alter children's behaviors and that may put the initial perceptions of parents to question. Not surprisingly, parents vary on the decision of medicating their children (Kendall \& Shelton, 2003; Leslie et al., 2007). In fact, the CDC report of 2008 estimates that $44 \%$ of diagnosed ADHD children do not take medications 
to control their behaviors. It is then likely, given all the literature and positions reviewed so far, that parents' willingness to medicate or not medicate children has some roots in the available time of these parents to spend with their own children.

\section{Similar Emotional and Behavioral Problems}

Undoubtedly, many other emotional and behavioral problems among children share some of the core characteristics of ADHD, such as the lack of biological markers, have imprecise definitions in the DSM, are disruptive behaviors, and commonly diagnosed based on parents' or other adults' judgment of children's behaviors.

Oppositional Defiant Disorder, for example, is a diagnostic category often considered as occurring simultaneously with ADHD (Egger \& Anglod, 2006) and characterized by disobedience and hostile behaviors of children towards authority. Like ADHD, ODD is also defined by DSM-IV by the use of undefined "often" (i.e., often looses temper, often

annoys people, often blames others). To diagnose ODD, clinicians rely upon accounts of parents and teachers on children's behaviors who rarely come to both agree on a child's behaviors (Munkvold et al., 2009), a requirement that may be soon removed from the DSM-5 and teacher/parent discrepancies may not be accountable. In addition, the nature of this childhood problem is considered to be nonspecific (Rey, Walter, \& Soutullo, 2007, p.458) and, like ADHD, characterized by disruptive behaviors.

Depression among children is another problem that seems to co-occur with ODD and/or suicidal ideation. In fact, a study found that children who exhibit symptoms of ODD at an early age are likely to feel depressed later, a relation that may explain the comorbidity between these two problems (Burke, Hipwell \& Loeber, 2010). By 
examining 2,451 girls between 5 to 8 years old for a period of 5 years, and evaluating their self reports, their teachers' reports, and those of their parents, researchers concluded that conducted disorder (CD) behaviors were not related to later depression of the child but ODD was related to depression. Clearly, the findings were based on the 5 years of the study and cannot predict future behaviors of these 2,451 girls.

Some other researchers believe that depressed children are more likely to manifest ODD than children without depression (Costello, Mustillo, Erkanli, Keeler, \& Anglod, 2003). These findings were based on a 7 year longitudinal study that evaluated 1,420 children from age 9 to age 16. Using the DSM-IV-TR criteria to evaluate a number of childhood disorders, researchers concluded that $25.5 \%$ of children with one diagnosis were likely to have another one by the time they were 16 years old. They also concluded that most children would still have the first diagnosed problem by that age, and commonly found that children with ADHD would also have ODD, children with depression would have anxiety, and children with anxiety would have depression by the age of 16 (Costello et al., 2003).

It is important to note here that children, who are already diagnosed with some problem or another, are also likely to take prescribed psychiatric medications that could cause additional health issues on any child. A diagnosed child is also more likely to embody the sick role, be considered as problematic by many surrounding adults, and is under teachers', parents', and doctors' frequent evaluation, a fact that may exacerbate his/her problematic behaviors. In addition, since the study was primarily focused on depression, it used the DSM-IV criteria to evaluate it. But depression also seems to share 
the ambiguity of its definition in the DSM-IV. Its diagnostic criteria have been criticized for not drawing a distinction between intense normal responses and abnormal responses, or disorders (Horwitz \& Wakefield, 2007, p. 683). Horwitz and Wakefield (2007) assert that people experiencing major life losses and transitions could experience depressed moods, have sleep irregularities, and diminished pleasure for two weeks. These behaviors, however, meet criteria for, and are often diagnosed as, Major Depressive Disorder (MDD).

Depression is sometimes accompanied by thoughts of suicide or the presence of suicidal ideation. Its presence among many other psychiatric categories triggers some researchers to think that suicidal ideation deserves its own unique category in DSM (Oquendo, Baca-Garcia, Mann, \& Giner, 2008). In fact, suicidal ideation is proposed to be a separate diagnosis in the upcoming DSM-5 (Otto, 2011). Suicidal ideation is defined as thoughts or talks about taking one's own life and is considered to be common among adolescents (Evans, Hawton, Rodham, \& Deeks, 2005) peaking in mid adolescence (Rueter \& Kwon, 2005). Although many children and adolescents seem to move in and out suicidal ideation, to fail assessing it could have potentially grave consequences for children and their parents (Kerr et al., 2008).

ODD, depression, and suicidal ideation share some similarities with ADHD. They lack biological signs, are mostly diagnosed based on parents' accounts of children's behaviors, are disruptive behaviors, have inconclusive diagnostic definitions in DSM-IV, and could easily be misinterpreted as mental disorders when they may actually also reflect normal reactions to adversity. It is important to mention that all these disruptive 
behaviors, although sharing a few core characteristics, also differ in terms of their consequences. A child exhibiting ADHD-like behaviors is likely to disrupt routines and structures that could be difficult to bear for teachers and parents, and that could influence the child's school performance. An ODD-like child may exhibit aggressive behaviors that could be problematic to teachers, other children, and parents of other children. A depressed child could show signs of unhappiness and isolation that may be troublesome for parents. A child who talks about killing himself could greatly disturb parents as well as harm himself. So, it would be of interest to see whether parents' willingness to medicate certain behaviors differentiates among these different childhood problems. From a functionalist perspective one could expect that the behavior parents are more willing to medicate is the behavior that they are less likely to have the available time to attend to and perhaps the one with the gravest potential consequences.

\section{Theoretical Model: Merton's Functionalist Perspective-The Purposive Action}

This study employs Merton's ideas of purposive action to investigate the relationship between parents' reported time spent with children in a regular workday and parents' willingness to medicate a child with ADHD-like behaviors. As discussed earlier, Merton maintains that purposive action is driven by motives-manifest and latent functions-which lead to a choice between alternatives. Manifest functions are "those objective consequences for a specified unit (person, subgroup, social, or cultural system), which contribute to its adjustment or adaptation and were so intended." Latent functions "refer to unintended and unrecognized consequences of the same order" (Merton, 1957, p. 117). Merton claims that one should look beyond the manifest functions to allow for a 
complete understanding of a specific purposive action. It is necessary to ignore the manifest function in order to concentrate and become aware of the latent function-one needs to move beyond the perceived obvious to grasp the implications of the less obvious. Also, in examining the latent function one should not consider "unforeseen consequences as undesirable consequences from the standpoint of the actor for though these results are unintended, they are not upon their occurrence always deemed axiologically negative" (Merton, 1936, p. 895). The intended function, on the other hand, could always be considered as "relatively desirable by the actor" (p. 895).

Traditional functionalism has been widely criticized as being a conservative perspective aiming to preserve social stability and not offer social change (Elwell, 2006). Merton argues that a traditional functionalist perspective focuses on stability whereas a focus on change alone leads to radical orientation; therefore it is upon the analyst to investigate and identify interrelated and mutually supported institutional and cultural elements (Merton, 1948, p.94-95). This is why Merton emphasizes the importance of latent functions, the inquiry of which can advance knowledge of sociocultural systems and advance understanding of human societies (Merton, 1968, p.122). Merton's theory of purposive action has been criticized by Anthony Giddens who analyzes Merton's ideas about the Hopi rain dance. Merton claims that the intended function of the Hopi rain-to rain - fails repeatedly and yet the Hopi rain dance continues. He explains this by the latent function of the society to socialize, and reinforce attachment to each other through the ceremony. Giddens maintains that such behaviors are unrelated to society's needs but rather to satisfy and fulfill the desires of people involved (Appelrouth \& Edles, 2006). 
The discussion of whose needs are fulfilled - those of the society's or the people directly involved - falls outside the realm of this research, since this study is merely focused on exploring a possible relationship between available time spent with children and parents' willingness to medicate ADHD-like behaviors.

This study appropriates the purposive action as the "willingness to medicate ADHD-like behaviors." Along these lines, the willingness to medicate ADHD-like behaviors involves motives and a choice between alternatives - to medicate, or to handle the situation differently. Following Merton's argument, we "cannot imply rationality of human action. Rationality or irrationality are not to be identified with the success or the failure of the respective action. For in a situation where the number of possible actions for attaining a given end is severely limited, one acts rationally by selecting the means which, on the basis of the available evidence, has the greatest probability of attaining this goal, and yet the goal may actually not be attained" (Merton, 1936, p. 896). Translating this logic to parents who are facing the choice of medicating or not medicating their children, one could see how their possible actions are indeed limited-considering all the dynamics: children's disruptive behaviors, possible consequences of such behaviors, teachers' claims, doctors' options, and parents' available time. Moreover, the available strategy that has the greatest probability of attaining the goal, for most parents, could be the practical choice to medicate children's behaviors. But, as previously stated, the practical choice should not be identified with the success or the failure of the respective action. That is, medicating children's behavior may not help to reach the desired goal. 
In his theory of purposive actions, Merton (1936) divides actions as unorganized or formally organized. He maintains that latent or unintended functions follow both types of actions, but the formally organized actions allow for a better sociological analysis of the latent function since "the very process of formal organization ordinarily involves an explicit statement of purpose and procedure" (p. 898). Parents' choice of medicating children's behaviors clearly fit the formally organized action because the purpose of medicating children (controlling their disruptive behaviors and consequences of behaviors) and the procedure (the actual administration of medications) follow explicit rules. This allows, therefore, for a better analysis of the latent function. In addition, Merton discusses the knowledge that is necessary for one to possess before undertaking any action. This is relevant to this research, since the topic of the amount and the kind of knowledge on medications and children's behaviors that parents receive from professionals is a sensitive one, and is not scientifically known. Although we are not certain about the amount of knowledge one has at hand before taking any actions, Merton's theory of purposive action predicts that in the face of limited knowledge people act based on opinion and estimate (p. 900). Importantly, when "situations demand for immediate action of some sort, the action will involve ignorance of certain aspects of the situation and will bring about unexpected results" (p. 900). Logically, time is an important factor when situations demand for immediate action, as Merton claims: "time and energy are scarce means" (p. 901). Turning to parents who need to choose to medicate or not medicate their children, time is crucial to gain knowledge about children's behaviors as well as about the means (i.e., medications) for controlling these 
behaviors. Time may also be critical because the decision to medicate or not medicate may impact a child's development.

To complement this body of reviewed literature, the current study is innovative in several ways: (1) this research does not take for granted that an objective definition of a condition ADHD is at present possible; it acknowledges the fact that different reasonable ideas exists about the nature of ADHD, including the idea that ADHD is nothing more than a concept; (2) its theory is drawn from a derivative of a functionalist perspectivemaking it the first study, to this author's knowledge, that employs this perspective to understand parents' willingness to medicate or not medicate problematic childhood behaviors; (3) it includes the perspectives of fathers as well as mothers; (4) it includes perspectives of parents reporting child with problems and parents reporting no child with problems; (5) it includes perspectives of parents who report belonging to different races and identifying with different ethnicities.

\section{Aims and Hypotheses}

The gist of this research is to examine the relationships between the time spent with children and parents' willingness to medicate ADHD-like behaviors, taking into account various sociodemographic variables. The conceptual model includes the direct and indirect relationships between sociodemographic variables (i.e., parents' working hours, level of satisfaction with work, gender, race, ethnicity, marital status, and the number of children) and parents' willingness to medicate ADHD-like behaviors among children. The following research aims and hypotheses were proposed: 
Aim 1: To determine the relationship between the amount of time working parents report spending with their children during a regular work day (predictor) and willingness to medicate ADHD-like behaviors (outcome).

Hypothesis $1 a\left(H_{1 a}\right)$ : Working parents' available time to spend with children during a regular work day will have a direct relation on parents' willingness to medicate ADHD-like behaviors. Specifically working parents who are able to spend more time with their children in a regular workday will be less willing to medicate ADHD-like behaviors. Such relation will hold only for parents reporting having a child with problems since reports of parents regarding likelihood to medicate behaviors-when reporting no child with problems—are expected to differ depending on parents being faced with the problem or not.

Aim 2: To determine the relationship between parents' work satisfaction (predictor) and willingness to medicate ADHD-like behaviors (outcome).

Hypothesis $2 a\left(H_{2 a}\right)$ : Parents' work satisfaction will have a direct effect on willingness to medicate ADHD-like behaviors such that working parents who are less satisfied with their work will be more willing to medicate children. This relation will hold only for parents reporting a child with problem.

Hypothesis $2 b\left(H_{2 b}\right)$ : Parents' work satisfaction will have an indirect effect on willingness to medicate ADHD-like behaviors via the intervening variable of time spent with the child. Parents who are less satisfied with their work will spend less time with the child; in turn, less time spent with the child will be associated with greater willingness to 
medicate ADHD-like behaviors among children. This relation will hold only for parents reporting having a child with problems.

Aim 3: To determine the direct and indirect relationships between parents' gender (predictor) and willingness to medicate ADHD-like behaviors (outcome).

Aim 4: To determine the direct and indirect relationships between parents' race and ethnicity (predictors) and willingness to medicate ADHD-like behaviors (outcome).

Aim 5: To determine the direct and indirect relationships between parents' family type (predictor) and willingness to medicate ADHD-like behaviors (outcome).

Aim 6: To determine the direct and indirect relationships between the number of children in a household (predictor) and parents' willingness to medicate ADHD-like behaviors (outcome).

Aim 7: To examine whether and how parents' perceptions of the most difficult aspect of raising a child differ between parents reporting a child with problems and parents reporting no child with problems.

As shown in the literature review, it is inconclusive whether and how gender, race, ethnicity, family type, and the number of children in the household influence the available parental time with children or willingness to medicate behaviors. Due to the literature's contradictory findings on the relations between gender, race, ethnicity, family type, and number of children in the household with the amount of time parents are able to spend with children, these aims do not have direct hypotheses. These relationships are 
investigated in this study. The same aims and hypotheses follow all other problematic behaviors that are investigated in this research such as ODD, depression, and suicidal ideation. 


\section{CHAPTER III: METHODOLOGY}

This chapter starts by introducing the original study and giving the specifics of the subsample used in this work. The research design, including the specifics of measures is discussed next followed by details on data analysis and data preparation. The chapter concludes by discussing the power effect and human participants consideration.

\section{Data Source}

Data analyzed and discussed in this work were collected from an original NIMH funded study (PI: David Cohen), the first known study that attempts to explain racial/ethnic differences in the frequency of prescriptions of psychotropic drugs to minors in the United States. A sample of 1,146 parents of children aged 4 to 17 years and living in South Florida was interviewed via telephone between May and October 2009. Because of its primary focus, this study used stratified random sampling to collect a similar proportion of parents considering themselves African Americans, Hispanics, or Whites.

The original study. Respondents were randomly selected through a commercially available "telephone frame" consisting of the first six digits (area code + exchange prefixes) of all telephone numbers in Miami-Dade and Broward counties. Computer software randomly generates lists of telephone numbers using four digit additions (from 0000 to 9999 ) to the original six-digits. This procedure generates listed, unlisted, and new telephone numbers of landlines only. The sample was stratified by race and ethnicity by attempting to select the same sample size for each of the above-mentioned population groups. Furthermore, the selection of respondents occurred in a two-step 
process. First, persons who answered the telephone were screened to determine their eligibility. If eligible and consenting, they were interviewed.

The Institute for Public Opinion Research (IPOR) at Florida International University (FIU) conducted the interviews. Since 1982 IPOR has been conducting survey research for FIU units, government, and the private sector. IPOR interviewers are fluent English/Spanish bilinguals. They participated in a 4-hour training session organized by the investigators, covering the study aims, the instrument, and the importance of properly selecting participants, before conducting the interviews. They utilized computer assisted telephone interviews (CATI), a system that allows for automatically using random digits dialing. The average interview lasted approximately 25 minutes. Fourteen experienced and bilingual interviewers collected the data.

Later, data were cleaned, entered into appropriate statistical software (SPSS) databases for testing and analysis. The original study is characterized by its unique focus - being the first study to gather information on parental willingness to prescribe psychotropic medications to children, the use of standardized measures and advanced analytic procedures. However, as with any scientific investigation limitations still exist. Because of its telephone interview methods, the sample could not include household without landline telephones, but at the time of the study approximately $97 \%$ of MiamiDade households had one (ACS, 2003). 


\section{Research Design}

This study aims to investigate the relationship between parents' willingness to medicate children's behaviors and the time they report spending with children in a regular workday. This study is specifically focused on working parents and considers a few other characteristics of the population sample that could influence the available time spent with children in regular workdays as well as the willingness to medicate behaviors. As depicted in the literature review, the characteristics this study controls for are: (1) race and ethnicity, (2) gender, (3) number of children in household, (4) family type, and (5) work satisfaction.

Because of its focus, the entire population of working parents who participated in the original study was employed for this cross sectional research design. In the original sample, 763 parents worked (618 full time and 145 part time). Among the working parents, 129 reported a child with problems whereas 634 reported no child with problems. This dissertation employed a subsample of the population of parents in the original study (763 out of 1145 parents) and 11 variables (1 intervening variable, 5 exogenous variables, 4 endogenous variables, and 1 open-ended variable).

\section{Measures: intervening, exogenous, endogenous variables, and open-ended}

variable. The following section details all the variables used in this cross sectional design study. Besides discussing the construction of each variable, some information is given about cleaning and preparation of variables. The section starts by discussing the intervening variable (time spent with children), followed by exogenous variables 
(predictors), and endogenous variables (outcomes). Finally the open-ended variable (parents' most challenging aspect of raising a child) is discussed.

Intervening variable. The available time spent with children is an intervening variable. Intervening variables play a dual role of being simultaneously independent (predictor) and dependent (outcome) variables in social statistics (Aneshesnel, 2002). This study focuses primarily on how time spent with children influences parents' willingness to medicate behaviors. In that instance the time spent with children is a predictor of the willingness to medicate. But, the literature pointed out a number of other predicting variables that could influence parents' available time to spend with children such as race and ethnicity, gender, number of children in household, family type, and work satisfaction. So, in this study, spending time with children is an endogenous (outcome) of all the predicting variables and simultaneously an exogenous (predictor) variable on all four types of willingness to medicate behaviors (outcomes).

To measure the available time parents spent with children, participants were asked an open-ended question: "how many hours are you able to spend with your child or a child you are the caregiver of, during a regular workday?" Most parents answered by giving a precise number of hours or an approximate (for example "2 to 4 hours"). A small number of parents had complicated circumstances so they answered by stating their situation. For example, one parent answered: "during workdays none because I work the night shift," whereas another parent stated: "I am divorced and only see my children three times a week." Although only 2 parents did not respond to this question, a few others ambiguously answered by sometimes adding the hours of night sleep, and at other times 
by describing the hours in terms of the entire week. In order to minimize error, all answers were screened and checked against other variables (e.g., type of work) to strengthen accuracy.

First, this variable was recoded since a good number of answers were in words. The respondents' comments were treated with care, for example, if a parent had answered: "about four hours," or "no more than two hours," or "less than seven hours," these answers were quantified as " 4, , "2," and " 7 " respectively. Two answers were missing, 11 answers were sentences that did not imply anything about the amount of time parents spend with their children (i.e., "not enough," or "less than I want to," or "not much in a regular workday.") These answers could not possibly be quantified in numbers, so these cases were removed. Finally, 83 additional answers were between 24 hours to 7.5 hours per workday for full time working parents. These answers were visible outliers in a simple boxplot graph. It was difficult to judge their accuracy or whether parents had simply added the sleeping time. Logically, it is impossible for anyone to work full time (implying 8 -10 hours per day including commuting), to sleep at least 7 hours per day and still spend more than 7.5 hours per day with the child. Therefore, a decision was taken to exclude such answers entirely from the subsample. In sum 96 answers $(83+11+2)$ were removed during cleaning of the intervening variable of time spent with children. All the answers indicating a time spent with children of $\leq 7.5$ hours were kept in.

Exogenous variables. The exogenous variables for the proposed study are variables that could influence the available parental time and that might directly predict the outcome or endogenous variables of willingness to medicate different behaviors 
(discussed ahead). The following is a detailed description of each exogenous variable in this study, and the way the data was collected and prepared for the analysis.

Work satisfaction was measured by asking parents: .How satisfied are you with your current employment? Are you very satisfied, satisfied, unsatisfied, or very unsatisfied?" Answers were coded in a scale from 1 to 4 (from very satisfied to very unsatisfied). Once collected, this variable was recoded into the same variable where a value of " 1 " corresponded to "very unsatisfied" and a value of "4" corresponded to "very satisfied." This transformation was done to simplify the analysis, so a higher number indicated a higher satisfaction rather than vice versa. This variable had only 3 missing values.

Gender was measured by simply writing down the gender of the participant without asking them. This variable was coded as female $=1$ and male $=2$. There are no missing values in this variable. There are 524 mothers and 239 fathers in the subsample used.

Two questions measured race and ethnicity. The first question asked participants: "With which of the following racial groups do you identify yourself? White, Black, Asian, American Indian, or something else?" Race was coded as: (1) white; (2) black; (3) Asian; (4) American Indian; (5) other, specify; (6) don’t know or no response and (7) bi or multi racial. Respondents were asked a second question at this point: "Are you of Hispanic or Latino descent?" Ethnicity was coded as (1) Hispanic or Latino; (2) nonHispanic or Latino; (3) don’t know, no response, or refused. Based on a combination 
from both these variables, a third variable was created in the dataset. These two variables were transformed and recoded into a new variable as (1) White non-Hispanic; (2) Hispanic; (3) African American. There are 226 White non-Hispanic participants, 234 African Americans, and 248 Hispanics. An additional 55 respondents chose a different race and ethnicity than these three groups and were therefore excluded from this study.

For the variable of family type, the original study contributed with its measure of marital status. Marital status was measured by asking participants: "What is your marital status?" Respondents could chose one of the following options: (1) single; (2) married; (3) living together not formally married; (4) separated; (5) divorced; (6) widowed; (7) never married; (8) other specify; (9) don't know; (10) no response. There are 8 missing values in this variable. The original variable of marital status was later transformed into the variable of family type since this study was interested in understanding whether there were differences between one-parent versus two-parent families. So, values from 1single; 2-married; 3-cohabiting together; 4-separated; 5-divorced; 6-widowed; 7-never married were recoded as 1-one-parent family (included single, separated, divorced, widowed, and never married) and 2-two-parent family (included married and cohabiting together).

The last exogenous variable used in this study is the number of children per family. Parents were simply asked: "How many children younger than 18 live with you?" Their answers were grouped as: (1) none; (2) one; (3) two; (4) three, and (5) four or more. Although there were no missing values in this variable, 11 respondents claimed they had no children but they could not participate in this study if they had no children. 
Also, three of these parents who claimed they had no children reported to having a child with emotional and behavioral problems and all of them answered the last open-ended question on what is the most challenging aspect of raising a child. This may have been a mistake of the data collection. Nevertheless, these 11 answers could not be used and were excluded. This variable was further recoded in a way that a value of 1 corresponded to having one child, a value of 2 corresponded to having two children, a value of 3 corresponded to having three children, and a value of 4 corresponded to having four or more children.

Endogenous variables. The endogenous variables of willingness to medicate childhood behaviors are the same as the outcome variables of the original study. The following description is taken verbatim from the original study. The endogenous variable, "willingness to medicate children," is measured using the 1998 General Social Survey scale, originally made up of three items. Chronbach's alpha (an internal reliability coefficient) calculated on 1114 GSS respondents, is .84. The items ask: "How likely would you be to give doctor-prescribed medication to your child or a child you were responsible for in the following situations..." The first, mapping roughly on DSM's ODD, asks about a child who "is hostile, often loses his/her temper, often argues with adults, actively defies authority and seems spiteful and vindictive"; the second, mapping on ADHD, is about a child who "is not paying attention in school, does not follow through with school work or chores, has difficulty organizing activities, is easily distracted, talks excessively, and seems to run around and fidget constantly"; and the third, illustrating suicidal ideation, is about a child who "was talking about killing him or 
herself." In this research, a fourth item, illustrating childhood depression, was added to the scale: "because he/she is depressed or irritable, withdraws from family, friends, and activities, and is not sleeping or eating properly." In relation to the suicidal child situation, this fourth item includes a more common but less severe symptom cluster of depression where, in the literature and in clinical practice, medication has been employed in America.

Responses were rated on a 5-point scale from "very willing" to "very unwilling." Although in the original study the willingness to medicate behaviors is considered as one global variable with four measures, the current study considers each of these measures as separate endogenous variables. Since this dissertation compares parents' willingness to medicate different behaviors, it suits this analysis to consider each variable separately as measuring willingness to medicate a behavior usually associated with a particular diagnosed disorder. Missing values for all endogenous variables are: 7 missing values in the medicating inattention variable, 11 missing values in medicating depression variable, 11 missing values in medicating suicidal talk, and 12 missing values in the medicating hostility variable. All these endogenous variables were recoded in a scale of 1 to 4 where the score 4 corresponds to being very likely to medicate a behavior and a score of 1 corresponds to very unlikely to medicate a behavior.

In sum, once data was cleaned from missing values and outliers were removed, the sample size for this study was reduced to 551 parents, of whom 99 reported having a child with problems and 452 parents reporting having no child with problems. 
Open-ended variable. One of the goals of this work is to build information that could further intervention strategies for parents of children with emotional and behavioral problems. To do so, a deeper insight on parents' situations is necessary and adds depth to this study. The questionnaire included one open-ended question to all respondents at the end of the phone interview. Parents were asked: "If you were to summarize it in one sentence, what would you say is the most challenging aspect of child rearing for you as a parent?" The answers varied from one word to a few short sentences per each respondent. There are no missing answers for this variable for the entire population of 1146 respondents. This dissertation, however, investigated only 551 answers from the cases used the analysis. Initially, answers were coded (discussed ahead in the data preparation section) and added as another column into the same dataset. This way, this new quantified variable could be easily used in relation to different characteristics of parents such as whether or not they had a child with emotional and behavioral problems, race and ethnicity, family type, and gender.

\section{Data Analytical Plan and Preparation}

Data analytical plan and preparation is a subchapter divided into two main parts. The first half details how the analysis was initially perceived, delineates the assumptions that needed to be considered for path analysis, and discusses the steps of the analysis. Information is provided on statistical procedures of preliminary analysis. The second half of the subchapter presents information on the open-ended variable included in this study. It shows how this variable was coded, what information was provided and most importantly how were these answers handled to complement this study. 
Part I: Details of the quantitative analysis. A description of the quantitative analysis is introduced below including rationale, steps of the analysis, and data preparation.

Rationale for path analysis. The aim of this study is to explore hypothesized relationships between time spent with children and parents' willingness to medicate children's behaviors. Path analysis is chosen to test these directional and non-directional hypotheses. Path analysis is a statistical technique used to examine causal relationships between two or more variables, and is based upon a linear equation system developed in 1920s and first used in social sciences in 1960s (Mosses, 2006). Path analysis helps to predict a cause-effect relationship and has an advantage over multiple regression in that it measures the direct and indirect effects through an intervening variable to explain the endogenous variable (Mertler \& Vannatta, 2005). In addition, path analysis allows for the estimate of strength of exogenous variables (race and ethnicity, gender, number of children in household, family type, and work satisfaction) and the intervening variable (time spent with children in a regular work day) on each endogenous variable (willingness to medicate ADHD-like behaviors, ODD-like behaviors, depression-like behaviors, and suicidal talk). The strengths of relationships are calculated from the perspective of a linear regression analysis that produces numbers analogous to partial relationships in the path model. These path coefficients represent the strengths of the relationships between pairs of variables with the effects of all other variables in the model held constant (Babbie, 2010). The main principle of path analysis is that any correlation coefficient between two variables can be decomposed into separate paths of influence 
that ultimately draw links to the endogenous variable (Kothari, 2008). So, path analysis is slightly more complex than multiple regression, but it is slightly less complex than structural equation modeling (SEM) in that it does not include latent variables.

The proposed study has a number of possible variables that could risk multicollinearity. Therefore a path analysis will draw a relationship between time spent with children and parents' willingness to medicate behaviors by simultaneously considering all other correlation coefficients between the exogenous variables and sociodemographic variables as well as the relationships between these sociodemographic variables and the endogenous variable of willingness to medicate. To run the path analysis, AMOS software (incorporated in SPSS 20.0) is used.

Steps of the analysis. Path analysis presumes a number of characteristics about the data. Path analysis assumes multivariate normality, linearity, and homoscedasticity. Therefore one must ensure that univariate distributions are normal; that the joint distribution of any pair of variables is bivariate normal; and all bivariate scatterplots are linear and homoscedastic. Outliers were removed to secure multivariate normality. The data was checked for negative or positive skewness and for leptokurtic (positive kurtosis) and platykurtic (negative kurtosis) because they could both be present in a single variable. Skewness implies an asymmetrical distribution with regards to the mean whereas kurtosis implies asymmetrical distribution with regards to the peak. Checking for skewness and kurtosis can be achieved by running frequency distributions. Continuous variables were deemed non-normal if they yielded absolute skewness and kurtosis values that exceed \pm 2 (Bachman, 2004; Kline, 2005). 
Linearity and homoscedasticity are evaluated by inspecting bivariate scatterplots after the variables are screened for outliers and their distribution is considered to be normal. Nonlinear relationships are impossible to analyze via any type of linear regression analysis. Scatterplots were run to check for linearity and homoscedasticity. Data are homoscedastic if residual plot is the same width for all values of the predicted dependent variable and heteroscedasticity is present if the plot shows a cluster of points that is wider as the values for the predicted dependent variable get larger.

Next, Pearson and Spearman rho two-tailed correlation analyses were conducted to examine relationships among the variables. Pearson's correlations were conducted to examine the relationships between continuous exogenous variables (work satisfaction, number of children, and time spent with children). Spearman rho two-tailed correlations were conducted for the categorical exogenous variables (race and ethnicity, gender, and family type).

Data preparation. To prepare the data for conducting path analyses a few steps were taken, starting with simple frequencies, examining boxplots and scatterplots, and running simple descriptive statistics. Normality is assumed by checking for skewness and kurtosis. Skewness and kurtosis, as well as other central tendency information, are captured in table 1. Running simple frequency distributions of all seven continuous numerical variables in the dataset retrieved this information. Values of skewness and kurtosis can be both positive and negative. For skewness a value of 0 implies a perfect symmetrical distribution whereas a negative and a positive value implies a skewed distribution either positive or negative. For kurtosis a value of 0 implies a perfect normal 
distribution whereas a negative kurtosis implies a flat distribution and a positive kurtosis implies a peaked distribution. As a rule for both skewness and kurtosis the values should not exceed \pm 2 (Bachman, 2004).

Table 1

Central distribution for continuous numerical variables

\begin{tabular}{ccccccccc}
\hline \multicolumn{2}{c}{ Parents reporting child with problems } & \multicolumn{5}{c}{ Parents reporting no child with problems } \\
\hline Variable & M & SD & Skewness & Kurtosis & M & SD & Skewness & Kurtosis \\
\hline Parental time & 4.16 & 1.54 & .12 & -.95 & 4.53 & 1.57 & -.31 & -.34 \\
Work satisfaction & 1.67 & .76 & .93 & .23 & 1.69 & .71 & .99 & 1.21 \\
Number of children & 1.94 & .81 & .56 & -.19 & 1.88 & .85 & .78 & -.002 \\
ADHD & 2.66 & 1.14 & -.33 & -1.3 & 1.92 & 1.0 & .61 & .95 \\
ODD & 2.56 & 1.2 & -.18 & -1.52 & 2.1 & 1.0 & .36 & -.95 \\
Depression & 3.05 & 1.01 & -.94 & -.15 & 2.58 & 1.07 & -.33 & -1.17 \\
Suicidal talk & 3.23 & 1.12 & -1.23 & -.46 & 2.96 & 1.16 & -.71 & 1.01
\end{tabular}

Path analysis assumes linearity and homoscedasticity. So, if variables are nonlinear, the statistical analysis will fail to estimate the strength of relationships or even the existence of relationships. Bivariate scatterplots were drawn in SPSS to check for linearity. Every endogenous variable was combined with each numerical and continuous exogenous variable. All relationships were linear.

At this point, the analysis proceeded by running Pearson and Spearman rho twotailed correlation analyses. Pearson correlation analyses were conducted for continuous 
exogenous variables (number of children, time spent with children, and work satisfaction) on endogenous variables. Spearman rho two-tailed correlation analyses were conducted for categorical exogenous variables (race and ethnicity, gender, and family type) on endogenous variables. A correlation coefficient $r$ needs to be less than \pm 0.8 for uncorrelated variables (Urdan, 2010). Results from these analyses are presented in the results section.

Finally, the categorical variables (race and ethnicity, gender, and family type) were transformed into dummy variables prior to running the path analysis. Dummy variables are used to make comparisons between two groups within the same variable. The category of interest is given the value of 1 and the reference group is given a value of 0 (and k-1 variables are created). Since the results are interpreted in regard to the reference group, it is more convenient for the analysis to give a value of 1 to the group needed for the investigation.

Prior to deciding on using dummy coding and creating dummy variables, other types of coding were considered such as effect and contrast coding. Effect coding (where categories take values of $-1,0,1)$ was considered inappropriate for this type of analysis because this type of coding compares the mean of the group of interest to the overall mean across all groups (Aguinis, 2004). The focus of this study was to compare the groups to each other (i.e., mothers versus fathers, one-parent families versus two-parent families, African American parents versus all others, and so on). Contrast coding on the other hand (categories take values of -1, 0,1 ), supports analyses that are interested in 
investigating comparisons between specific combinations of the groups defined in the theoretical conceptualization of a study and allows for specific combinations (Aguinis, 2004).

This work used dummy coding and transformed three categorical variables into dummy variables. The variable that measures race and ethnicity (three categories) was transformed into two dummy variables: (1) White parents were given a value of 1 and everyone else a value of 0 (literature suggests that white parents may be more willing to medicate their children); and (2) African American parents were given a value of 1 and everyone else a value of 0 (literature suggests that African American parents may be spending less time with children). This allowed investigating these parents' willingness to medicate behaviors compared to Hispanic parents who became the reference group. The variable of gender was transformed into a dummy variable where mothers were given a value of 1 and fathers a value of 0 , to allow for comparisons of mothers versus fathers. Similarly, the variable of family type was transformed into a dummy variable where oneparent families were given a value of 1 and two parent families were given a value of 0 . Lastly, path analyses were conducted using Amos incorporated in SPSS 20.0.

Part II: Details of the preparation of the open-ended variable. Parents were asked one open-ended question at the end of the interview regarding what they thought was the most challenging aspect of raising a child (discussed earlier in the measures section). To be able to use this information in relation to other characteristics collected in the dataset, it was decided to code and numerically quantify the open-ended variable. 
This way, a few descriptive statistics and chi square non-parametric tests could reveal more about parents' concerns in regard to their race and ethnicity, gender, and family type.

Answers were commonly short (one word to one sentence) and easily grouped into categories. Following guidelines of coding from Auerbach and Silverstein (2003), the answers were initially read and copied in a Word file under different headings exactly as the actual text (for example if the answer was "keeping the family values," the answer was copied verbatim under the heading "family values/moral values/ religious values/ honor/ good character." If the answer was "time to dedicate and care for my children," the answer was copied under the heading "time constraints/ lack of time/ work-family balance" and so on). There were cases when the answer spoke of two or more categories at once such as: "Being a single mother. Time and money." Such answers were put under each heading they belonged in (in this case under "marital problems/ single parents," "time constraints," and "financial problems" followed by a number 3 in parenthesis indicating that this same answer was simultaneously under three categories. Twenty-six answers were in Spanish. These were first translated in English by a qualified EnglishSpanish speaker (who had also helped with the translation of the original study questionnaire in Spanish), and later coded in the same way as the rest of the answers.

Once all 551 answers were categorized as described above, the contents of all categories were examined closely. Two categories of "parenting" and "control/ discipline" were expanded into four categories of "parenting: becoming better parents," "parenting: building the child for success," "control over the child/ discipline," and 
"outside influences/ peer pressure." Three other categories ("government," "everything," and "general") were merged into one category "general and other." The new version was read again, to try and categorize all the 46 answers that belonged to more than one category ( 41 belonged to 2 categories and 5 belonged into three categories). These ambiguous answers were interpreted based on the entire meaning of the sentences and on what seemed to be emphasized prominently from the parent. For example an answer such as: "Teach values and morals. Make my daughter understand the value of study. I am worried about values because kids have access to TV and programs not appropriate for children" was initially put under three categories: "family values and morals," "education," and "outside influences." During the second read this same sentence is put under the heading of "family values and morals" only, because the word values and morals are repeated three times in these sentences and the answer begins by that concern. In addition, it seems that the outside influences and the education concern are both a function of the values and morals. Fifteen answers were sorted in this way, but this was not possible for all the answers under more than one category. A decision was taken to categorize the rest of the answers under the first heading they corresponded to. If the answer seemed balanced in its importance, the first mentioned heading was used to categorize it. So, answers such as the one illustrated above: "Being a single mother. Time and money" were now categorized under "marital issues/ single parent" since that is the first mentioned heading in the answer. This decision was taken to avoid confusion with more than one category. 
Lastly, these categories were coded. Coding of raw information is a form of organizing text and discerning emerging patterns (Auerbach \& Silvertstein, 2003). To code these open-ended answers inductive coding was employed (codes emerged from the data). First, all the information within one category was read to look for repeated patterns within the text. The words or repeated phrases were highlighted (i.e., family values, outside influences, education) using different colors for the same word or phrase. Repeated words or phrases were counted for each category and patterns emerged. For example, reading answers such as:

"having to fight everyday for educational services; give the best education; make them study at all times; giving them the proper education; getting good grades in school; education; schooling my children has been the most challenging aspect for me; keeping them focused in school; education; providing a good education; be able to educate them; maintaining them interested in daily learning activities; good education; helping her with homework; education can steer them in the right way"

and highlighting the repeated words, it became clear that "education" in this random sample from the raw data is repeated 9 times in 15 answers where two additional times "good grades" and "homework" are mentioned. At this point an inclusive title was assigned to each category by going back to the original question these parents were asked: "if you were to summarize it in one sentence, what would you say is the most challenging aspect of child rearing for you as a parent?" and attempting to answer this questions by looking at the repeated patterns in each group of answers. In the above example "providing a satisfactory education" captures parents' concerns of the group. Finally, the categories grouped under specific titles were transformed into numerical codes (Table 2 details this information) and entered as a new variable in the dataset. 
Once this new numerical variable was added in the dataset a final check of the coding was conducted by going back to the original variable with all open ended answers and coding them again by organizing all the answers in respect to the codes already assigned. A second numerical variable was produced this way and was checked against the first one. Eighteen answers showed different codes from the first to the second time around. These answers were taken separately from the original open-ended variable and coded a third time using the already assigned codes. These were the codes that were kept for these answers ( 16 answers took the same codes as the second round of coding and 2 answers were coded similarly to the first round of coding). A period of four weeks passed between the first and the second coding and one week of time was allowed between the second and the third coding of the 18 answers.

\section{Table 2}

Frequencies of the most challenging aspect of childrearing for all the parents in the study and ten random examples per category

Description of codes $\quad N(\%)$

$551(100)$

\section{Spending time with children}

(time and time and time with them; time to care and dedicate to them; quality time with my children; not enough time in a day. too exhausted when you get home; giving all of my children separate quality time and meeting their individual needs because they are different people; not spending enough time with my children; not spending enough time with the kids because both parents have to work; creating a balance between work and spending enough time with my children; conflict between spending time with children and having to work; it's difficult to find time between work and school to make free time for my children)

\section{Handling negative outside influences on the child}

(keep the children away from the external influences; the exposure to things immoral - like sex and violence; the exposure they get from society, dealing with peer pressure; having to deal with media influence has been most challenging; other children behaviors; outside influences 
and how they affect my children; overexposure to the world (internet, texting, computer) and trying to set boundaries to let them grow at a certain pace so that you don't have to do everything at once; the social influences that my children encounter; the outside influences can be most challenging; keeping away my children of negatives external influences; teaching them how to be independent and not take bad influences)

\section{Controlling and disciplining the child}

(controlling and disciplining them; being consistent with discipline; discipline; to get children agree with parents standards; making sure that my children don't outsmart me; getting them to do what you want them to do; obedience is a really big challenge; to set boundaries for the children and discipline them; just discipline; getting them to obey and follow the rules; control them)

\section{Instilling family values and moral values}

(i.e., to make them good people with good will; consistency with family values, guide my children to be independent beings with strong values; teaching them to be honorable human beings; respect for moral and family values; instilling family values; make sure they have the right

values; make them understand that morals and integrity are the basis of a human being; making sure they understand our family values and not worldly views; to have a strong structure and values)

\section{Providing a satisfactory education}

(giving them proper education; giving them a good education because the quality at school (both public and private) is not sufficient; he doesn't have the same focus that we have so it's frustrating-school and what not; dealing with the school system because some teachers are not being patient enough with the children; giving them an education in order to prepare them for life; make sure they do good in school; to ingrain education and integrity; multiple kids homework; education is the most difficult challenge for a parent because they have to keep repeating over and over because doesn't focus sometimes; education is the best gift that you can give to a child)

\section{Raising successful children and fulfilling their needs} (giving them everything they need to succeed; teaching her the right

things so that she can make good decisions when parents are not around; to advise them so they could be professionals; making sure they become responsible adult; providing them with the environment to be successful while at the same time trying not to spoil them; helping them achieve their self confidence; giving them everything they want and need; trying to make sure they are prepared to deal with the things they are exposed to; teaching them to believe in themselves; allowing them to find their way with guidance)

\section{Handling children's behavioral problems and keeping them safe and healthy}

(dealing with behavior issues; raising a child with emotional problems; handling their behaviors in public; knowing the different options in 
terms of treatment, real diagnosis and the most updated information about the treatment of diseases; balance of something wrong with the child or lack of discipline; taking them to the store and the children running all over the place, and also getting them to bed on time; finding the right discipline for the behavior to modify the child's behavior; dealing with the emotion first and then health problems; worrying about their well being, just keeping them out of trouble and keeping them safe from all elements)

\section{Becoming a better parent}

(to be an example of who they need to be; be honest with the child, and be a good listener; keeping their trust along with setting good examples; being a good mother is most challenging for me; having the parents display an example of good behavior for their children; adjusting your parenting style as they grow older, to meet their current needs; trying to be a good parent; give to the children a good example and guide; learning the most effective parenting techniques that are best for the individual needs of my child; understanding their social dynamic; $i$ think the most difficult challenge is being the right example or role model for the child;)

\section{Handling teenagers}

(teenage years; control my children when they are teenagers; raising teenagers; when they become teenagers is a whole battle; when they are teenagers because they think that they know it all; having the children go through adolescence and allowing them to have their freedom; teenage years of life are the most difficult; teenagers' push for independence; the teenage years, because they listen more to their peers than to their parents; now that they are teenagers some things are a challenge)

\section{Communicating with children}

(trials and tribulations of understanding their thoughts; being a friend and being a mom; communicating with my children, having them to listen and being truthful; achieving a true and reciprocated communication; lack of communication; become their best friend; communicating with the children; good communication; to communicate with them on a daily basis; to have effective communication with them)

\section{Having financial difficulties}

(not having enough money; I wished I were financially stable; the availability to be able to put a roof over them and have time for your children; financial stress can be a huge factor for me when sometime you cant provide; receiving no financial help or contribution; providing clothing, shoes, and food as they get older; being able to provide for the children with the economic problems of today; be able to provide a roof and food for them until the day they die; mostly financial problems and I work a lot but I had to pay 3 day care fees at the same time; most of the time money is never sufficient for the household) 


\section{Raising children alone}

$17(3.1)$

(not having a father figure to raise the child with; lack of participation from the husband; be a single widow parent; as a single parent to make decision and do not have a second opinion on it; being alone taking care of my children; share custody of my children with their father; raising a child as a single parent; being a single parent means I have to do every thing on my own; being separated is not easy. its a broken family; being a single parent)

\section{Other concerns}

(there is too much. cannot be summarized in one sentence; I wish children came with a manual from the time they come out to the time they are independent; generation gap; government. they want to tell us how to raise our children; we keep asking for babies and then we don't know how to raise. we need time to think about these issues; the rules change with each child and what works with one child does not work with the other; giving up my freedom; when they are playing in the house and running around the house. you have to run after them; not having a manual that tells you how to raise a well-rounded child that will be good to themselves and their community; I have triplets so that there are three at once)

None

(no problems so far. I do not see any difficulty bringing up my children. they are very good kids; personally I don't think there is a challenge, its a matter of choice; cannot thing of anything that is most challenging for her, no idea; do not have any problems in childrearing; I don't face any problems with my children. they are wonderful; nothing is difficult; we only have joy for our kids. no negative aspects; I don't have any. my children are wonderful;

The coded and quantified new variable was included in a number of descriptive frequencies conducted in SPSS 20.0. This allowed for an investigation of what parents considered the most difficult aspect of raising a child and their demographic characteristics. So, detailed information was retrieved on what were the concerns for parents of children with emotional and behavioral problems compared to parents reporting no child with problems. In addition simple frequency analysis were run to see if there were any differences and/or similarities between concerns of Hispanic, African American, and White parents as well as mothers versus fathers, and one-parent versus 
two-parent families. These frequencies were run for all 551 parents to examine the differences and similarities as well as each separate group (99 parents reporting child with problems and 452 parents reporting no child with problems).

\section{Human Participants Consideration}

Since this study was based on secondary data analysis, it posed no risk of harming participants. The data was already collected following NIH and IRB-approved procedures at Florida International University. In addition, a specific human subject application for this study to the FIU Institutional Review Board was submitted for review and approval was granted prior to initiation of any analysis.

\section{Post-Hoc Power Analysis}

Power is defined as the probability that a statistical test will reject the null hypothesis. Power is equal to $1-\beta$ where $\beta$ is the probability of type II error (the probability that the null hypothesis is not rejected even if it is false). The generally accepted power level is .8. The larger the sample size, the greater the power. When the sample size of a study is predetermined, as in this secondary data analysis, it is crucial to conduct a post-hoc power analysis to determine the study's power. In this study, the smallest subgroup sample size is 99 (the subgroup of parents reporting child with problems); thus this sample size is used in the power analysis.

The significance level chosen or the probability of type I error (alpha) is the probability of rejecting the null hypothesis when in fact the null hypothesis is true. To minimize type I error, the proposed research chooses a significance level of $5 \%$ or $\alpha=.05$. 
Power analysis also requires an estimate of the expected effect size. In this study, an effect size $\left(R^{2}\right)$ of .15 is expected, based on a conventionally accepted small effect (Cohen, 1988).

To determine the power for this study, G*Power 3 was used. G*Power 3 is a free power analysis program for a variety of statistical tests (Faul, Erdfelder, Buchner, \& Lang, 2009). Using the above-identified sample size, alpha level, effect size, and 6 predictors (independent and intervening variables) for a multiple regression analysis, the calculated power is .95 , above the acceptable standard of .8 . 


\section{CHAPTER IV: RESULTS}

This chapter presents the results from this work. The first part introduces results from quantitative analyses of variables. Initially, the samples are described sociodemographically and correlations between key variables are reported. Then, results of path analyses are presented for each endogenous variable. A brief summary of the quantitative analyses concludes the first part of the results. In the second part results of the open-ended variable are presented. A few relationships between the open-ended variable and key demographic variables are investigated further. The chapter concludes with a summary of these results.

\section{Part I: Results of the Quantitative Analysis}

The following subsections highlight demographic information of the sample used in this work followed by distribution of the endogenous variables. Next, details are given on correlations and crosstabs between variables. Finally results from path analyses are presented.

Demographic representativeness. In this section demographic information is

introduced on all exogenous and endogenous variables. The section starts by presenting the makeup of both groups of parents, information on race and ethnicity, gender, family type, number of children per family, and work satisfaction. Further, information about the distribution of endogenous variables is highlighted.

Parents reporting child with problems and parents reporting no child with

problems. In this study, 99 parents (18\%) reported having a child with emotional or 
behavioral problems. Therefore, in terms of the proportion of diagnosed or diagnosable children, the sample of working parents in this study was broadly representative of Florida or U.S. populations. In the most recent available data, according to parental report about $9.5 \%$ of US children between 4 and 17 years of age in 2007 were diagnosed with ADHD (CDC, 2010). The numbers of children so diagnosed in the state Florida varies from $11 \%$ to $14 \%$ (CDC, 2008). CDC also reports that in 2005 around $16 \%$ of U.S. children were diagnosed with some type of emotional and behavioral disorder (Simpson, Pastor, Cohen, and Reuben, 2006).

Race and ethnicity. The original study collected an equal number of African American, Hispanic, and White parents. This allowed for an accurate comparison between the groups. The subsample of working parents used in this study represents the same proportion of African American, Hispanic, and White parents as the original study. Among the 551 working parents, there is a slight over-representation of Hispanics (35.4\%), compared to 33.9\% White non-Hispanic parents and 30.7\% African American parents. These almost exact percentages are also true for the subgroup of parents reporting no child with problems (Hispanic parents - 36.5\%; African American parents 33\%; and White-non-Hispanic parents - 30.5\%). These proportions however, show statistically significant differences, $\left[\chi^{2}(551)=13.80, p<.001\right]$ when compared to racial and ethnic proportions of parents reporting child with problems. White non-Hispanic parents dominate among parents reporting having a child with problems - almost $50 \%$ of the entire subsample. African American and Hispanic parents are less represented respectively $20 \%$ and $30 \%$. 
Some data about children's prevalence of emotional and behavioral problems are indicated from the results of the Strengths and Difficulties Questionnaire (SDQ) conducted by retrieving data from the National Health Interview Survey (NHIS) 20012007. The original SDQ questionnaire (although developed by Robert Goodman as a screening tool to identify emotional and behavioral problems among children) was adjusted to collect parents' reports and included in the NHIS. According to this study, Hispanic parents who were interviewed in Spanish were among the group who reported fewer scores in the SDQ indicating less problems with their children. White and African American parents did not differ in their SDQ scores (Pastor, Reuben, \& Duran, 2012). Data from the National Health Interview Survey $(1998$ - 2009) reports differences between their findings between 1998 - 2000 and 2007-2009 in terms of race and ethnicity and prevalence of ADHD. Whereas the proportion between ethnicities for parents reporting having a child with problems in this study would be in accordance to their 1998-2000 findings (where White non-Hispanic children were among the most diagnosed with ADHD compared to other groups), they would not be in accordance to their 20072009 study findings where African-American children rates of diagnoses had been drastically increased (5.1\% to 9.5\%). Both White non-Hispanic and African American children are now being diagnosed at higher rates than Hispanic children (Akinbami, Liu, Pastor, \& Reuben, 2011).

The results from the current study point to a higher prevalence of children with emotional and behavioral problems among White parents compared to African American and Hispanic parents. These findings of racial and ethnic proportions are in accordance 
with other scientific studies that report a higher prevalence of diagnoses and medication use among White children compared to other ethnic groups (Bussing \& Gary, 2003; DosReis et al., 2011; Zito et al., 2003).

Gender, family types, number of children, and work satisfaction. In the entire subsample of 551 working parents, $65.3 \%(n=360)$ are mothers and $34.7 \%(n=161)$ are fathers. These results are not significantly different from results of parents reporting having a child with problems, $\left[\chi^{2}(99)=.59, p<.257\right]$. Mothers make $68.7 \%(n=68)$ of this subsample and $31.3 \%(n=31)$ were fathers. A review of 30 scientific studies that use parents of ADHD diagnosed children as primary informants revealed that from a total of 1521 parents (participating in all studies together) only 12\% were fathers (Pajo \& Cohen, 2012). The percentages of fathers in the current study $(34.7 \%$ for all parents and $31.3 \%$ for parents reporting child with problems) allows for some additional information about fathers and their willingness to medicate behaviors that may have been missing from previous literature.

Twenty-two percent $(n=124)$ of parents reporting no child with problems said they were in one-parent families whereas $24.2 \%(n=24)$ of parents reporting having a child with problems said so, a non significant difference $\left[\chi^{2}(551)=.21, p<.368\right]$. This finding is at odds with data from the National Health Interview Survey to the effect that there were twice as many children with emotional and behavioral problems among single parent families compared to two-parent families (Pastor, Reuben, \& Duran, 2012). 
Distribution of parental time with children in a regular workday. There are no statistically significant differences between the time spent with children for parents reporting having a child with problems and parents reporting no child with problems $\left[\chi^{2}\right.$ $(551)=12.91, p<.609]$. However, a few differences are to be noted about the distribution of time in a regular workday for parents reporting child with problems and parents reporting none. Figure 2 details the percentages of parents of two groups and the distribution of time spent with children by hours. As shown, about $32.5 \%$ of parents reporting no child with problems spent 3.5 hours or less with their children in a typical workday whereas $41.4 \%$ of parents reporting child with problems do so.

Figure 2

Percentages of parents and time spent with children in a regular workday

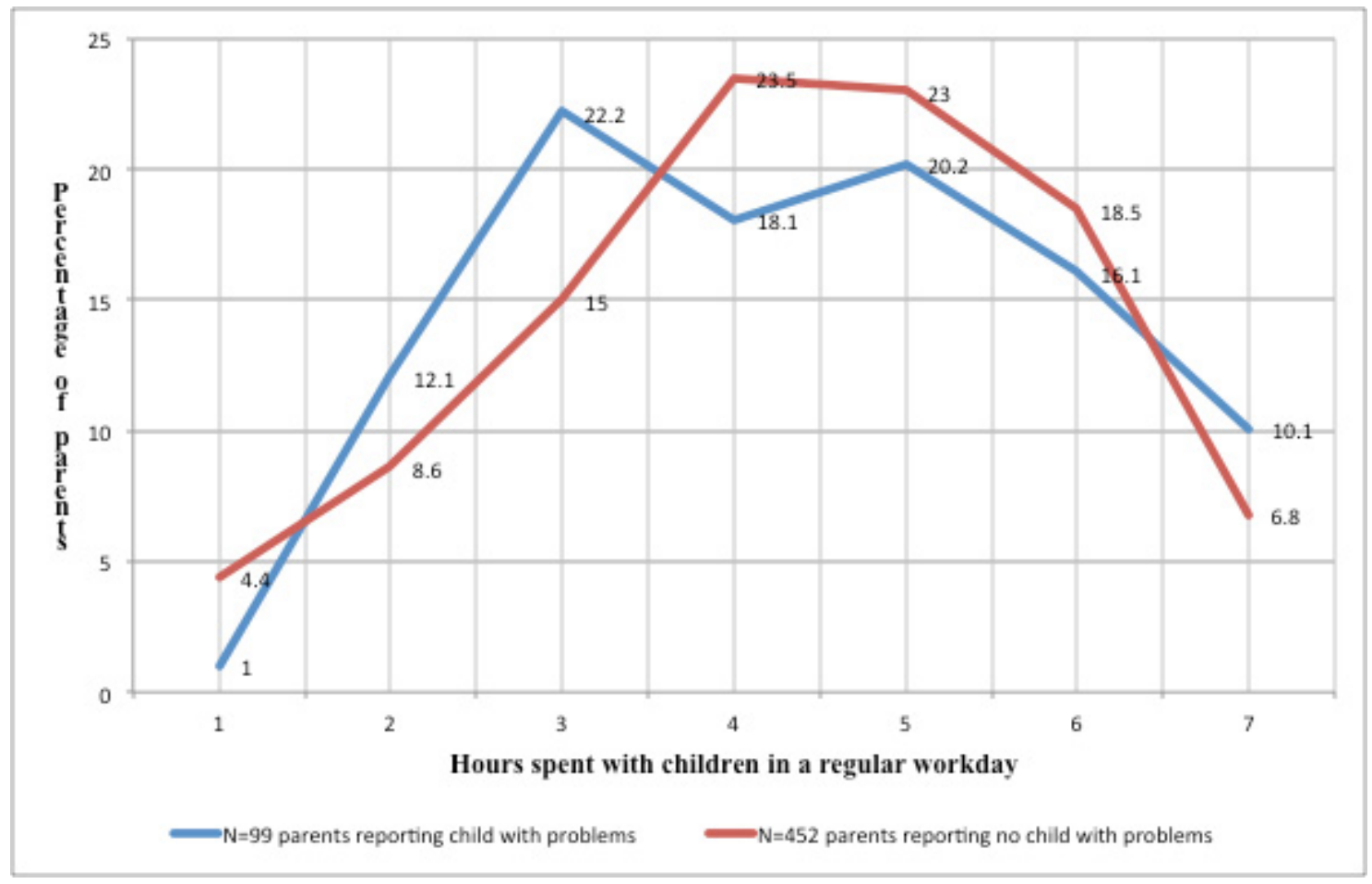


Distribution of willingness to medicate behaviors. Parents reporting child with problems are more willing to medicate behaviors associated with ADHD, ODD, depression, and suicidal talk compared to parents reporting no child with problems. As shown in Table 3 these differences between the groups although statistically significant for all behaviors, are more pronounced for behaviors associated with ADHD than suicidal talk, $\left[\chi^{2}(551)=45.84, p<.000\right]$ for willingness to medicate ADHD and, $\left[\chi^{2}(551)=\right.$ $8.70, p<.034]$ for suicidal talk. Parents reporting no child with problems are more likely to medicate behaviors associated with suicidal talk, depression, and ODD compared to ADHD, which explains the progressive smaller difference between the two groups. The findings below show that $62.6 \%$ of parents reporting child with problem are willing to medicate their children for behaviors associated with ADHD. This is in accordance with the national statistics from CDC that "as of 2007, 2.7 million children (66.3\% of children diagnosed) use prescribe medications to control their behaviors" (CDC, 2010, p.1443). 
Table 3

Willingness to medicate behaviors among both groups of parents

\begin{tabular}{cccccc}
\hline $\begin{array}{c}\text { Willingness } \\
\text { to medicate } \\
\text { behaviors }\end{array}$ & $\begin{array}{c}\text { Parents reporting child } \\
\text { with problems } \\
n=99(\%)\end{array}$ & $\begin{array}{c}\text { Parents reporting no child } \\
\text { with problems } \\
n=452(\%)\end{array}$ & $\chi^{2}$ \\
\hline & Likely & Unlikely & Likely & Unlikely & \\
\hline ADHD & $62(62.6)$ & $37(37.4)$ & $143(31.6)$ & $309(68.4)$ & $45.84 * * *$ \\
ODD & $58(58.5)$ & $41(41.4)$ & $174(38.5)$ & $278(61.5)$ & $26.50 * * *$ \\
DEPR. & $79(79.8)$ & $20(20.2)$ & $285(63.1)$ & $167(36.9)$ & $19.22^{* * *}$ \\
SUIC. & $80(80.8)$ & $19(19.2)$ & $323(71.5)$ & $129(28.5)$ & $8.70 *$ \\
*** $p<.001 ; * p<.05$ & & & & \\
$\begin{array}{l}\text { Note: The original categories of "very likely" and "somewhat likely" are merged together in this table as } \\
\text { "likely." The same procedure was followed for the category of "unlikely." }\end{array}$
\end{tabular}

The distribution of willingness to medicate behaviors for all parents shows no significant differences across gender or family type. This is true for all 551 parents together as well as for each group of parents separately. Willingness to medicate behaviors, however, shows statistically significant differences when combined with race and ethnicity, specifically on willingness to medicate ODD, $\left[\chi^{2}(551)=14.23, p<.027\right]$ and willingness to medicate depression, $\left[\chi^{2}(551)=12.88, p<.045\right]$ for all 551 parents. In both cases white parents are more willing to medicate behaviors compared to Hispanic parents.

These racial and ethnic differences are also pronounced when parents reporting child with problems are examined separately. Table 4 shows the distribution of willingness to medicate for all four types of behaviors across race and ethnicity for parents reporting child with problems. As shown, white parents were more willing to 
medicate across all behaviors compared to Hispanic parents (ranging from $33.6 \%$ to $42.5 \%$ in each behavior), but the differences were statistically significant for willingness to medicate ADHD and depression.

Table 4

Willingness to medicate behaviors across race and ethnicity for parents of children reporting child with problems

\begin{tabular}{|c|c|c|c|c|c|c|c|}
\hline \multirow{3}{*}{$\begin{array}{l}\text { Willingness to } \\
\text { medicate } \\
\text { behaviors }\end{array}$} & \multicolumn{6}{|c|}{$\begin{array}{l}\text { Race and ethnicity } \\
n=99(\%)\end{array}$} & \multirow[t]{2}{*}{$\chi^{2}$} \\
\hline & \multicolumn{2}{|c|}{ White non-Hispanic } & \multicolumn{2}{|c|}{ Hispanic } & \multicolumn{2}{|c|}{ African American } & \\
\hline & Likely & Unlikely & Likely & Unlikely & Likely & Unlikely & \\
\hline ADHD & $35(34.6)$ & $14(13.8)$ & $19(18.8)$ & $11(10.9)$ & $8(7.9)$ & $12(11.8)$ & $13.00 * *$ \\
\hline ODD & $34(33.6)$ & $15(14.8)$ & $16(15.8)$ & $14(13.8)$ & $8(7.9)$ & $12(11.8)$ & 8.25 \\
\hline DEPR. & $43(42.5)$ & $6(5.9)$ & $23(22.7)$ & $7(6.9)$ & $13(12.8)$ & $7(6.9)$ & $12.22 * *$ \\
\hline SUIC. & $40(39.6)$ & $9(8.9)$ & $27(26.7)$ & $3(2.9)$ & $13(12.8)$ & $7(6.9)$ & 6.71 \\
\hline
\end{tabular}

Parents reporting no child with problems, when examined separately across race and ethnicity, show statistical significant differences only in their willingness to medicate ODD, $\left[\chi^{2}(452)=18.34, p<.005\right]$. In sum, these demographics show that White parents are more likely to report having a child with emotional and behavioral problems and they also report a higher willingness to medicate problematic behaviors of their children, compared to Hispanic parents.

Correlations and crosstabs. This section presents the results of correlations and crosstabs conducted between variables. Correlation tables and crosstabs were conducted 
to check for multicollinearity. Multicollinearity can occur when exogenous variables are highly correlated $(<.80)$ that obtaining reliable estimates of their individual regression coefficients becomes problematic (Rajdeep, Cote \& Baumgartner, 2004). A Pearson correlation (presented in table 5) was conducted between the numerical continuous variables in this sample. As shown there are no strong correlations between variables in the sample, so there is no risk of multicollinearity. Statistically significant coefficients are only present between four endogenous variables, but these are not used in the path analysis simultaneously and create no problems for the analyses.

Table 5

Pearson's correlation table for the numerical continuous variables

\begin{tabular}{llllllll}
\hline & $\begin{array}{l}\text { Work } \\
\text { satisfaction }\end{array}$ & $\begin{array}{l}\text { Nr of } \\
\text { children }\end{array}$ & $\begin{array}{l}\text { Parental } \\
\text { time }\end{array}$ & ADHD & ODD & Depression & $\begin{array}{l}\text { Suicidal } \\
\text { talk }\end{array}$ \\
\hline Work satisfaction & 1 & .026 & .013 & -.032 & .003 & -.102 & -.012 \\
Nr. of children & & 1 & .027 & -.127 & -.141 & -.102 & -.061 \\
Parental time & & & 1 & -.117 & -.080 & -.067 & .418 \\
ADHD & & & & 1 & .609 & .536 & .501 \\
ODD & & & & 1 & .501 & .633 \\
Depression & & & & & & 1 & .642 \\
Suicidal talk & & & & & & & \\
\hline
\end{tabular}

A Spearsman rank order correlation, interpreted similar to the Pearson's correlation coefficients (Lehman, 2005), was conducted to check for correlations among categorical variables. Since this type of correlation analysis can only show the existence of correlations among variables, conducting crosstabs for these categorical variables seemed necessary. Crosstabs revealed statistically significant relationships between race and ethnicity, family type, and gender for both groups of parents.

Particularly, African American parents reporting no child with problems were 
more likely (34.2\%) to be in one-parent families compared to White (10.9\%) and Hispanic $(20.9 \%)$ parents, $\left[\chi^{2}(452)=23.04, p<.000\right]$. This was true for African American parents reporting child with problems who also were more likely $(41.7 \%)$ to be in one-parent families compared to White (33.3\%) and Hispanic $(25.0 \%)$ parents, $\left[\chi^{2}(99)\right.$ $=9.2, p<.01]$. Mothers of both groups were more likely to be in one-parent families compared to fathers. Specifically, $28.1 \%$ of mothers reporting no child with problems led one-parent families compared to $11.3 \%$ of fathers, $\left[\chi^{2}(452)=16.90, p<.000\right]$, and $30.9 \%$ of mothers reporting child with problems led one-parent families compared to $9.7 \%$ of fathers, $\left[\chi^{2}(99)=5.2, p<.02\right]$. Finally a crosstab between gender and race and ethnicity revealed that African American fathers (27.5\% for parents reporting no child with problems and 5\% for parents reporting child with problems), were the least represented in the sample. Significant statistical differences were found in both groups when compared to Hispanic and White fathers, $\left[\chi^{2}(452)=8.00, p<.018\right]$ for parents reporting no child with problems and, $\left[\chi^{2}(99)=8.56, p<.014\right]$ for parents reporting child with problems.

In sum, African American parents were more likely to be in one-parent families compared to other groups. Mothers were more likely to be in one-parent families compared to fathers and African American fathers were the least represented in this sample. These findings point to the need to control for the variables of gender, race and ethnicity, and family type during the analysis.

Results of path analyses. Path analysis has an advantage over multiple regression in that it helps to predict a cause-effect relationship and can measure the direct and 
indirect effects through an intervening variable on the endogenous variable(s) (Mertler \& Vannatta, 2005). Path analysis also allows directional predictions among a set of exogenous or a set of endogenous variables (Hoyle \& Smith, 1994). The analysis for this study was conducted using Amos 20.0 software incorporated in SPSS 20.0 because of its easy-to-use graphical interface. The following subsections detail the results of all paths conducted for this study. There were eight paths in total, from which four paths were conducted for each endogenous variable for both groups of parents. Subsections are organized following each endogenous variable (willingness to medicate each behavior) and reporting the results for both groups of parents. Figures of statistically significant paths are included in most subsections.

Willingness to medicate ADHD-like behaviors. This subsection presents the results of two paths where willingness to medicate ADHD-like behaviors is the endogenous variable for both subsamples of parents.

Willingness to medicate ADHD-like behaviors for parents reporting child with problems. This study hypothesizes that working parents reporting child with problems and are able to spend more time with their children in a regular workday, will be less willing to medicate ADHD-like behaviors. Results show that time spent with children has a direct relationship with willingness to medicate ADHD-like behaviors for parents reporting child with problems $(\beta=-.20 ; p<.006)$. The relationship is statistically significant and negative and can be further interpreted to mean that when the time spent with children increases by one standard deviation from its mean, willingness to medicate ADHD-like behaviors is expected to decrease (less likely to medicate) by .20 standard 
deviations from its mean. So, the null hypothesis is rejected in this case in favor of the alternative hypothesis.

Figure 3

Statistical significant paths for willingness to medicate ADHD-like behaviors for parents reporting child with problems

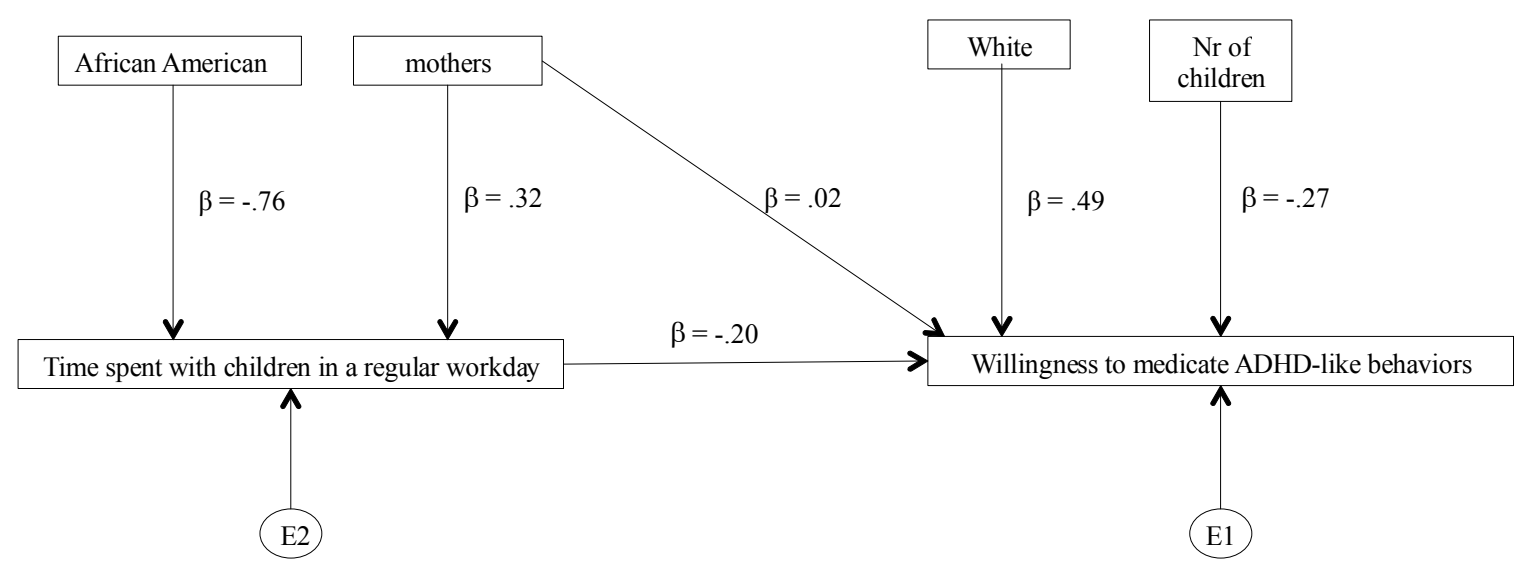

Additionally from the investigation of the other relationships in the path, a positive significant relationship between White parents and willingness to medicate ADHD-like behaviors suggests that White parents are more willing to medicate ADHDlike behaviors compared to Hispanic and African American parents $(\beta=.49 ; p<.04)$. This variable (dummy-white) had no direct effect on the variable of time spent with children. The number of children in a family is also directly related willingness to medicate ADHD-like behaviors $(\beta=-.27 ; p<.04)$, but has no indirect effect on willingness to medicate through the intervening variable of time spent with children (see figure 3). This relationship is negative, implying that having fewer children per family is directly related to being more likely to medicate ADHD-like behaviors for this group of 
parents. No other exogenous variables (gender, family type, work satisfaction) were directly related to willingness to medicate ADHD-like behaviors in this path.

A relationship was found between African American parents and time spent with children. This direct relationship $(\beta=-.76 ; p<.04)$, is negative, indicating that African American parents reporting child with problems in this subsample spend less time with their children compared to Hispanic parents (captured in Figure 3). None of the other exogenous variables (gender, family type, number of children, and work satisfaction) has any direct relationship with time spent with children for this subsample.

Willingness to medicate ADHD-like behaviors for parents reporting no child with problems. This study hypothesized that time spent with children will only have an influence on willingness to medicate ADHD-like behaviors for parents reporting child with problems but not for parents reporting no child with problems. Results from path analysis show that time spent with children also relates to willingness to medicate ADHD-like behaviors for parents reporting no child with problems $(\beta=-.065 ; p<.04)$, thus we cannot reject the null hypothesis. It should be noted here, however, that although the relationship is statistically significant, its $\beta$ value of -.065 indicates a weak effect that cannot be used to infer any particularly strong relationship between these two variables. 
Figure 4

Statistical significant paths for willingness to medicate ADHD-like behaviors for parents reporting no child with problems

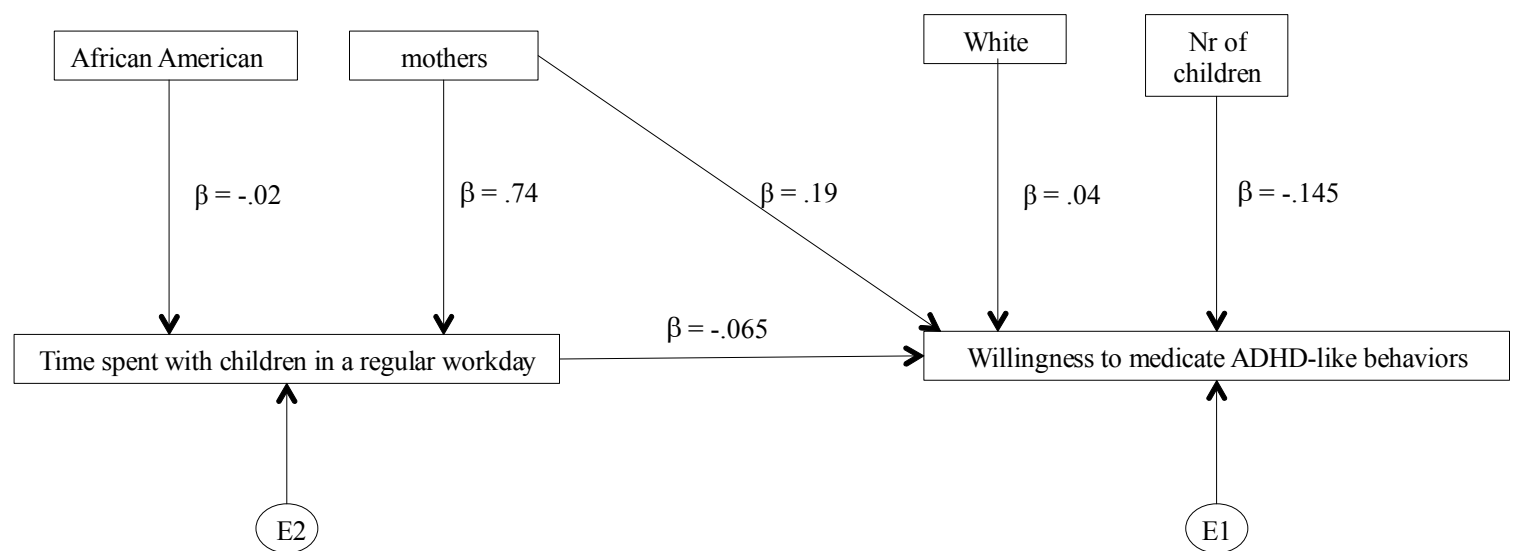

In addition, the number of children per family is directly associated with willingness to medicate ADHD-like behaviors for this group of parents $(\beta=-.145 ; p<$ .008). Here again, the relationship is negative implying that having fewer children relates to being more willing to medicate behaviors associated with ADHD. Mothers from this group of parents are more willing to medicate ADHD-like behaviors compared to fathers $(\beta=.19 ; p<.04)$. The variable that measured gender (mother-dummy) is directly related to willingness to medicate ADHD-like behaviors (the indirect effect through time spent with children $\beta=.05$ is weaker than the direct effect on willingness to medicate ADHDlike behaviors $\beta=.19$ ). The rest of predictors (race and ethnicity, family type, and work satisfaction) are not directly or indirectly related to willingness to medicate ADHD-like behaviors for parents reporting no child with problems. Although most predictors are not related to the time spent with children (i.e., race and ethnicity, family type, work satisfaction, and number of children), gender shows a direct and strong relation with time 
for this group of parents (details shown in figure 4). Mothers spend more time with children than fathers for parents reporting no child with problems $(\beta=.74 ; p<.001)$.

In sum, time spent with children has a statistical significant relationship with willingness to medicate ADHD-like behaviors for both groups of parents in this sample. However, the strength of relationship between variables indicates that the association between parental time and willingness to medicate ADHD-like behaviors can only be considered as such only among parents reporting child with problems. In addition, White parents are more willing to medicate ADHD-like behaviors for parents reporting child with problems but that relationship is not replicated for parents reporting no child with problems. The number of children per family seems to negatively influence parents' willingness to medicate ADHD-like behaviors, so that having fewer children relates to an increased willingness to medicate behaviors. Here, the association is true for all parents but more pronounced for parents reporting child with problems. Meanwhile mothers reporting no child with problems are more willing to medicate ADHD-like behaviors compared to fathers, but this does not apply to parents reporting child with problems. Lastly, African American parents spend less time with their children for parents reporting child with problems, whereas mothers reporting no child with problems spend more time with their children compared to fathers. 
Willingness to medicate ODD-like behaviors. This subsection presents the results of path analyses for willingness to medicate behaviors associated with ODD for both groups of parents.

Willingness to medicate ODD-like behaviors for reporting child with problems. The results of the path analysis show that there is no relationship between time spent with children on parents' willingness to medicate ODD-like behaviors for parents reporting no child with problems. The direct relationship between the two variables is weak and not significant $(\beta=-.09 ; p<.273)$. There is no direct or indirect relationship between most exogenous variables (race and ethnicity, gender, family type, and work satisfaction) on willingness to medicate ODD-like behaviors. However, the number of children per family is negatively associated with willingness to medicate ODD-like behaviors $(\beta=$ $.33 ; p<.02)$. The relationship is negative implying that having more children relates to being less willing to medicate ODD-like behaviors for parents reporting child with problems. Since this is the same sample $(n=99)$ of parents reporting child with problems (only the endogenous variable has changed), the relationship between African American parents and time spent with children is still the same as in the model of willingness to medicate ADHD-like behaviors.

Willingness to medicate ODD-like behaviors for parents reporting no child with problems. Results show no relationship between time spent with children and parents' willingness to medicate ODD-like behaviors for parents reporting no child with problems $(\beta=-.043 ; p<.184)$. The number of children per family, here again shows an association with willingness to medicate ODD-like behaviors for parents reporting no child with 
problems $(\beta=-.169 ; p<.003)$ but no other exogenous variable presents any significant relationships. Here the sample of parents reporting no child with problems is the same as in the previous model ( $n=452)$, so the relationship between being a mother and spending time with children is again visible.

In sum, time spent with children shows no association with willingness to medicate ODD-like behaviors for parents reporting child with problems and parents reporting no child with problems. No other variables showed any other significant relationships but the number of children per family. Having fewer children was associated with being less willing to medicate ODD-like behaviors for both groups of parents.

Willingness to medicate behaviors related to depression. This subsection presents results on parents' willingness to medicate children's behaviors that are recognized and diagnosed as depression. For convenience, the term depression is used in the following subsection to indicate behaviors that are commonly diagnosed with this label.

Willingness to medicate depression for parents reporting child with problems. The results of the path analysis show that there is relationship between time spent with children and parents' willingness to medicate depression for parents reporting child with problems. These two variables have a weak and insignificant relationship $(\beta=-.082 ; p<$ .226). No other exogenous variable is related to willingness to medicate depression for this group of parents. 
Willingness to medicate depression for parents reporting no child with problems.

Time spent with children shows no relationship with parents' willingness to medicate depression $(\beta=-.033 ; p<.33)$. However, a number of exogenous variables are related directly to willingness to medicate depression for parents reporting no child with problems. The number of children per family is associated with willingness to medicate depression in a significant and negative relationship $(\beta=-.15 ; p<.01)$ implying that having fewer children may relate to being more willing to medicate depression.

The variable that measures work satisfaction for parents is strongly related to willingness to medicate depression for parents reporting no child with problems $(\beta=-.16$; $p<.02)$. A negative relationship here implies that parents who are less satisfied with their own work are more willing to medicate their children's behaviors perceived as depression. Additionally, family type is also related to parents' willingness to medicate depression $(\beta=.28 ; p<.01)$. The relationship is significant and positive indicating that one-parent families are more willing to medicate behaviors related to depression compared to two-parent families.

In sum, time spent with children is not related to willingness to medicate depression for any group of parents. Willingness to medicate depression for parents reporting child with problems shows no association with any other exogenous variable. On the other hand, leading one-parent families, being less satisfied with work, and having more children was associated with being more willing to medicate behaviors for parents reporting no child with problems. 
Willingness to medicate suicidal talk. The following subsection presents results from the last two paths on parents' willingness to medicate suicidal talk.

\section{Willingness to medicate suicidal talk for parents reporting children with}

problems. The results of the path analysis show that time spent with children is related to parents' willingness to medicate suicidal talk for parents reporting child with problems ( $\beta$ $=-.14 ; p<.05)$. The relationship between these two variables is significant and negative implying that spending less time with children relates to an increase in willingness to medicate suicidal talk (see Figure 5).

Figure 5

Statistical significant paths for willingness to medicate suicidal talk for parents reporting child with problems

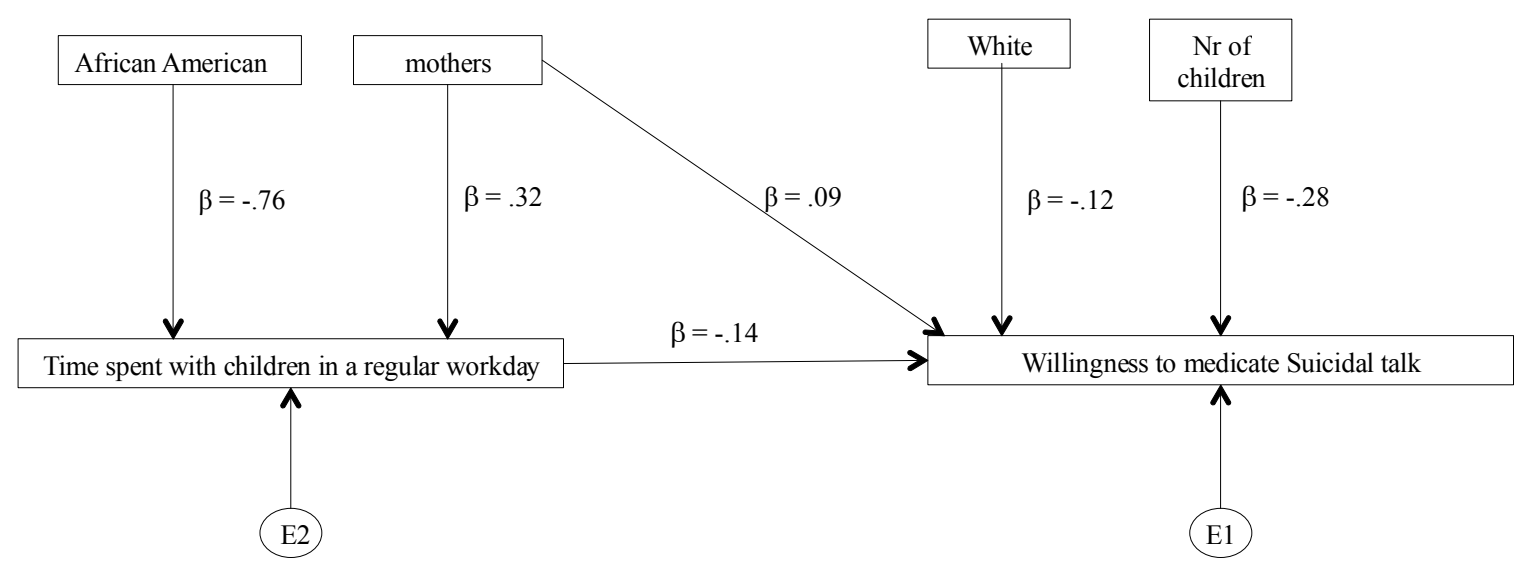

The results from path analysis also show that the number of children per family has a strong and negative relationship with willingness to medicate suicidal talk for this group of parents $(\beta=-.28 ; p<.03)$. This relationship implies that having more children per family is associated with being less willing to medicate suicidal talk. No other 
exogenous variable is related to willingness to medicate suicidal talk for parents reporting child with problems.

\section{Willingness to medicate suicidal talk for parents reporting no child with}

problems. An even stronger relationship was found between time spent with children and parents' willingness to medicate suicidal talk for parents reporting no child with problems $(\beta=-.20 ; p<.001)$. Again, the relationship is significant and negative implying that less time spent with children leads to a higher willingness to medicate a child who speaks about killing oneself (details in Figure 6).

Figure 6

Statistical significant paths for willingness to medicate suicidal talk for parents reporting no child with problems

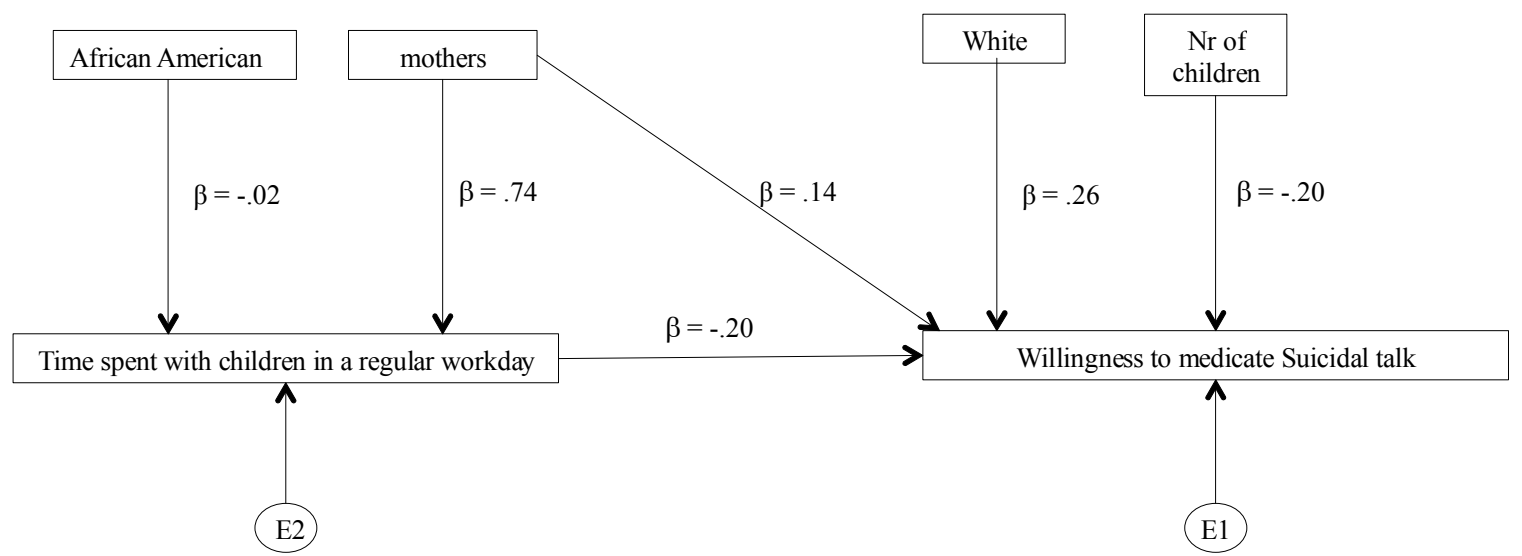

A number of other exogenous variables were related to willingness to medicate suicidal talk for parents reporting no child with problems. The number of children per family negatively relates to willingness to medicate suicidal talk for this group $(\beta=-.20$; $p<.001)$ implying that having fewer children may imply being more willing to medicate 
suicidal talk. Similar to willingness to medicate ADHD-like behaviors, White parents are more willing to medicate suicidal talk compared Hispanic parents $(\beta=.26 ; p<.04)$. Gender, family type, and work satisfaction did not show any significant relationships in this path.

In sum, time spent with children shows a negative statistical significant relationship with both groups of parents indicating that spending less time with children is associated with being more willing to medicate suicidal talk. The number of children per family showed again significant relationships for both groups of parents in the same direction as all the others paths. Finally, being White was associated with being more willing to medicate a child who talks about killing oneself among parents reporting no child with problems.

Summary of quantitative results. In this subsample, the time spent with children has a direct relation with willingness to medicate ADHD-like behaviors and suicidal talk for both groups of parents. The relationship is negative and significant (the same direction as it was hypothesized in this study). Time spent with children, on the other hand, showed no association with willingness to medicate ODD-like behaviors or behaviors recognized as depression for any group of parents. In this sample of 551 parents, spending time with children seems to have different associations on willingness to medicate different behaviors.

Results from this study also show that the number of children in the household is directly related to willingness to medicate across all behaviors for both groups of parents. The relationships in all cases were significant and negative implying that fewer children 
in a household may relate to a higher willingness to medicate children's behaviors. In accordance with the literature on parents of ADHD children, in this study was also found that White parents are more willing to medicate ADHD-like behaviors for parents reporting child with problems. Among parents reporting having a child with problems, White parents are also more willing to medicate suicidal talk compared to Hispanic parents. In addition, being less satisfied with work and being a single parent is related to being more willing to medicate depression among parents reporting no child with problems.

Finally, in terms of time spent with children, results show that African American parents reporting child with problems spend less time with their children, but this was not the case for parents reporting no child with problems. Also, mothers reporting no child with problems report of spending more time with their children compared to fathers. This relation was not found for mothers reporting child with problems.

\section{Part II: Results From the Open-Ended Variable: The Most Challenging Aspects of Childrearing}

The phone interviews concluded by asking parents a straightforward question on what parents thought was the most challenging aspect of raising a child (details provided in the methodology section, p.65-66). Answers varied between one word to a few short sentences. First these answers were coded (details provided in the methodology section p.75-82), then simple frequencies and crosstabs were conducted to examine this information. 
The most challenging aspect of childrearing for both groups of parents. As shown in table 2 (p.79), spending time with children is the most challenging aspect of childrearing for $n=78(14.2 \%)$ out of 551 parents in the sample, followed by handling negative outside influences on the child - the answer of $n=62(11.3 \%)$ of all parents. At the other end of the spectrum having financial difficulties (3.4\%) and raising children alone $(3.1 \%)$ were the least mentioned as challenging aspects.

Results show that, as a group, parents reporting child with problems differ statistically significantly on their responses about the most challenging aspect of childrearing compared to parents reporting no child with problems $\left[\chi^{2}(551)=25.03, p<\right.$ $.02]$. Figure 7 details these concerns for both groups of parents.

Figure 7

Percentages of each group of parent and the first ten most challenging aspects of childrearing $^{a}$

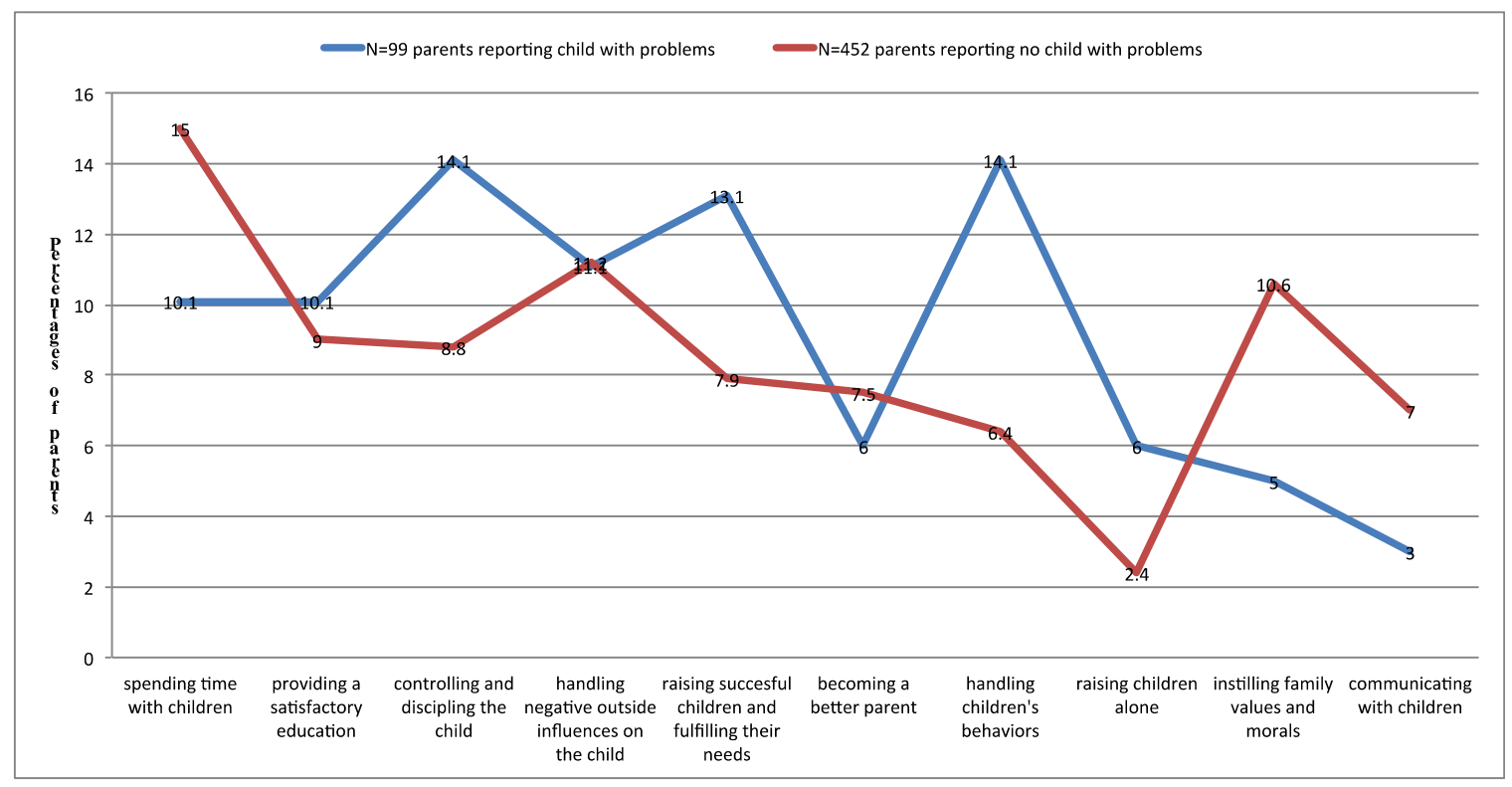

${ }^{\mathrm{a}}$ Chi square $(551)=25.03, \mathrm{df}=13, \mathrm{p}<.02$ 
Spending time with children is the most repeated concern for parents reporting no child with problems $(15 \%)$ whereas it is ranked the fifth most repeated concern for parents reporting child with problems (10.1\%). Parents reporting child with problems consider as the most challenging aspect of childrearing controlling and disciplining the child (14.1\%) whereas this ranks the fifth most repeated concern for parents reporting no child with problems (8.8\%). Another major difference between the groups is instilling family values and moral values. Parents reporting no child with problems are often considering this as the most challenging aspect of childrearing $(10.6 \%)$ whereas it was only voiced by 5 participants (5\%) among parents reporting child with problems.

Other noticeable differences between the groups are handling children alone, a prominent concern for parents reporting child with problems (6.1\%) and mentioned by only $2.4 \%$ from parents reporting no child with problems. Handling behavioral issues seem to occupy a top concern for parents reporting child with problems (14.1\%) but it is a lesser priority among parents no child with problems (6.4\%).

Challenging aspects of childrearing and race and ethnicity. Results show that the most challenging aspects of childrearing show statistical significant differences between African American, Hispanic, and White parents for the entire subsample, $\left[\chi^{2}\right.$ $(551)=77.43, p<.000]$. These differences noted in the entire sample are still apparent among each separate group of parents. The most challenging aspects reported from parents reporting child with problems are significantly different between African American, Hispanic, and White parents $\left[\chi^{2}(99)=42.12, p<.02\right]$. The same is true for differences in race and ethnicity and challenges of childrearing among parents reporting 
no child with problems $\left[\chi^{2}(452)=64.83, p<.000\right]$. Table 6 presents parents' concerns organized around their race and ethnicity and whether they report a child with emotional and behavioral problems. 
Table 6

The most challenging aspects of childrearing according to parents' race and ethnicity ${ }^{a b c}$

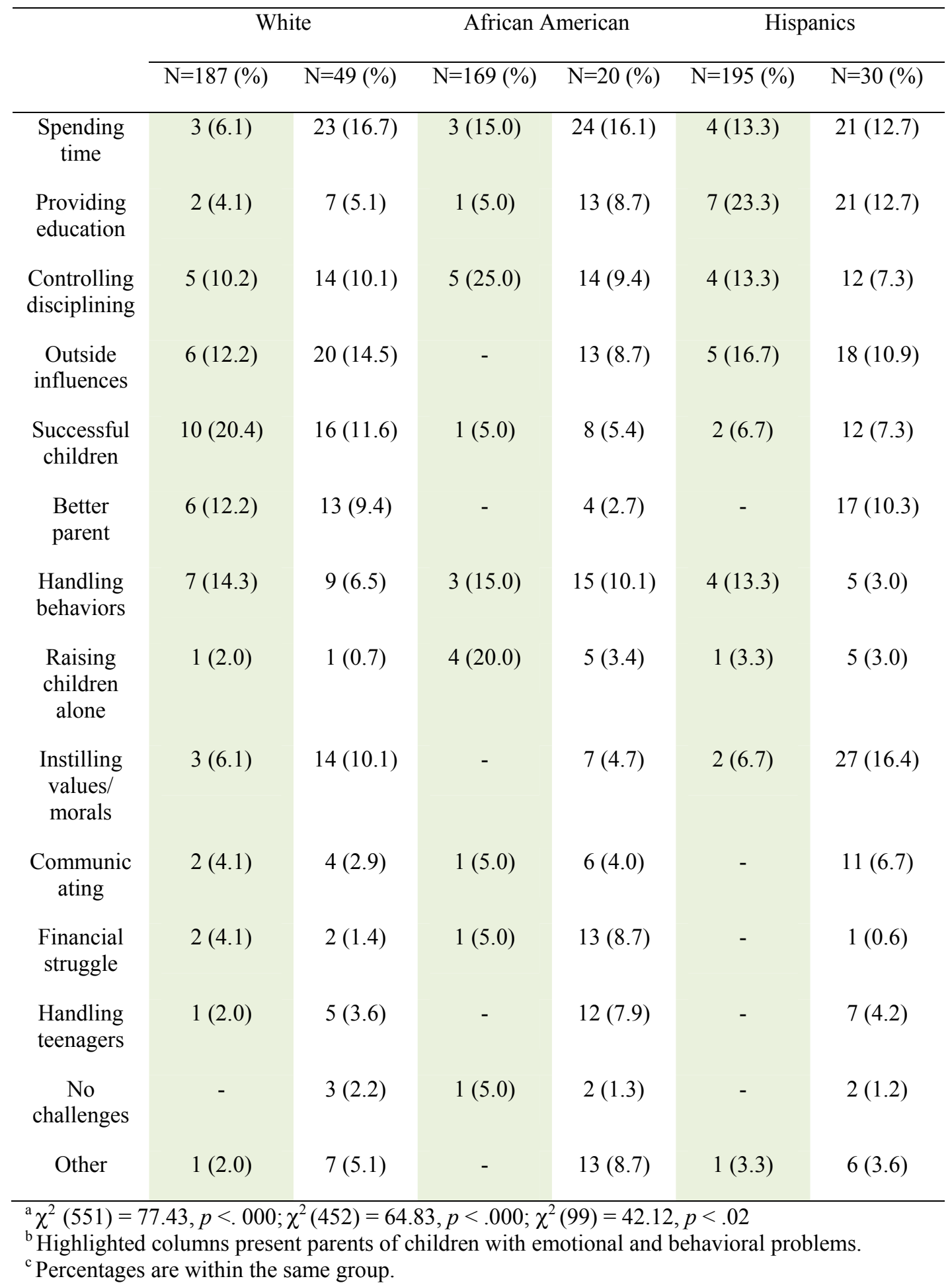




\section{Challenging aspects of childrearing and race and ethnicity among parents}

reporting having a child with problems. Spending time with children is a challenge most reported by African American parents reporting child with problems (15.0\%) followed by Hispanic parents $(13.3 \%)$, but less so for White parents $(6.1 \%)$. In this same group, providing a good education is more often reported from Hispanic parents $(23.3 \%)$ compared to African American and White parents (5.0\% and 4.1\% respectively). African American parents are primarily concerned with disciplining and controlling their children (25.0\%) compared to only $13.3 \%$ for Hispanic parents and $10.2 \%$ for White parents. Hispanic parents are more concerned about outside influences on their child (16.7\%) followed by White parents (12.2\%), whereas none from African American parents expressed such concern. Having successful children, on the other hand, is desirable and a challenging aspect of childrearing for White parents (20.4\%) but much less so for Hispanic and African American parents (6.7\% and 5.0\% respectively). Being a better parent is a challenge voiced among White $12.2 \%$ ) but not mentioned by Hispanic or African American parents of the same group. One last notable difference in this group is the fact that raising children alone is commonly a concern expressed by African American parents $(20.0 \%)$ but not apparent among Hispanic (3.3\%) or White $(2.0 \%)$ parents.

\section{Challenging aspects of childrearing and race and ethnicity among parents} reporting no child with problems. Although spending time with children is a priority for all the parents reporting no child with problems, White (16.7\%) and African American (16.1\%) mention the lack of time more often than Hispanic parents (12.7\%). Hispanic 
parents, similar to the group of parents reporting child with problems are concerned with providing a good education to their children (12.7\%) more than African American (8.7\%) and White parents $(5.1 \%)$. White parents of this group are more concerned with outside influences on their child (14.5\%) compared to Hispanic parents (10.9\%) or African American parents $(8.7 \%)$. They are also the group of parents who consider a desirable and challenging aspect to raise successful children (11.6\%) compared to Hispanic $(7.3 \%)$ and African American parents (5.4\%). Handling difficult behaviors, on the other hand, is more often found among African American parents (10.1\%) compared to White $(6.5 \%)$ and Hispanic parents (3.0\%). Hispanic parents are more concerned with instilling family and moral values to their children (16.4\%) compared to White (10.1\%) and African American (4.7\%) parents of the same group. Lastly, financial difficulties are most mentioned by African American parents (8.7\%) but are almost inexistent among White (1.4\%) and Hispanic $(0.6 \%)$ parents reporting no child with problems.

Challenging aspects of childrearing and gender. The differences between what mothers report as the most challenging aspect of childrearing compared to fathers for the entire sample are statistically significant, $\left[\chi^{2}(551)=25.18, p<.02\right]$. Results show that fathers $(32.4 \%)$ are more likely to voice the lack of time with their children compared to mothers $(23.5 \%)$ for the entire sample of 551 parents. In fact mothers reporting child with problems are the least concerned with time compared to other groups (see table 7). Mothers (28\%) are more concerned with discipline and control compared to fathers $(12 \%)$, and specifically mothers reporting child with problems $(17.6 \%)$.

Table 7 
The most challenging aspects of childrearing and gender ${ }^{a b c}$

\begin{tabular}{|c|c|c|c|c|}
\hline & \multicolumn{2}{|c|}{ Mothers N=360 (\%) } & \multicolumn{2}{|c|}{ Fathers $\mathrm{N}=191(\%)$} \\
\hline Spending time & $5(7.4)$ & $42(14.4)$ & $5(16.1)$ & $26(16.3)$ \\
\hline $\begin{array}{l}\text { Providing } \\
\text { education }\end{array}$ & $7(10.3)$ & $21(7.2)$ & $3(9.7)$ & $20(12.5)$ \\
\hline $\begin{array}{l}\text { Controlling/ } \\
\text { disciplining }\end{array}$ & $12(17.6)$ & $31(10.6)$ & $2(6.5)$ & $9(5.6)$ \\
\hline $\begin{array}{l}\text { Outside } \\
\text { influences }\end{array}$ & $8(11.8)$ & $29(9.9)$ & $3(9.7)$ & $22(13.8)$ \\
\hline $\begin{array}{l}\text { Successful } \\
\text { children }\end{array}$ & $8(11.8)$ & $22(7.5)$ & $5(16.1)$ & $14(8.8)$ \\
\hline Better parent & $5(7.4)$ & $21(7.2)$ & $1(3.2)$ & $13(8.1)$ \\
\hline $\begin{array}{l}\text { Handling } \\
\text { behaviors }\end{array}$ & $8(11.8)$ & $21(7.2)$ & $6(19.4)$ & $8(5.0)$ \\
\hline $\begin{array}{c}\text { Raising } \\
\text { children alone }\end{array}$ & $6(8.8)$ & $9(3.1)$ & - & $2(1.3)$ \\
\hline $\begin{array}{c}\text { Instilling } \\
\text { values/ morals }\end{array}$ & $1(1.5)$ & $31(10.6)$ & 4 (12.9) & $17(10.6)$ \\
\hline Communicating & $2(2.9)$ & $12(4.1)$ & $1(3.2)$ & $9(5.6)$ \\
\hline $\begin{array}{l}\text { Financial } \\
\text { struggle }\end{array}$ & $2(2.9)$ & $10(3.4)$ & $1(3.2)$ & $6(3.8)$ \\
\hline $\begin{array}{l}\text { Handling } \\
\text { teenagers }\end{array}$ & $1(1.5)$ & $21(7.2)$ & - & $3(1.9)$ \\
\hline No challenges & $1(1.5)$ & $2(0.7)$ & - & $5(3.1)$ \\
\hline Other & $2(2.9)$ & $20(6.8)$ & - & $6(3.8)$ \\
\hline
\end{tabular}




\section{Challenging aspects of childrearing and gender for parents of children}

reporting child with problems. When combined with the variable of difficulties of childrearing, gender for parents reporting child with problems shows no statistically significant differences, $\left[\chi^{2}(99)=15.46, p<.28\right]$. However, a few differences can be noted from the table above. For example fathers of this group report that handling children's behaviors (19.4\%), spending time with children (16.1\%), and raising successful children (16.1\%) are among the top three most common challenges. Mothers, on the other hand, prioritize controlling and disciplining (17.6\%) and then equally report outside influences on the child (11.8\%), handling behaviors (11.8\%), and raising successful children (11.8\%). Another notable difference is in the fact that fathers are more concerned with instilling values and morals (12.9\%) whereas among mothers of this group this category is considerably unreported (1.5\%). Controlling and disciplining children is a top priority among mothers $(17.6 \%)$ but is far from the case for fathers $(6.5 \%)$. Lastly, the concern about the available time with children also shows some differences between the groups. Fathers consider this to be among their top challenges $(16.7 \%)$ whereas only 5 mothers $(7.4 \%)$ in this group report it as a concern.

\section{Challenging aspects of childrearing and gender among parents reporting no}

child with problems. Differences between mothers and fathers and their reports on the most challenging aspects of childrearing are statistically significant, $\left[\chi^{2}(452)=21.95, p\right.$ $<.05]$. Unlike parents reporting child with problems, in this group both mothers and fathers are concerned with the lack of time to spend with children $(14.4 \%$ and $16.3 \%$ respectively). Also, they are both equally concerned with instilling family values and 
morals (10.6\% in both cases). Mothers in this group are more concerned with disciplining and controlling (10.6\%) compared to fathers (5.6\%). In addition, fathers point out difficulties in providing a good education to their children (12.5\%) more often than mothers (7.2\%). Similarly, fathers (13.8\%) mention more often the challenge of handling outside influences on the child compared to mothers $(9.9 \%)$. It is also important to note here that difficulties with teenage years are by mothers in this group (7.2\%) but not often by fathers $(1.9 \%)$.

Challenging aspects of childrearing and family type. The most challenging aspects for parents in one-parent families differ substantially from those reported by parents in two-parent families, $\left[\chi^{2}(551)=42.88, p<.000\right]$. Spending time with children is the concern of $15.2 \%$ of all parents in two-parent families, but only the concern of $10.4 \%$ of parents in one-parent families. Another considerable difference is about raising successful children. This is reported to be a challenge from $10.07 \%$ of parents in twoparent families but it is only reported by $4.7 \%$ of parents in two-parent families. Instilling family values also seems to be reported more often by parents in two-parent families (10.3\%) compared to parents in one-parent families (7.0\%). Table 8 details the information on most difficult aspects of childrearing according to family type and whether parents report of having a child with emotional and behavioral problems. 
Table 8

The most challenging aspects of childrearing and family type $e^{a b c}$

\begin{tabular}{|c|c|c|c|c|}
\hline \multirow[b]{2}{*}{ Spending time } & \multicolumn{2}{|c|}{$\begin{array}{c}\text { One-Parent families } \\
\mathrm{N}=124(\%)\end{array}$} & \multicolumn{2}{|c|}{$\begin{array}{l}\text { Two-Parent families } \\
\mathrm{N}=427(\%)\end{array}$} \\
\hline & $1(4.2)$ & $12(12.0)$ & $9(7.6)$ & $56(15.9)$ \\
\hline Education & $2(8.3)$ & $9(9.1)$ & 8 (10.7) & $32(9.1)$ \\
\hline $\begin{array}{l}\text { Controlling } \\
\text { disciplining }\end{array}$ & $5(20.8)$ & $7(7.0)$ & $9(12.0)$ & $33(9.4)$ \\
\hline $\begin{array}{l}\text { Outside } \\
\text { influences }\end{array}$ & $1(4.2)$ & $9(9.0)$ & $10(13.3)$ & $42(11.9)$ \\
\hline $\begin{array}{l}\text { Successful } \\
\text { children }\end{array}$ & $1(4.2)$ & $5(5.0)$ & $12(16.0)$ & $31(8.8)$ \\
\hline Better parent & $1(4.2)$ & $5(5.0)$ & $5(6.7)$ & $29(8.2)$ \\
\hline $\begin{array}{l}\text { Handling } \\
\text { behaviors }\end{array}$ & $4(16.7)$ & $9(9.0)$ & $10(13.3)$ & $20(5.7)$ \\
\hline $\begin{array}{c}\text { Raising } \\
\text { children alone }\end{array}$ & $4(16.7)$ & $8(8.0)$ & $2(2.7)$ & $3(0.9)$ \\
\hline $\begin{array}{c}\text { Instilling } \\
\text { values/ morals }\end{array}$ & - & $9(9.0)$ & $5(6.7)$ & $39(11.1)$ \\
\hline Communicating & $3(12.5)$ & $3(3.0)$ & - & $18(5.1)$ \\
\hline $\begin{array}{l}\text { Financial } \\
\text { struggle }\end{array}$ & $1(4.2)$ & $7(7.0)$ & $2(2.7)$ & $9(2.6)$ \\
\hline $\begin{array}{l}\text { Handling } \\
\text { teenagers }\end{array}$ & - & $9(9.0)$ & $1(1.3)$ & $15(4.3)$ \\
\hline No challenges & - & - & $1(1.3)$ & $7(1.5)$ \\
\hline Other & $1(4.2)$ & $8(8.0)$ & $1(1.3)$ & $18(5.1)$ \\
\hline
\end{tabular}




\section{Challenging aspects of childrearing and family type for parents of children}

reporting child with problems. What parents of children reporting child with problems consider to be the most challenging aspect of childrearing differs according to family type $\left[\chi^{2}(99)=33.88, p<.001\right]$. Obviously raising children alone is mostly a concern of parents in one-parent families $(16.7 \%)$ whereas it is reported only by $2.7 \%$ of parents in two-parent families. Spending time with children is more often found among reports of parents in two-parent families (7.6\%) compared to parents in one-parent families (4.2\%). So, is outside influences, which seems to concern mostly parents in two-parent families (13.3\% versus $4.2 \%)$, and raising successful children (16.0\% versus $4.2 \%)$. On the other

hand, parents in one-parent families who also report of having a child with emotional and behavioral problems are far more concerned with disciplining and controlling children (20.8\%) compared to parents in two-parent families (12.0\%). Also, communicating with children is a concern only mentioned by parents in one-parent families $(12.5 \%)$ and not reported by parents in two-parent families. Finally, financial struggles are more often reported by parents in one-parent families (4.2\%) than other parents (2.7\%).

Challenging aspects of childrearing and family type among parents reporting no child with problems. Differences because of family type are also found among reports of parents reporting no child with problems, $\left[\chi^{2}(452)=24.20, p<.029\right]$. Some of these differences are noted in the concern of spending time with children - more often reported by parents in two-parent families (15.9\% versus $12.0 \%$ ), as well as raising successful children $(8.8 \%$ versus $5.0 \%)$, and becoming a better parent $(8.2 \%$ versus $5.0 \%)$. On the other hand, parents in one-parent families report more struggles in raising children alone 
( $8.0 \%$ versus $0.9 \%)$, handling difficult behaviors ( $9.0 \%$ versus $5.7 \%)$, handling teenagers (9.0\% versus $4.3 \%)$, and financial difficulties ( $7.0 \%$ versus $2.6 \%)$.

Highlights of the open-ended answers. This study focuses on the time spent with children and its influence on parents' willingness to medicate behaviors. The purpose of investigating the open-ended answers of the most challenging aspects of childrearing is to better understand parents' concerns with their children. Results presented above show that parents reporting no child with problems were more often concerned with the lack of available time with children compared to parents reporting child with problems. African American parents reporting child with problems were more likely to report the lack of time as a challenging aspect of childrearing compared to Hispanic and White parents in the same group. Fathers were more likely to consider the lack of time as a challenging aspect compared to mothers in both groups.

Disciplining and controlling children were more often reported from parents reporting child with problems. African American parents were more concerned with disciplining and controlling children regardless of whether they reported of having a child with emotional and behavioral problems. This was true for mothers in both groups and parents in one-parent families. Providing a good education, on the other hand, was more often reported from Hispanic parents (regardless of whether they reported of having a child with emotional and behavioral problems). Finally, raising successful children was more often a priority for White parents; handling children's behaviors was more often found among African American parents' reports; and instilling family values and morals was more often repeated in Hispanic parents' reports. 


\section{Limitations}

The most conspicuous limitation of the proposed study is the fact that it cannot establish the cause and effect relationship between parental time reported and willingness to medicate behaviors. It remains unclear whether the association found between these two variables is caused by the lack of available time, or by parents' willingness to medicate children's behaviors. Second, this study does not control for family income. Although the variable of family income was available in the dataset, it had 75 missing answers for the 551 parents included in this subsample. Including the family income variable would have led in a substantially reduced sample, especially for the group of parents reporting child with problems, thus violating our minimum number of cases to conduct path analyses. Third, the quality of time is an important characteristic of times that parents spend with children. Even if the amount of time parents spend with children may relate to their willingness to medicate or not medicate ADHD-like behaviors, the quality of time may actually provide a more valid insight on these parents' circumstances and motivations. This study could provide no measure of quality of time. Having more than a single question that measured time would have provided for a stronger internal validity. Fourth, the open-ended answers from this data were interpreted and coded by only one researcher. Although coding was conducted twice, no triangulation or member check-in was possible.

It should be noted here that the sample of parents with emotional and behavioral problems was relatively small for some of the investigations conducted in this study (such as the results from the open-ended answers). Finally, as in the original study, 
households that did not own a home telephone (probably, about 2-3\% of households in both counties surveyed) were excluded from the sampling method. 


\section{CHAPTER V: DISCUSSION}

The following chapter discusses and interprets the results of this study. First, results are examined in light of the ongoing controversy regarding the nature of ADHD and medication use among children. Then results are interpreted in relation to the current literature on parents of ADHD children and parental time, and Merton's theory of purposive action is also discussed in light of these results. Finally, future research paths that could allow for investigation on the dynamics of parents' understanding of children's behaviors are delineated. This chapter concludes by discussing the implications to the profession of social work.

\section{Part I: Addressing the controversy of ADHD}

The controversy about the nature of ADHD as well as about the use of medications to treat children's problematic behaviors is well documented from the literature (Mayes, Bagwell, \& Erkulwater, 2009; Zwi, Ramchandani, \& Joughin, 2000). This work adds to the ongoing controversy by opening the door to questions regarding the nature of ADHD and possible non-medical interventions that tackle children's behaviors. Results show that parents reporting having a child with problems may be spending fewer hours in the company of their children compared to parents reporting no child with problems. It also shows that spending less time with children on a regular basis is related to being more willing to medicate children's behaviors associated with ADHD or suicidal talk for all the parents in the subsample, especially for parent reporting having a child with problems. Taking this information at face value and considering that spending less time with children has weighty consequences on children's development 
(Hofferth \& Sandberg, 2001; Leibowitz, 2003), one may question whether time spent with children - in quantity and quality - influences the inception of ADHD-like behaviors to begin with? Also, if restored, does spending time with children change children's problematic behaviors?

This reasoning opens the door to a number of other questions, such as: is ADHD a neurobiological disorder or is it a label for parents who, among other experiential characteristics, have limited available time to spend with their children? If we entertain such possibility, a number of issues emerge starting with the need of psychiatric medications - or even other interventions — to modify children's behaviors. The literature informs us that medicating children can, at its best, alter their behaviors temporarily or for the duration of the medicating (Barkley, 2000), often at the cost of consequential side effects for them (Whitaker, 2004). Is it not useful therefore, to explore every other possibility that may explain the existence of such behaviors, before embracing a biomedical approach to children's behaviors and administering psychiatric medications to them? Is it not useful to attempt to understand the initiation of the problem rather than medically treat the outcome? If treating the outcome is the only choice, should we not consider permanent changes of these problematic behaviors before considering quick and temporary ones? This study showed that time spent with children is related to parents' willingness to medicate ADHD-like behaviors. If spending time with children is associated with parents' willingness to medicate behaviors, then its role in how parents perceive behaviors should be prioritized. 
It is clear from the literature that parents are the main actors for diagnosing and treating children (Nigg, 2006). In face of this circumstance, when reporting their children's behaviors to doctors, shouldn't parents also report how much time they spend with children and what type of activities they do together? Isn't it necessary to know how they arrive to a specific conclusion about their children's behaviors? In order for parents to have a good understanding of their children's behaviors, shouldn't they spend time with them? When diagnosing children, parents are only asked about the nature of children's behaviors, characteristics of such behaviors, and their frequency. Practitioners often overlook on how parents reached to these interpretations of children's behaviors. Because of the subjectivity that surrounds the entire problem of ADHD, its nature remains questionable and cannot be determined without a thorough investigation of each child's specific circumstances.

The number of children per family. This study distinguished between similar problematic behaviors of children and showed that the available parental time in the sample was associated with lower willingness to medicate ADHD-like behaviors and suicidal talk. It also showed that other characteristics such as race, ethnicity, gender, and work satisfaction were related to the actual time available to spend with children as well as willingness to medicate different behaviors.

Additionally, it brought to light one variable that was constantly related to parents' willingness to medicate all behaviors discussed in this study: the number of children at home. Having more children seems to lower willingness to medicate behaviors across all parents for all types of behaviors in the sample. This seemingly 
unexpected finding finds some support in the literature. Chen and Escarce (2006) conducted a study on family structure and children's visits to doctors as well as medication use based on longitudinal data from Medical Expenditure Panel Survey (1996-2001). They concluded that families with more children had fewer doctor visits and used fewer medications than parents with one child. They also concluded that this was true even for children who lived in families with additional adults besides their parents. Although this study is not focused on children's behavioral problems, it shows that increasing the number of children per family seems to reduce parents' general attachment to the medical world such as conducting doctors' visits or using prescribed medications. In this work it was shown that the number of children per family relates to parents' willingness to medicate ADHD-like, ODD-like, depression, and suicidal talk regardless of whether parents reported of having a child with emotional and behavioral problems.

Reasons behind such associations remain unknown. One way of interpreting these findings would be that an increased number of children means more experience in child rearing, or more involvement of children with each other, and less preoccupation with behavioral problems. That could explain why having additional adults in the household has the same decreasing effects on the number of doctors' visits in the Chen and Escarce (2006) study. Another interpretation may be parents' lack of trust in the medical world (Avis \& Reardon, 2008). If they have created mistrust towards physicians from their experience with their first child, they may attempt to solve subsequent health issues on their own, thus reducing doctors' visits. Researchers have documented how parents have 
difficulties in creating a trusting relationship with their children's doctors in all areas of health. The literature on parents of ADHD children also documents this lack of trust in physicians (Fernandez \& Arcia, 2004; Klasen \& Goodman, 2000; Malacrida, 2001), and is also portrayed in public media (Gaviria, 2008) and self-help books that target parents of children with emotional and behavioral problems (Sonna, 2005).

There are a number of possible explanations as to why parents who have fewer children also seem to rely more on doctors. Regardless of any explanations, the point remains that parents' and families' sociodemographic and interpersonal circumstances are important to look at. This raises again questions about the nature of ADHD. If the number of children per family is even slightly decisive on whether a child is diagnosed and medicated, then is ADHD the reification of a specific set of social circumstances in late 20th-century America or a real neurobehavioral disorder? It is very important to investigate further this relationship between the number of children and parents' willingness to medicate behaviors. Do parents know better because of experience when they have more than one child? Do they trust doctors less because of experiences with previous children? Or, perhaps, are they being careless because they have too many children to handle?

Discipline and control versus lack of available time. Findings from this work may shed some light on parents' concerns with raising a child. As shown, parents reporting child with problems spend less time with their children during regular workdays. But, they are less concerned about this limited time compared to parents reporting no child with problems who are simultaneously more sensitive to this limitation 
and report of spending more time with their children. The open-ended answers showed that parents reporting child with problems are primarily concerned with disciplining and controlling children. This type of division is also noted from a recent study that compares parents of ADHD diagnosed and non-diagnosed children on their involvement with children's learning. Rogers, Wiener, Marton, and Tannock (2011) compared 53 parents of ADHD diagnosed children and 48 parents of non-diagnosed children. They concluded that parents of ADHD children spent less time and energy with their children's academic lives (the most problematic aspect of ADHD diagnosed children), and reported lower self-efficacy in their ability to help children (Rogers et al., 2011).

A quest for discipline and control from parents reporting child with problems may have its roots on what parents are exposed to from doctors, teachers, and even self-help books (Pajo \& Stuart, 2012). In fact, it is unclear whether these parents are inherently worried about disciplining and controlling their children or whether such worry is part of what their environment is made of. The literature clearly speaks of the pressure these parents face when teachers contact them and inform them about their children's behaviors (Cohen, 2006; Leslie et al., 2007). Furthermore, teachers also recommend parents to meet with pediatricians, psychiatrists, or psychologists (Cohen, 2006; Malacrida, 2003), a sign of seriousness and pressure put on parents. This type of environment could drive these parents to see increased discipline and control of their children as the only way out of their problematic situation.

However, there exists the possibility that these parents were genuinely concerned with discipline and control over their children before facing intricate situations with 
teachers and doctors. This possibility raises another important issue that needs investigation. If parents reporting child with problems are inherently concerned with discipline and control whereas other parents focus on spending time with their children, then parenting styles are different between these groups of parents. When parents are focused on controlling their children, their attitudes, behaviors, communication, and general parenting should vary considerably than in parents who are trying to spend more time with their children. The latter group of parents would be less focused on controlling than on understanding children, so the resulting attitudes and communication would be undoubtedly different. The likelihood remains that whether parents of children reporting child with problems are inherently concerned with discipline or are molded into focusing on discipline from their environmental experiences, their parenting style would differ from that of parents whose focus is on spending time with children. That difference is crucial in that it leaves open the interpretation of whether a diagnosis of ADHD and even ADHD-like behaviors are related to childrearing practices. This again raises another question related to diagnosing children with ADHD: Are parents asked about their parenting styles during the diagnostic process?

Ranking of behaviors. Differences were observed between the two groups of parents (reporting or no a child with problems) in their willingness to medicate specific behaviors. When considered together, however, parents seemed to have an inclination to medicate certain disruptive behaviors more than others. Behaviors associated with ADHD, ODD, suicidal talk, and depression, are different types of behaviors as described in the literature. For example, an ADHD diagnosed child may have difficulties doing 
homework or sitting still whereas a depressed-like child may be isolated and not talk much. This sample shows that parents have a predetermined idea on what behavior is more deserving to be medicated and what behavior is more likely to be tolerated. A child who talks about killing oneself seems to disturb parents a lot more compared to a child who shows incapability to sit still or not perform well in school. Although this may be obviously logical to many parents, it also speaks to the fact that the way parents feel or are affected by children's behaviors may have a priority over the severity of children's behaviors.

Parents in this sample were given hypothetical vignettes describing children who did not pay attention to school, were unfriendly or feisty towards others, showed signs of solitude, or talked about killing oneself. They were given these examples in a similar fashion without emphasizing the severity of each case or how often children would exhibit these behaviors. The fact that respondents in this sample showed a higher inclination to use medications among children depicted in some vignettes and not others, shows how they were emotionally affected from the descriptions.

The reasoning goes that when parents come face to face with the need to interpret and describe their own children's behaviors, are they in fact reporting how they are emotionally affected by children's behaviors or are they merely reporting children's behaviors? Clearly, it is a difficult distinction for most people, but the point remains that the way parents feel and are emotionally affected by children's behaviors should be 
considered when diagnosing a child. ADHD and other similar problematic behaviors or children cannot be interpreted without an understanding of the social dynamics around a specific child.

As extensively discussed in the literature, parents are at the core of the ADHD problem (Hansen \& Hansen, 2006). They observe and report children's behaviors (Bussing \& Gary, 2001), they attend parent-teacher meetings about their children's behaviors (Sax \& Kautz, 2003), they decide on whether their child should use medications (Taylor et al., 2006), and they even go through a process of trial and error until they get the right dosage of the medication that "works" for their child (Dennis et al., 2008). In fact, parents are so involved in the process that seems difficult for them to avoid any subjectivity. In turn, parents' subjectivity in judgment of behaviors leads to an understanding of these behaviors from the way it affects the parents. The ranking of disturbance such as shown in this study may be an indicator of that subjectivity, or at least an indicator of the parents' perceived burden in having to deal with the anticipated negative consequences of the behavior. So, again, the results of this study lead us to ask whether these problematic behaviors of children are genuine medical disorders or are they a reflection of specific circumstances of families?

\section{Part II: Discussion of Theoretical Implications.}

This study used a theoretical framework appropriated from Robert Merton's theory of purposive action. According to this theory people's actions have specific functions, manifest and latent, a distinction which is crucial in better understanding human behavior. Merton maintains that manifest functions are intended and clearly 
defined from the acting human. Latent functions, on the other hand, are often unintended and unrecognized. Merton's theory of purposive action becomes quite intriguing when he proposes that the manifest function of specific actions be ignored in order to understand their latent function: "It is necessary to ignore the manifest function in order to concentrate and become aware of the latent function—one needs to move beyond the perceived obvious to grasp the implications of the less obvious" (1936, p. 890).

Applying Merton's theory to this study means attempting to look beyond the "obvious" or "manifest" reason for medicating ADHD diagnosed children (i.e., that they manifest symptoms of a neurobehavioral disorder that causes disruptions in their cognitive and social functioning). Clearly, if the manifest function is literally removed from the picture, other reasons start to emerge. This study hypothesized that "lack of available time" is - for working parents - a latent function of medicating ADHDdiagnosed children, even though it may remain unrecognized and unintended by parents. Based on the subsample used in this study, it was shown that parents reporting child with problems spent less time with their children, worried less about this lack of time, and were more willing to medicate ADHD-diagnosed children. Unexpectedly, this association between time and willingness to medicate ADHD-diagnosed children was also observed among parents reporting no child with problems. So, if these observations are put in Merton's framework, parents may opt for medication use not only to put a stop to problematic behaviors of their children (manifest function), but also to cope with the lack of available time to handle these behaviors in a different way (latent function). 
The theory of purposive action emphasizes that the latent function is unintended and unrecognized. Following the theory, if parents are in fact using medications to cope with their lack of time, they are also unaware of this function. This study showed how parents reporting child with problems were more likely to opt for medications, less likely to be concerned with the lack of time, and also the group of parents who spent less time with their children. On the other hand, the relationship between the limited available time and willingness to medicate was also apparent among parents reporting no child with problems. Although this latter relationship was statistically significant, it was a weak relationship. Also, as a group, parents reporting no child with problems were more concerned with the lack of available time, so one could say that in this case the latent function was recognized, and the theory of purposive action cannot be applied for these parents. Then, the question remains whether reporting child with problems are a distinct group with somewhat similar characteristics?

\section{Part III: Future Studies}

This study attempted to investigate the relationship between parents' available time with children and their willingness to medicate ADHD-like behaviors. Investigating this sample of parents, it became clear that such relationship may in fact exist and needs to be explored further. This study opened the door to a number of possible new inquiries.

Cause-effect relationships. This study shows that time spent with children is associated with parents' willingness to medicate ADHD-like behaviors. The association, as for now, remains without a clear direction. Do parents who spend less time with their children are as a consequence more willing to medicate behaviors for a number of 
reasons from paying less attention to children's behaviors to following a medical framework and not even seeing the need to pay attention? Or is it that parents who are more willing to medicate behaviors for a variety of unrelated reasons also spend less time with children? Or, is it even that parents who are more willing to medicate behaviors also see no reason to spend more time to understand children's behaviors and as a consequence spend less time with them? Being able to answer these questions scientifically should be a tremendous contribution to the literature on ADHD, on other children's behaviors, as well as, will help practitioners to aid to parents in need. The immediate follow up of this study should address the issue of causality between spending time with children and willingness to medicate behaviors.

Quality of time. The literature on parental time draws attention to the quality of time as an important characteristic in child development (Hofferth \& Sandberg, 2001). The quality of time refers to the activities parents do with children. Some authors divide time in passive and active, where passive entails parents and children simply being in the same space together and active entails some form of constructive interaction between them in this same space. Researchers believe that spending active time with parents often results in better academic development and less behavioral problems for children (Hofferth \& Sandberg, 2001). Nevertheless, very little is known as to how parents spend their time with children, what type of activities they do together, and whether parents who spend more time with their children are less or more likely to turn to medications for controlling their children's behaviors. From the results of this work, one would go further and try to initially explore whether spending time with children is related to parents' 
goals in childrearing. Are parents more or less likely to focus on controlling children's behaviors when they spend substantial time interacting with their children? Moreover, are they more or less likely to turn to medications to control their children's behaviors when they spend substantial time interacting with them? Besides the quantity of time, it is crucial to explore the quality of time parents spend with their children and ask additional questions that will detail parent-child interaction better. Ideally, a small qualitative study allowing parents to describe their interaction with children or even record their activities for a short period would bring out essential material in understanding parent-child relationships. A small qualitative study would, in fact, provide basic information to design a larger quantitative study that will attempt to measure parents' time with children (quantity and quality), their perception of children's behaviors, as well as their willingness to control these behaviors by medications.

Time is a difficult concept to measure. Generally, parental time is measured by using direct observation, questioning, and time diaries (Monna \& Gauthier, 2008). Time diaries are considered the best measure (Folbre et al., 2005) although not without challenges. Monna and Gauthier (2008) conducted a systematic review of literature on parental time and showed that using time diaries presents the challenge of being unable to report when the interaction with the child is happening simultaneously with some other activity (such as cooking dinner or cleaning). They note that some researchers have attempted to avoid this issue by measuring the primary as well as secondary activities 
with children when such interactions will also be recorded. To increase accuracy, these time diaries could be designed based on findings from a small qualitative study with parents.

Race, ethnicity, culture, and medication of behaviors. This study reported that White parents reporting child with problems were more willing to medicate ADHD-like behaviors. This is in accordance with findings from studies that use parents of ADHD children as their primary informants. It is very important to look at such dynamics of race and ethnicity and medication of behaviors further to understand the reasons behind this observed difference.

The literature on parental time suggests that African American fathers spend less time with their children because they often do not live in the same household as them (Golden, 2008). However, another author who considered socioeconomic status found that time with children between African American and White parents is not different among families of the same socioeconomic status (Hofferth, 2003). The results from this study support the first claim that African American parents spend less time with children. The path analysis showed that to be the case for both parents (African American mothers reporting child with problems were mostly represented in this sample compared to fathers). However, the socioeconomic status was not controlled for in this particular relationship.

The investigation of the open-ended answers in this study showed a different categorization of parents - based on whether they reported of having a child with emotional and behavioral problems. African American and White parents reporting no 
child with problems did not differ in their concerns about lack of time with children. Simultaneously, African American and White parents reporting child with problems were more worried about disciplining their children. There were no racial differences when reports on having a child with emotional and behavioral problems were considered. Hispanic parents reporting no child with problems were more concerned with education whereas Hispanic parents reporting child with problems were more worried about outside influences on their children. This portrayal of findings calls for further investigation in differences between African American, White, and Hispanic parents, but also calls for investigation in cultural differences.

Culture in itself is a complicated construct, even called by researchers as a "conceptual short cut" that people use to imply different things (Mahler, 2012). Most anthropologists who have attempted to tackle its meaning may have concluded with different definitions. But, for the most part, they agree that culture is a learned and continually adjusted mindset which humans use from very early stages to understand, interact with, and interpret the world around them. Cultural differences become a moot issue when people move from one geographic location to another, carrying not only their belongings, but also a specific understanding of how the world works and how we interact with each other. Cultural differences may be invisible or limited to language accents in most daily things, but they may become pronounced when people come face to face with complicated situations such as the possibility of diagnosing a child with emotional and behavioral problems. 
Therefore a deeper exploration of the association between cultural differences and willingness to medicate behaviors is called for. Besides racial and ethnic differences, other characteristics of parents, such as their birthplace and the time of migration to United States may be an important ingredient related to cultural exposure. Since culture is learned by first hand experience (Mahler, 2012), one could expect that parents of children who were not born in the United States will be less willing to medicate childhood behaviors compared to parents who were born here. The United States may have been cultivating a pharmaceutical friendly culture over the past few decades: "The pharmaceutical industry, ... modern biological psychiatry, ... and the American judicial system were quick to introduce and embrace a cult of pharmacology, not as a conspiracy but as a belief system" (DeGrandpre, 2006, p. viii). Such investigation of place of birth and willingness to medicate behaviors can quickly follow up this study since a variable on where parents were born is included in the original dataset.

One-parent families versus two-parent families. Whether one-parent families or two-parent families spend more or less time with their children is inconclusive from the literature on parental time. Although this issue still remains inconclusive despite this study's results, some insights were brought to light from the parents' open-ended answers. One-parent families in this sample are generally less concerned with the lack of time compared to two-parent families, especially one-parent families reporting child with problems. Particularly, these latter parents are preferentially concerned with disciplining and controlling their children. So, it seems important that these findings are put to work in further research where a close consideration should be placed on both one-parent and 
two-parent families, their quantity and quality of time with children, as well as their parenting goals and concerns. First, is it accurate that one-parent families reporting child with problems are particularly worried about disciplining their children? How is the distribution of time among these families? What particular challenges do they face regarding time and discipline? Are one-parent families more willing to medicate children's behaviors?

Gender, time, and medication of behaviors. The literature on time and parents' gender suggest that mothers may spend more time with their children compared to fathers. Mothers, however, often use this time to do chores such as cleaning, feeding, and bathing. Conversely, fathers are more likely to spend their available time in interactive activities such as playing or reading. The path analysis from this study also supports the idea mothers spend more time with their children compared to fathers. It is of crucial importance, however, to emphasize that this fact is true only for mothers reporting no child with problems. According to the path analysis, mothers reporting child with problems in this sample do not spend more time with their children compared to fathers.

A study by Singh (2002) informs the literature that fathers of children with emotional and behavioral problems are less likely than mothers to buy into the biomedical approach to children's problematic behaviors and often reluctantly do so. Although not directly related to those findings, this study adds the observation that fathers are generally more concerned with having limited available time with their children compared to mothers. Also, mothers reporting no child with problems are more worried about lack of available time compared to mothers reporting child with problems. 
Thus gender constitutes another characteristic that should be considered in future investigations on parents reporting child with problems.

\section{Implications for social work}

According to the Bureau of Labor Statistics, there were approximately 642,000 social workers in the United States in 2008, with about 293,000 (46\%) of them working with families, children, and as school social workers. School social workers engage in various issues regarding children and their parents. They play an important role in identifying, referring, and serving children with different emotional and behavioral problems (Woolley \& Curtis, 2007). They also develop and provide treatments for parents of ADHD children but information on such treatments is rarely present in the social work literature (McCleary, 2002). The position of school social workers allows them to provide crucial help to parents of ADHD children who seem to experience some feelings of animosity toward the education and the healthcare system (Arcia et al., 2004; Blum, 2007), and above all, are uncertain as to what is the best approach to their child's problem. Having extensive expertise in child welfare, health, and mental health setting (Azzi-Lessing, 2010), social workers are capable to administer different types of trainings for parents of ADHD children (McCleary, 2002), but such trainings are usually conducted by other professionals and not by social workers (Thomas \& Corcoran, 2003).

The results from this study, that spending time with children may in fact relate to parents' willingness to medicate behaviors, provide useful information to school social workers and others engaged in intervention programs and trainings. If these results are taken at face validity, social workers could consider adding time-management training in 
the list of interventions designed for parents of ADHD children. They can also use the information to distinguish parents who experience scarcity of time and guide them to time-management programs.

Moreover, school social workers could use the information from the open-ended answers to gain insights on what seems to be the most difficult aspect of raising children. As shown in the results, parents reporting child with problems are mostly concerned with disciplining and controlling their children. The literature also tells us that they are in the middle of a confusing situation: having a disruptive child at home, listening to teachers who may suggest checking with a professional, and a professional who is recommending medications, may cause distress to any parent. It is also likely that most parents have friends and family who may have their own beliefs on what these emotional and behavioral problems are and how should they be tackled. It is crucial, therefore, for school social workers to understand these parents' situation and attempt to help these parents accordingly. Perhaps the focus on disciplining and controlling children may not be the best approach compared to increasing the amount of time spent with children or increasing parental activities with them. 
Figure 1: Search of publications on parental time with children

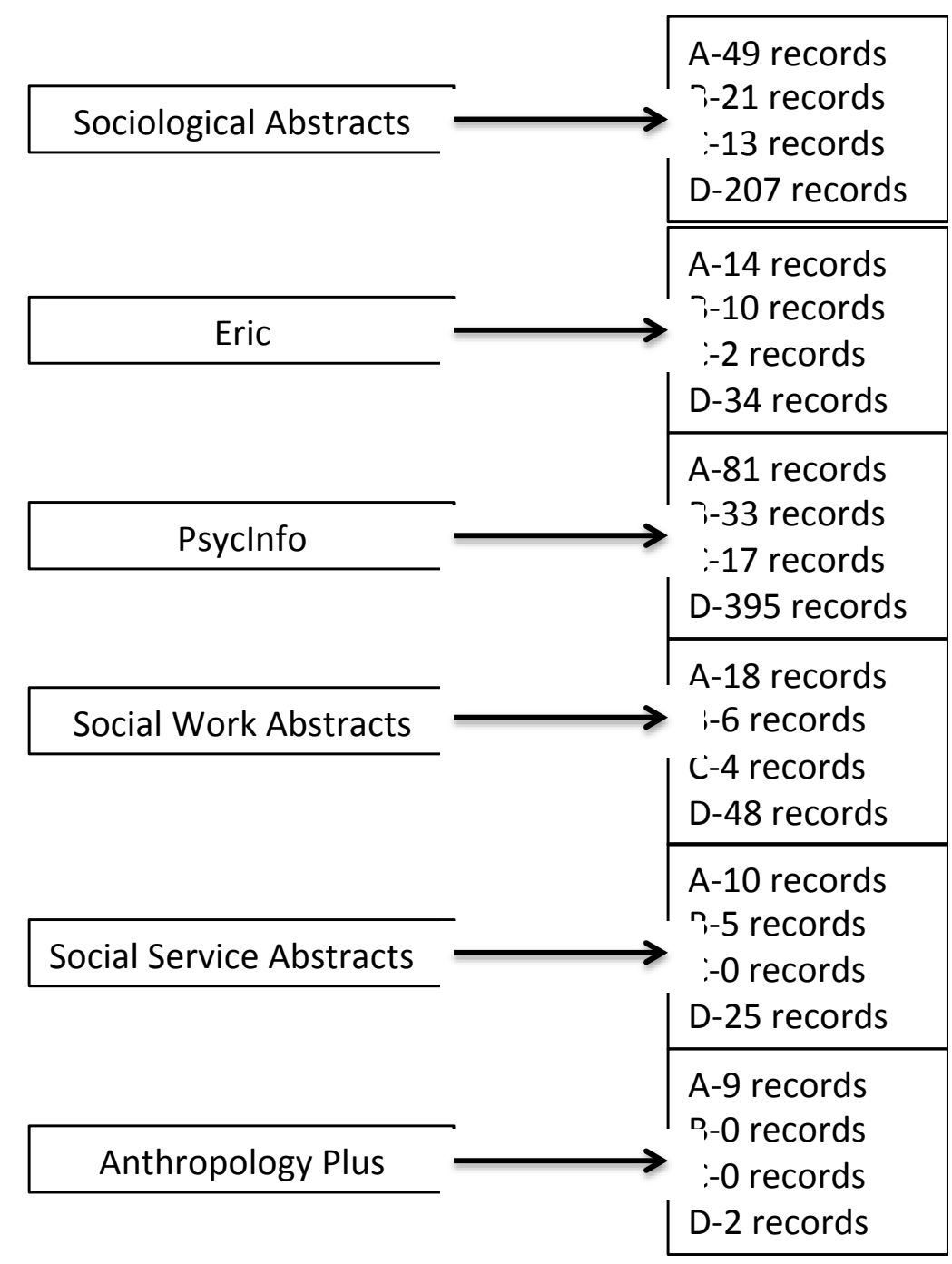

Total: 928 records

671 records unrelated to "parental time"

216 records: duplicates

41 records: used in the literature

Keywords used: A-parental time; B-time spent with children; C-parents' time with children; D-time with children. 


\section{REFERENCES}

Abroms, L. C., \& Goldscheider, F. K. (2002). More work for mothers: How spouses, cohabiting partners, and relatives affect the hours mothers work. Journal of Family and Economic Issues, 23, 144-66.

Aguinis, H. (2004). Regression analysis for categorical moderators, The Guilford Press: NY.

Akinbami, L. J., Liu, X., Pastor, P. N., \& Reuben, C. A. (2011). Attention deficit hyperactivity disorder among children aged 5-17 years in the United States, 19982009. NCHS Data Brief, 70, 1-8.

Aneshesnel, C. (2002). Theory-based data analysis for social sciences. Pine Forge Press: CA.

Appelrouth, S., \& Edles, L. D. (2006). Classical and contemporary sociological theory: Text and readings. Pine Forge Press: CA.

Arcia, E., \& Fernández, M. C. (2003). From awareness to acknowledgment: The development of concern among Latina mothers of children with disruptive behaviors, Journal of Attention Disorders, 6(4), 163-175.

Arcia, E., Fernández, M. C., \& Jáquez, M. (2004). Latina mothers' stances on stimulant medication: Complexity, conflict, and compromise. Journal of Developmental \& Behavioral Pediatrics, 25(5), 311-317. doi: 10.1097/00004703-200410000-00002

Armstrong, T. (2006). Canaries in the coal mine: The symptoms of children labeled 'ADHD' as biocultural feedback. In Cohen, D., Lloyd, I., \& Stead, J. (Eds.), Critical new perspectives on $A D H D$ (pp. 156-176). London: Routledge.

Auerbach, C. E., \& Silverstein, L. B. (2003). Qualitative Data: An introduction to coding and analysis, New York University Press, NY.

Avis, M., \& Reardon, R. (2008). Understanding the views of parents of children with special needs about the nursing care their child received when in hospital: A qualitative study. Journal of Child Health and Care, 12(1), 7-17.

Azzi-Lessing, L. (2010). Growing together: Expanding roles for social work practice in early childhood settings. Social Work, 55(3), 255-63.

Babbie, E. R. (2010). The practice of social research. California: Wadsworth.

Bachman, L. F. (2004). Statistical analysis for language assessment. UK: Cambridge University Press.

Balt, S. (2011). Is the criticism of DSm-5 misguided? Psychiatric Times. 
Barkley, R.A. (2000). Genetics of childhood disorders: XVII. ADHD, Part 1: The executive functions and ADHD. Journal of American Academy of Child and Adolescent Psychiatry, 39(8), 1064-8.

Barkley, R.A., Cook, E.H., Dulcan, M., Campbell, S., Prior, M., Atkins, M., \& Lewandowski, L. (2002). Consensus statement on ADHD. European Child \& Adolescent Psychiatry, 11(2), 96-98. doi: 10.1007/s007870200017

Barnes, G.R., Cerrito, P.B. and Levi, I. (2003). An examination of the variability of understanding of language used in ADHD behavior rating scales. Ethical Human Sciences and Services, 5(3), 195-208.

Barnett, R. V., \& Gareis, K. (2007). Shift work, parenting behaviors, and children's socioemotional wellbeing: A within family study. Journal of Family Issues, 28(6), $727-48$.

Bauer, D.J., \& Curran, P.J. (2011). Introduction to Structural Equation Modeling: Course Notes.

Beaujot, R., \& Andersen, R. (2007). Time-Crunch: Impact of time spent in paid and unpaid work and its division in families. The Canadian Journal of Sociology,32(3), 295-315.

Berger, L., Brooks-Gunn, J., Paxson, C., \& Waldfogel, J. (2008). First year maternal employment and child outcomes: Differences across racial and ethnic groups. Children and Youth Services Review, 30, 365-87.

Biederman, J. (2003). Pharmacotherapy for attention-deficit/hyperactivity disorder (ADHD) decreases the risk for substance abuse: Findings from a longitudinal follow-up of youths with and without ADHD. Journal of Clinical Psychiatry, 64 (Suppl. 11), 3-8.

Biederman, J., Spencer, T., Wilens, T., Prince, J., \& Faraone, S. (2006). Treatment of ADHD with stimulant medications: Response to Nissen's perspective in The New England Journal of Medicine. Journal of the American Academy of Child \& Adolescent Psychiatry, 45(10), 1147-1150. doi:

10.1097/01.chi.0000227883.88521.e6

Blum, L. (2007). Mother-Blame in the Prozac nation: Raising children with invisible disabilities. Gender \& Society, 21(2), 202-226. doi: 10.1177/0891243206298178

Bressman, S., \& Nass, R. (2002). Attention Deficit Hyperactivity Disorder and Tourette syndrome: What is the best treatment? Neurology, 58(4), 513-514.

Browna, J. E., Broomb, D. H., Nicholson, J. M., Bittman, M. (2010). Do working mothers raise couch potato kids? Maternal emnployment and children's lifestyle 
behaviors and weight in early childhood. Social Science and Medicine, 70(11), 1816-24.

Bryant, K. W., \& Zick, C. D. (1996). Are we investing less in the next generation? Historical trends in time spent caring for children. Journal of Family and Economic Issues, 17(3-4), 365-92. doi: 10.1007/BF02265026

Burke, J. D., Hipwell, A. E., \& Loeber, R. (2010). Dimensions of oppositional defiant disorder as predictors of depression and conduct disorder in preadolescent girls. Journal of the American Academy of Child and Adolescent Psychiatry,49(5), 48492.

Bussing, R., \& Gary, F. A. (2001). Practice guidelines and parental ADHD treatment evaluations: Friends or foes? Harvard Review of Psychiatry, 9(5), 223-233. doi:10.1080/10673220127905

Byrne, B. M. (2009). Structural equation modeling with AMOS: Basic concepts, applications, and programming. CRC Press.

Carpenter, L., \& Austin, H. (2007). Silenced, silence, silent. Qualitative Inquiry, 13(5), 660-674. doi:10.1177/1077800407301179

Carstensen, L. L. (2006). The influence of a sense of time on human development. Science, 312(5782), 1913-15. doi: 10.1126/science.1127488

Carstensen, L.L., Isaacowitz, D. M., \& Charles, S. T. (1999). Taking time seriously. A theory of socioemotional selectivity. American Psychologist, 54(3), 165-81.

Castellanos, F. X., Lee, P.P., Sharp, W., Jeffries, N. O., Greenstein, D. K., Clasen, L. S., ... Rapoport, J. L. (2002). Developmental trajectories of brain volume abnormalities in children and adolescents with attention-deficit/hyperactivity disorder. JAMA, 288, 1740-1748.

Centers for Disease Control and Prevention (2003). Behavioral Risk Factor Surveillance System Survey Data. (Publication of National Center for Chronic Disease Prevention and Health Promotion).

Centers for Disease Control and Prevention (2008). Diagnosed Attention Deficit Hyperactivity Disorder and Learning Disability: United States, 2004 -2006. Vital and Health Statistic, 10(237).

Centers for Disease Control and Prevention (2010). Increasing prevalence of parentreported Attention-Deficit/Hyperactivity Disorder among children - United States 2003 and 2007. Morbidity and Mortality Weekly Report, 59(44), 1439-43.

Chalasani, S. (2007). The changing relationship between parents' education and their time with children. International Journal of Time Use Research, 4(1), 93-117. 
Charach, A., Skyba, A., Cook, L., \& Antle, B. (2006). Using stimulant medications for children with ADHD: What do parents say? A brief report. Journal of Canadian Academy of Child and Adolescent Psychiatry, 15(2), 75-83.

Chen, A. Y., \& Escarce, J. J. (2006). Effects of family structure on children's use of ambulatory visits and prescription medications, Health Service and Research, 41(5), 1895-1914.

Cline, F., \& Fay, J. (2006). Parenting with love and logic: teaching children responsibility. Canada: NavPress.

Cohen, J. (1988). Statistical Power Analysis for the Behavioral Sciences, Lawrence Erblaum Associates, New Jersey.

Cohen, D. (2006). Critiques of the 'ADHD' enterprise. In Cohen, D., Lloyd, I., \& Stead, J. (Eds.), Critical new perspectives on ADHD (pp. 12-34). London: Routledge.

Cohen, D. (2006). How does the decision to medicate children arise in cases of 'ADHD'? In Cohen, D., Lloyd, G., \& Stead, J. (Eds.), Critical new perspectives on ADHD (pp. 236-252). London: Routledge.

Concannon, P. E., \& Tang, Y. P. (2005). Management of attention deficit hyperactivity disorder: A parental perspective. Journal of Paediatrics and Child Health, 41(12), 625-630. doi:10.1111/j.1440-1754.2005.00771.x

Costello, J. E., Mustillo, S., Erkanli, A., Keeler, G., \& Angold, A. (2003). Prevalence and development of psychiatric disorders in childhood and adolescence. Archival of General Psychiatry, 60, 837-44.

Craig, L. (2006). Does father care mean fathers share? A comparison of how mothers and fathers in intact families spend time with children. Gender and Society, 20(2), 259-81.

Craig, L., \& Mullan, K. (2010). Parenthood, gender, and work-family time in the United States, Australia, Italy, France, and Denmark. Journal of Marriage and Family, 72(5), 1344-61. doi: 10.1111/j.1741-3737.2010.00769.x

Craig, L., Mullan, K., \& Blaxland, M. (2010). Parenthood, policy and work-family time in Australia 1992-2006. Work Employment Society, 24(1), 27-45. doi:10.1177/0950017009353778

DeGrandpre, R. (2006). The cult of pharmacology: How America became the world's most troubled drug culture, Duke University Press, NC.

Delgado, E. A., \& Canabal, M. E. (2006). Factors associated with negative spillover from job to home among Latinos in the United States. Journal of Family and Economic Issues, 27(1), 92-112. 
Dennis, T., Davis, M., Johnson, U., Brooks, \& H., \& Humbl, J. (2008). Attention Deficit Hyperactivity Disorder: Parents' and professionals' perceptions. Community Practitioner, 81(3), 24-28.

Dhar, R., \& Nowlis, S. M. (1999). The effect of time pressure on consumer choice deferral. The Journal of Consumer Research, 25.

Diller, L. H., \& Tanner, J. L. (1996). Etiology of ADHD: Nature or nurture? American Journal of Psychiatry, 153(3), 451-2.

DosReis, S., Mychailyszyn, M. P., Myers, M. A., Riley, A. W. (2007). Coming to terms with ADHD: How urban African-American families come to seek care for their children. Psychiatric Services, 58(5), 636-41.

DeGrandpre, R. (2006). The cult of pharmacology: How America became the world's most troubled drug culture, Duke University Press.

Egger, H. L., \& Angold, S. (2006). Common emotional and behavioral disorders in preschool children: Presentation, nosology, and epidemiology. Journal of Child Psychology and Psychiatry, 47(3-4), 313-37. doi:10.1111/j.14697610.2006.01618.x

Elwell, F. (2009). Robert K. Merton's functional analysis, In Elwell, F. (Eds.) Macrosociology: The study of sociocultural systems, p.137-168. Mellen Publisher.

Evans, E., Hawton, K., \& Rodham, K. (2005). In what ways are adolescents who engage in self-harm or experience thoughts of self-harm different in terms of helpseeking, communication and coping strategies. Journal of Adolescence, 28(4), 573-87.

Faul, F., Erdfelder, E., Buchner, A., \& Lang, A. C. (2009). Statistical power analyses using $\mathrm{G}^{*}$ Power 3.1. Tests for correlations and regression analyses. Behavior Research Methods, 41, 1149-1160.

Fernández, M. C., \& Arcia, E. (2004). Disruptive behaviors and maternal responsibility: A complex portrait of stigma, self-blame, and other reactions. Hispanic Journal of Behavioral Sciences, 26(3), 356-372.

Folbre, N., Yoon, J., Finnoff, K., \& Fuligni, A. S. (2005). By what measure? Family time devoted to children in the United States, Demography, 42(2), 373-90.

Forsberg, L. (2009). Managing time and childcare in dual earner families. ACTA Sociologica, 52(2), 162-75. doi:10.1177/0001699309104003

Gaviria, M. (Producer/Director). (2007). The medicated child. In D. Fanning (Executive Producer), Frontline.

Retrieved from http://www.pbs.org/wgbh/pages/frontline/medicatedchild/. 
Golden, L. (2008). Limited access: Disparities in flexible work schedules and work at home, Journal of Family and Economic Issues, 29(1), 86-109. doi:10.1007/s1083400790907

Gornall, J. (2007). Research ethics: Hyperactivity in children: The Gillberg affair. British Medical Journal, 335, 370-3. doi:10.1136/bmj.39304.486146

Gould, M. S., Walsh, B. T., Munfakh, J. L., Kleinman, M., Duan, N., Olfson, M., Greenhill, L., \& Cooper, T. (2009). Sudden death and use of stimulant medications in youths. American Journal of Psychiatry, 166, 992-1001.

Guryan, J., Hurst, E., \& Kearny, M. (2008). Parental education and parental time with children, Journal of Economic Perspectives, 22(3), 23-46.

Han, W. (2008). Shift work and child behavior outcomes, Work, Employment, \& Society, 22(1), 67-87.

Han, W., \& Miller, D. P. (2008). Parental work schedules and adolescent depression. Health Sociology Review, 18(1), 36-49.

Hancock, G.R., \& Mueller, R.O. (2001). Rethinking construct reliability within latent variable systems. In R. Cudeck, S. du Toit, D. Sorebom (Eds.), Structural equation modeling: Present and future - a festschrift in honor of Karl Jöreskog, (pp. 195-21). Lincolnwood, IL: Scientific Software International.

Hansen, D. L., \& Hansen, E. H. (2006). Caught in a balancing act: Parents' dilemmas regarding their ADHD child's treatment with stimulant medication. Qualitative Health Research, 16(9), 1267-1285. doi: 10.1177/1049732306292543

Heininger, J. E., \& Weiss, S. K. (2001). From chaos to calm: effective parenting of challenging children with ADHD and other behavioral problems. New York: Penguin Group.

Hill, J. E. (2005). Work-family facilitation and conflict, working fathers and mothers, work-family stressors and support. Journal of Family Issues, 26, 793-819. doi:10.1177/0192513X05277542

Hofferth, S. L. (2001). Women's employment and care of children in the United States. In van der Lippe, T., \& van Dijk. L. (Eds.) Women's Employment in a Comparative Perspective, New York: Aldine de Gruyter.

Hofferth, S. L. (2003). Race/ethnic differences in father involvement in two-parent families: Culture, context, or economy? Journal of Family Issues, 24(2), 185-216. doi:10.1177/0192513X02250087

Horwitz, A. V., \& Wakefield, J. C. (2007). The loss of sadness: How psychiatry transformed normal sorrow into depressive disorder, New York: Oxford University Press. 
Hoyle, R. H., \& Smith, G. T. (1994). Formulating clinical research hypotheses as structural equation models: A conceptual overview, Journal of Consulting and Clinical Psychology, 62, 429-40.

Hsin, A. (2009). Parents' time with children: Does time matter for children's cognitive achievement? Social Indicators Research, 93(1), 113-26. doi: 10.1007/s11205008-9413-6

Jackson, D., \& Peters, K. (2008). Use of drug therapy in children with attention deficit hyperactivity disorder: Maternal views and experiences. Journal of Clinical Nursing, 17(20), 2725 - 2732 doi: 10.1111/j.1365-2702.2008.02444.x

Jacobson, K. (2006). ADHD from a cross-cultural perspective: Insights into adult-child power relationships. In Cohen, D., Lloyd, I., \& Stead, J. (Eds.), Critical new perspectives on $A D H D$ (pp. 156-176). London: Routledge.

Jureidini, J. N. (2002). Does the international consensus statement on ADHD leave room for healthy skepticism? European Child \& Adolescent Psychiatry, 11(5), 240-242.

Kalenkoski, C. M., \& Foster, G. (2008). The quality of time spent with children in Australian households, Review of Economics of the Household, 6(3), 243-66.

Kalenkoski, C. M., Ribar, D. C., \& Stratton, L. S. (2007). The effect of family structure on parents' child care time in the United States and the United Kingdom. Review of Economics of the Household, 5(4), 353-84. doi: 10.1007/s11150-007-9017-y

Kalil, A., \& Ziol-Guest, K. (2008). Parental employment circumstances and children's academic progress. Social Science Research, 37, 500-15.

Kendall, J. (1998). Outlasting disruption: The process of reinvestment in families with ADHD children. Qualitative Health Research, 8(6), 839-857. doi:10.1177/104973239800800609

Kendall, J., \& Shelton, K. (2003). A typology of management styles in families with children with ADHD. Journal of Family Nursing, 9(3), 257-280. doi: $10.1177 / 10748407032$

Kendig, S. M., \& Bianchi, S. M. (2008). Single, cohabiting, and married mothers' time with children. Journal of Marriage and Family, 70, 1228-40.

Kerr, D. C. R., Owen, L. D., \& Capaldi, D. M. (2008). Suicidal ideation and its recurrence in boys and men from early adolescence to early adulthood: An event history analysis. Journal of Abnormal Psychology, 117(3), 625-36. doi: $10.1037 / \mathrm{a} 0012588$. 
King, G., Honaker, J., Joseph, A., Scheve, K. (2001). Analyzing incomplete political science data: An alternative algorithm for multiple imputation. American Political Review, 95(1), 49-69.

Klasen, H., \& Goodman, R. (2000). Parents and GPs at cross-purposes over hyperactivity: A qualitative study of possible barriers to treatment, British Journal of General Practice, 50(452), 199-202.

Kline, R.B. (2005). Principles and practice of structural equation modeling (2nd ed.). New York: Guilford.

Konstantareas, M., Homatidis, S., \& Cesaroni, L. (1995). Brief report: Variables related to parental choice to medicate their autistic children. Journal of Autism and Developmental Disorders, 25(4), 443-52. doi:10.1007/BF02179378

Kothari, C. R. (2008). Research Methodology: Methods and techniques. New Dehli: New Age International.

Lehman, A. (2005). JMP basic univariate and multivariate statistics: A step by step guide, e-book.

Leibowitz, A. A. (2003). In-home training and the production of children's human capital. Review of Economics of the Household, 1(4), 305-17. doi:10.1023/B:REHO.0000004791.30664.ef

Leo, J. (2002). American preschoolers on Ritalin. Society, 39(2), 52-60. doi:10.1007/BF02717529

Leslie, L. K., Plemmons, D., Monn, A. R., \& Palinkas, L. A. (2007). Investigating ADHD treatment trajectories: Listening to families' stories about medication use. Journal of Developmental \& Behavioral Pediatrics, 28(3), 179-188. doi:10.1097/DBP.0b013e3180324d9a

Lueck, M. D. (2007). Anxiety levels: Do they influence the perception of time? Journal of Undergraduate Research, X, 1-5.

Mahalanobis, P. C. (1936). On the generalized distance in statistic. Proceedings of the National Institute of Science of India, 2(1), 49-55.

Mahler, S. (2012). Culture as comfort, Pearson Education.

Malacrida, C. (2001). Motherhood, resistance, and attention deficit disorder: Strategies and limits. Canadian Review of Sociology and Anthropology, 38(2), 141-165.

Malacrida, C. (2003). Cold comfort: Mothers, professional, and Attention Deficit Disorder, University of Toronto Press, CA. 
Mayes, R., Bagwell, C., \& Erkulwater, J. L. (2009). Medicating children: ADHD and pediatric mental health, Harvard University Press, Cambridge, MA.

McCleary, L. (2002). Parenting adolescents with attention deficit hyperactivity disorder. Health and Social Work, 27(4), 285-92.

McCracken, J. T., Biederman, J., Greenhill, L. L., Swanson, J. M., McGough, J. J., Spencer, T.J., ... Tulloch, S. (2003). Analog classroom assessment of a once-daily mixed amphetamine formulation, SLI381 (ADDERALL XR), in children with ADHD. Journal of the American Academy of Child \& Adolescent Psychiatry, 42(6), 673-683. doi:10.1097/01.CHI.0000046863.56865.FE

Mechanic, D. (1995). Sociological dimensions of illness behavior, Social Science and Medicine, 41, 1207-1216.

Meja, V., \& Stehr, N. (1998). Robert K. Merton's structural analysis: The design of modern society. In Mongardini, C., \& Tabboni, S. (Eds.), Robert K. Merton and Contemporary Sociology (pp. 21-45). New Brunswick: Transaction Publishers.

Mertler, C. A., \& Vannatta, R. A. (2005). Advanced and Multivariate Statistical Methods, (Third Edition), Pyrczak Publishing: Los Angeles, CA.

Merton, R. K. (1936). The unanticipated consequences of purposive social action. American Sociological Review, 1(6), 894-904.

Merton, R. K. (1938). Social structure and anomie. American Sociological Review 3(5), 672-682.

Merton, R. K. (1948/1968). Social Theory and Social Structure, The Free Press: New York.

Merton, R. K. (1957). Priorities in scientific discovery: A chapter in the sociology of science. American Sociological Review, 22(6), 635-59.

Milkie, M. A., Kendig, S. M., Nomanguchi, M., \& Denny, K. E. (2010). Time with children, children's wellbeing and work family balance among employed parents. Journal of Marriage and Family, 72(5), 1329-1343.

Milkie, M. A., Raley, S. B., \& Bianchi, S. M. (2009). Taking on the second shift: Time allocations and time pressures of U.S. parents with preschoolers. Social Forces, $88,487-518$.

Monastra, V. J. (2005). Parenting children with ADHD: 10 lessons that medicine cannot teach. Washington DC: American Psychological Association.

Monna, B., Gauthier, A. (2008). A review of the literature on the social and economic determinants of parental time, Journal of Family and Economic Issues, 29(4), 634-653. 
Mosses, E. O. (2006). A user's guide to path analysis. Maryland: University Press of America.

Munkvold, L., Lundervold, A., Lie, S. A., \& Manger, T. (2009). Should there be separate parent and teacher-based categories of ODD? Evidence from a general population. Journal of Child Psychology and Psychiatry, 50(10), 1264-72. doi: 10.1111/j.1469-610.2009.02091.x

Nigg, J. T. (2006). What causes ADHD? Understanding what goes wrong and why, Guilford Press, NY.

Nissen, S. E. (2006). ADHD drugs and cardiovascular risk. The New England Journal of Medicine, 354(21), 1445-1448.

Nock, S. L., \& Kingston, P. W. (1988). Time with children: The impact of couples' work-time commitments. Social Forces, 67, 59-86.

Nomanguchi, K. M. (2009). Change in work-family conflict among employed parents between 1977-1997. Journal of Marriage and Family, 71(1), 15-32. doi:10.1111/j.1741-3737.2008.00577.x

Nomanguchi, K. M., Milkie, M. A. \& Bianchi, S. M. (2009). Time strains and psychological wellbeing: Do dual earner mothers and fathers differ? Journal of Family Issues, 26, 756-792.

Olanyian, O., DosReis, S., Garriett, V., Mychailyszyn, M., Anixt, J., \& Rowe, P. C. T. (2007). Community perspectives of childhood behavioral problems and ADHD among African American parents. Ambulatory Pediatrics, 7(3), 226-231.

Oquendo, M. A., Baca-Garcia, E., Mann, J. J., \& Giner, J. (2008). Issues for DSM-V: Suicidal behavior as a separate diagnosis on a separate axis. American Journal of Psychiatry, 166(3)1383-4.

Pajo, B., \& Cohen, D. (2012). The problem with ADHD: Researchers' constructions and parents' accounts. International Journal of Early Childhood, 45(1).

Pajo, B., \& Stuart, P. H. (2012). A comparative review of "how to" books for parents of ADHD children and "how to" books for parents of typical children. Children and Youth of Services Review, 34(4), 826-33.

Pastor, P. N., \& Reuben, C. A. (2008). Attention deficit disorder and learning disability: United States, 1996-2006. (DHHS Publication 10-237). Retrieved from National Center for Health Statistics website: http://www.cdc.gov/nchs/data/series/sr_10/sr10_237.pdf

Pastor, P. N., Reuben, C. A., \& Duran, C. R. (2012). Identifying emotional and behavioral problems in children aged 4-17 years: united States, 2001-2007, National Health Statistics Report, 24(48), 1-17. 
Perry, C. E., Hatton, D., \& Kendall, J. (2005). Latino parents' accounts of Attention Deficit Hyperactivity Disorder. Journal of Transcultural Nursing, 16(4), 312-321. doi: $10.1177 / 1043659605278938$

Plomin, R. (1989). Environment and genes: Determinants of behavior. American Psychologist, 44(2), 105-111.

Pocock, B., Skinner, N., \& Williams, P. 2008, 'Work-Life Outcomes in Australia: Concepts, Outcomes and Policy in Work Less, Live More? Critical analysis of the work-life boundary ed. C.Warhurst, D.R. Eikhof, A. Haunschild, Palgrave MacMillan, London, pp. 22-43.

Rajdeep, G., Cote, J. A., \& Baumgartner, H. (2004). Multicollinearity and measurement error in structural equation models: Implications for theory testing, Marketing Science, 23 (4), 519-29.

Reiff, M. I., \& Tippins, S. (2004). ADHD: A complete authoritative guide. American Academy of Pediatrics.

Rey, J. M., Walter, G., \& Soutullo, C. A. (2007). Oppositional Defiant and Conduct Disorders, In Martin, A., Volkmar, F. R., \& Lewis, M. (Eds). Lewis's child and adolescent psychiatry: A comprehensive textbook. Philadelphia: Lippincott Williams \& Wilkins.

Reynolds, J., \& Aletraris, L. (2007). Work-family conflict, children, and hour mismatches in Australia. Journal of Family Issues, 28(6), 749-72. doi: 10.1177/0192513X06296634

Rice, M. L. (1989). Children's language acquisition. American Psychologist, 44(2), 14956.

Rieskamp, J., \& Hoffrage, U. (2008). Inferences under time pressure: How opportunity costs affect strategy selection. Acta Psychologica, 127(2), 258-76. doi:10.1016/j.actpsy.2007.05.004

Roeters, A., \& Treas, J. L. (2010). Parental work demands and parent-child, family, and couple leisure in Dutch families: What gives? Journal of Family Issues, doi:10.1177/0192513X10379204

Roeters, A., van der Lippe, T., \& Kluwer, E. S. (2009). Parental work demands and the frequency of child-related routine and interactive activities. Journal of Marriage and Family, 71(5), 1193-1204. doi: 10.1111/j.1741-3737.2009.00663.x

Rogers, M. A., Wiener, J., Marton, I., \& Tannock, R. (2009). Parental involvement in children's learning: Comparing parents of children with and without AttentionDeficit/Hyperactivity Disorder, Journal of School Psychology, 47(3), 167-185. 
Rucklidge, J. (2006). Impact of ADHD on the neurocognitive functioning of adolescents with bipolar disorder. Biological Psychiatry, 60(9), 921-928

Rueter, M. A., \& Kwon, H. (2005). Developmental trends in adolescent suicidal ideation. Journal of Research on Adolescence, 15(2), 205-22.

Ruhm, C. J. (2004). Parental employment and child cognitive development. The Journal of Human Resources, 39(1), 155-192.

Runkel, H.E. (2007). Screamfree parenting: The revolutionary approach to raising your kids by keeping your cool. New York: Broadway Books.

Sandberg, J. F., \& Hofferth, S. L. (2001). Changes in children's time with parents: United States, 1981-1997. Demography, 38, 423-36.

Sax, L., \& Kautz, K. J. (2003). Who first suggests the diagnosis of Attention Deficit Hyperactivity Disorder? Annals of Family Medicine 1, 171-174. doi: 10.1370/afm.3

Sayer, L., Gauthier, A., \& Frustenberg, F. F. (2004). Social class differences in parental time with children: Cross national variations, Journal of Marriage and Family, 66(5), 1152-1169.

Schwartz, Z. (2005). Prescription of medication for ADHD: An unethical practice. Ivy Journal of Ethics, 4(2), 18-21.

Singh, I. (2002). Bad boys, good mothers, and the miracle of Ritalin, Science in Context, 15(4), 577-603.

Sonna, L. (2005). The everything parent's guide to children with ADD/ADHD: A reassuring guide to getting the right diagnosis, understanding treatments, and helping your child focus. Adams Media: Avon, MA.

Sorokin, P. A., \& Merton, R. K. (1937). Social time: A methodological and functional analysis. The American Journal of Sociology, 42(5), 615-629.

Stolzer, J. M. (2005). The ADHD epidemic in America. Ethical Human Psychology and Psychiatry, 9(2), 109-116.

Taylor, M., O’Donoghue, T., \& Houghton, T. (2006). To medicate or not to medicate? The decision making process of Australian parents following their child's diagnosis with an Attention Deficit Hyperactivity Disorder. International Journal of Disability, Development and Education, 53(1), 111-128. doi: $10.1080 / 10349120500510115$

Theroux, L. (Producer/Director). (2011). America's medicated kids, BBC, Retrieved from http://www.bbc.co.uk/programmes/b00s56gx.html 
Thomas, C., \& Corcoran, J. (2003). Family approaches to attention deficit disorder: A review to guide school social work practice. Children and Schools, 25(1), 19-34.

Timimi, S., \& Leo, J. (2009). Rethinking ADHD: From brain to culture. Basingstoke, Hampshire: Palgrave Macmillian.

Timimi, S., \& Taylor, E. (2004). ADHD is best understood as cultural construct. The British Journal of Psychiatry, 8(9), 184-89.

United States, Department of Labor (2010). Trends and Challenges for Work in the $21^{\text {st }}$ Century: The time-squeeze in American Families: From causes to solutions, Clarkberg, M.

Vitiello, B., \& Towbin, K. (2009). Stimulant treatment of ADHD and risk of sudden death in children. [Editorial]. American Journal of Psychiatry, 166(9), 955-957.

Voydanoff, P. (2005). Work demands and work-to-family and family-to-work conflict: Direct and indirect relationships. Journal of Family Issues, 26(6), 707-26. doi: $10.1177 / 0192513 X 05277516$

Urdan, T. C. (2010). Statistics in plain English. Routledge Academic.

Waitzkin, H. (1991). The politics of medical encounters: How patients and doctors deal with social problems. New Haven: Yale University Press.

Whitaker, R. (2004). Mad in America: Bad science, bad medicine, and the enduring mistreatment of the mentally ill. Perseus Book Group, NY.

Wilens, T. E., Biederman, J., \& Spencer, T. J. (2002). Attention Deficit Hyperactivity Disorder across the lifespan. Annual Review of Medicine, 53, 113-131. doi:10.1146/annurev.med.53.082901.103945

Wolraich, M. L. (1999). The referral process: The pediatrician as gatekeeper. In Brown, R. T. (Eds.). Cognitive aspects of chronic illness in children. New York: The Guilford Press.

Woolley, M. E., \& Curtis, H. W. (2007). Assesing depression in latency age children: A guide for school social workers. Children and Schools, 29, 209-218.

Zwi, M., Ramchandani, P., \& Joughin, C. (2000). Evidence and beliefs in ADHD, BMJ, 321, 975-6. 
VITA

\section{EDUCATION}

BORA PAJO

PhD., Social Work, (upcoming graduation

December 2012)

M.A., Comparative

Sociology (2007)

M.A., Anthropology

(2005)

Diplomë (2002)
Dissertation: Time spent with children and working parents' willingness to medicate ADHD-like behaviors (D. Cohen, Chair). School of Social Work, Florida International University, Miami, FL

Department of Global and Sociocultural Studies, School of International and Public Affairs, Florida International University, Miami, FL

Department of Anthropology and Sociology, St. John's University, New York, NY

Fakulteti i Drejtësisë, Universiteti i Tiranës, Tirana, Albania (Equivalent of a combined BA/MA degree, School of Law)

\section{AWARDS}

Dissertation Year Fellowship Award, Florida International University, Miami, FL (2012).

\section{PUBLICATIONS}

Pajo, B., \& Stuart, P. (2012). A comparative review of "how to" books for parents of ADHD children and "how to" books for parents of typical children, Children and Youth Services Review, 34(4), 826-33.

Pajo, B., \& Cohen, D. (2013). The problem with ADHD: Researchers' constructions and parents' accounts, International Journal of Early Childhood, 44(3).

Pajo, B., \& Cohen, D. (in progress). Time spent with children and working parents' willingness to medicate ADHD-like behaviors.

Pajo, B., \& Cohen, D. (in progress). Parents' concerns with the most difficult aspect of childrearing.

Pajo, B., \& Cohen, D. (in progress). Perception of illness, country of birth, and willingness to medicate emotional and behavioral problems.

\section{PRESENTATIONS}

Cohen, D., \& Pajo, B. (April 25, 2012) TDAH et familles: La gestion pharmacologique du social, Université Paris-Descartes, Paris, France.

Pajo, B. (June 30, 2011). Screening and eligibility in juvenile mental health courts. Intermountain Mental Health Court Conference, Utah State University, Logan, UT.

Dillon, F.R., Rojas, P., De La Rosa, M., Duan, R., \& Pajo, B. (2010). Nonmedical use of sedatives among adult Latinas in the United States. Poster to be presented at the 
annual convention of the American Psychological Association, August 2010, San Diego.

Pajo, B. (January 14, 2009). Accounts of parenting an ADHD child, Center for Research on U.S. Latino HIV/AIDS and Drug Abuse, Florida International University, Miami, FL.

\section{EXPERIENCE}

Teaching Assistant (2009-2011)

Research Associate (2007-2011)

Research Assistant (2009-2011)

Research Assistant (2008-2009)

Teaching Assistant (2006-2008)
Robert Stempel College of Public Health and Social Work, School of Social Work, Florida International University, Miami, FL

Taught for eight semesters three required courses in the Bachelor of Social Work program: Research Methods in Social Work, HSBE I: Individuals and Families, HSBE II: Groups and Organizations.

Completed two workshops sponsored by the Academy for the Art of Teaching: Introduction to Teaching, Fundamentals of Teaching.

Institute of Homeless Studies, Camillus House, Miami, FL

Acted as administrator for the Homeless Management Information System (HMIS), conducted trainings for HMIS users, administered annual "time in point" surveys, performed data analysis of Camillus House incident reports.

"CriticalThinkRX: A prescription for critical thinking about psychiatric medications." PI: David Cohen, Miami, FL

Performed website maintenance and provided technical assistance to site users.

Center for Research on U.S. Latino HIV/AIDS and Drug Abuse, Funded by National Institute on Drug Abuse (NIDA), Florida International University, Miami, FL

Collected and analyzed literature on domestic violence focused on Latina women, provided peer-review of articles for publication, and assisted with data entry of large cross-sectional surveys.

Global and Sociocultural Studies, Florida International University, Miami, FL 